\title{
A Distributed Bi-behaviors Crow Search Algorithm for Dynamic Multi-Objective Optimization and Many-Objective Optimization
}

\author{
Ahlem Aboud ${ }^{\mathrm{a}, \mathrm{b}, *}$, Nizar Rokbani ${ }^{\mathrm{b}, \mathrm{f}}$, Seyedali Mirjalili ${ }^{\mathrm{d}, \mathrm{e}}$ and Adel M. Alimi ${ }^{\mathrm{b}, \mathrm{c}}$ \\ ${ }^{a}$ University of Sousse, ISITCom, 4011, Sousse, Tunisia. \\ ${ }^{\mathrm{b}}$ REGIM Lab: REsearch Groups in Intelligent Machines, University of Sfax, National Engineering School of Sfax (ENIS), BP \\ 1173, Sfax, 3038, Tunisia. \\ ${ }^{\mathrm{c}}$ Department of Electrical and Electronic Engineering Science, Faculty of Engineering and the Built Environment, University of \\ Johannesburg, South Africa. \\ ${ }^{\mathrm{d}}$ Centre for Artificial Intelligence Research and Optimisation, Torrens University Australia, Brisbane, Australia. \\ ${ }^{\mathrm{e}}$ Yonsei Frontier Lab, Yonsei University, South Korea. \\ ${ }^{\mathrm{f}}$ High Institute of Applied Science and technolgy of Sousse, University of Sousse, Tunisia.
}

${ }^{*}$ Corresponding author.

E-mail addresses: ahlem.aboud@ @egim.usf.tn (A. Aboud), nizar.rokbani@ieee.org (N. Rokbani), adel.alimi@ieee.org (A. M. Alimi), seyedali.mirjalili@griffithuni.edu.au (S. Mirjalili). 


\section{Abstract}

Dynamic multi-objective optimization problems (DMOPs) and Many-Objective Optimization Problems (MaOPs) are two classes of the optimization filed which have potential applications in engineering. Modified Multi-Objective Evolutionary Algorithms hybrid approaches seem to be suitable to effectively deal with such problems. However, the Crow Search Algorithm has not yet considered for both DMOP and MaOP. This paper proposes a Distributed Bi-behaviors Crow Search Algorithm (DB-CSA) with two different mechanisms, one corresponding to the search behavior and another to the exploitative behavior with a dynamic switch mechanism. The bi-behaviors CSA chasing profile is defined based on a large Gaussian-like Beta-1 function which ensures diversity enhancement, while the narrow Gaussian Beta-2 function is used to improve the solution tuning and convergence behavior. The DB-CSA approach is developed to solve several types of DMOPs and a set of MaOPs with 2, 3, 5, 7, 8, 10 and 15 objectives. The Inverted General Distance, the Mean Inverted General Distance and the Hypervolume Difference are the main measurement metrics are used to compare the DBCSA approach to the state-of-the-art MOEAs. All quantitative results are analyzed using the nonparametric Wilcoxon signed rank test with 0.05 significance level which proving the efficiency of the proposed method for solving both 44 DMOPs and MaOPs utilized.

Keywords: Beta Function, Crow Search Algorithm, Dynamic Multi-Objective Optimization, Evolutionary Algorithm, Many-Objective Optimization.

\section{Introduction}

During the last decade, a wide range of metaheuristics are designed to solve many complex problems based on Evolutionary Algorithms (EA) like the Genetic Algorithm (GA) [1] and the Swarm Intelligence (SI) such as the Particle Swarm Optimization (PSO) approach [2]- [5]. Different Multi-Objective Evolutionary Algorithms (MOEAs) have been employed to solve static single and multi-objective optimization problems, where the main challenge is to find the best global solutions through a compromise between convergence and diversity on the search space. However, this process becomes more challenging when solving Dynamic MultiObjective Optimization Problems (DMOPs) characterized by several types of time-varying Pareto Optimal Set (POS) and Pareto Optimal Front (POF) [6].

Generally speaking, MOEAs are designed to track and react effectively to the change that may affect the POS and the POF while conserving both convergence and diversity concepts [7], [8]. On the other hand, Evolutionary Dynamic Optimization (EDO) approaches should include explicit and implicit mechanisms to detect and correctly react to those changes. A change 
detection mechanism can be maintained through detectors from a feasible search population like the current best solutions, the memory of optimal solutions or some predefined subpopulation. Also, it can be assumed separately to the search space using a set of random selected solutions, a fixed point, a regular grid of solutions or a set of determined points. In addition, the algorithm behaviors have considered as a robust detection strategy based-on the average of bestfound solutions, the time-varying observation of different sub-swarms, the diversity of the solutions compared to the success rate, time-varying distributions and statistical methods.

Five groups of EDO methods are available in the literature to solve DMOPs; diversity-based techniques, memory-based approaches, prediction methods, parallel systems and the transfer learning-based algorithms. Increasing the mutation rate (hyper-mutation) or adding a randomly new member and relocate some useful solutions are the main mechanisms to manage the diversity in dynamic optimization, this technique may fall within undetected regions while of interests. The diversity-based approach [1] shown their ability for solving dynamic problem with continuous and small time-varying parameters and show their limits in problems with severe environmental changes. Furthermore, many DMOPs have presented some periodical or recurrent changes making storing historical experience of solutions useful to preserve diversity.

Memory-based approaches use redundant representation of an evolutionary algorithm using extra- memory components to help detecting future changes [9]. This category of approaches is very effective to solve DMOPs with periodically time-varying properties. However, such mechanisms slow down the convergence and strengthen diversity in the EDO approaches. The main disadvantage of memory-based algorithms is the ineffectiveness of redundant solutions stored in the archive. On the other hand, the prediction-based methods tend to predict changes based-on limited patterns. Such system can detect the global best solution quickly but they fail when the changes are stochastic which increases their relative training error rates. The parallel approaches present an optimization process over multiple sub-swarms that may handle the problem on separate search space and are recommended for multi-modal problems while are computationally expensive. A key challenge for these methods is finding the appropriate number of sub-swarm and their sizes. Last but not least, the transfer learning-based methods [5], [10]-[12] have the advantage to re-use previous computational experience to improve the efficiency of the new generated populations after each change detection by adding transfer learning mechanisms which is a time-consuming process.

The efficiency of MOEAs significantly decreases when dealing with MaOPs. In MaOPs, the number of objectives to satisfy is in general equal or higher to 3. Furthermore, three main issues are introduced when solving MaOPs thus including; (i) the inutility of dominance operator 
when dealing with a large number of objectives, (ii) the lack of convergence and diversity and (iii) the limited population size in a large dimension of objectives space that increase exponentially. Many Pareto-based approaches showed their limits to deal with the increasing number of non-dominated solutions using the dominance operator causing the issue of poor convergence implicated by the Active Diversity Promotion (ADP) phenomenon [13].

As a solution, a variety of enhancements are adopted to the original MOEAs when solving MaOPs including the decomposition-based and indicator-based approaches. Decomposition mechanisms combine multiple objectives into a single one or sub-problems. Some of the popular techniques of this type are Pareto sampling [14], improved Pareto sampling (MSOPSII) [15] and multi-objective evolutionary algorithm based on decomposition (MOEA/D) [16]. The decomposition-based approach become more effective with a set of sub-MOPs such as presented in the reference vector-guided evolutionary algorithm (RVEA) [17], MOEA/D-M2M [18], NSGA-III [19] and the MOEA/DD [20] and the MOEA/D-ROD [21]. In addition, a set of performance metrics are considered to guide the optimization process over different indicatorbased approaches like the fast hypervolume based evolutionary algorithm (HypE) [22], the Smetric selection based evolutionary multi-objective algorithm (SMS-EMOA) [23], the indicator based evolutionary algorithm (IBEA) [24], the Evolutionary Many-Objective Optimization Algorithm based on IGD Indicator with Region Decomposition [25] and the MaOEA/IGD [26]. A set of new techniques are proposed to deal with the issue of the ineffectiveness of the dominance operator over a set of Pareto-based methods like L-optimality [27], $\varepsilon$-dominance [28], fuzzy dominance [29], Grid-based Evolutionary Algorithm (GrEA) [30], $\theta$ Dominancebased Evolutionary Algorithm ( $\theta$-DEA) [31] and the preference order ranking [32]. Diversity management techniques are proposed to arrange a good balance between the convergence and the diversity when solving MaOPs. In [30] a three grid-based criterion was proposed to maintain diversity including the grid crowding distance, the grid coordinate point distance and the grid ranking. A diversity promotion mechanism, DM, is introduced in [33] to activate or disactivate the diversity of the population based on the spread and the crowding distance of solutions.

In NSGA-III algorithm [19], the reference point-based strategy is used to solve MaOPs. The shift-based density estimation (SDE) strategy [34] has been utilized to replace the dominance operators of MOEAs. Also, the knee point-driven evolutionary algorithm (KnEA) [35] has developed using both knee point-based selection and dominance-based selection. Three groups of preference-based approaches including priori algorithms, interactive algorithms and posteriori algorithms are employed to deal with the issue of population size limitation in regards to the large dimension of the objective space. The most known posteriori approaches are the 
Preference-Inspired Coevolutionary Algorithms (PICEA-g) [36], the novel two-archive algorithm (TAA) [37] and its improved version (Two_Arch2) [38].

In addition, the Particle Swarm Optimization (PSO) algorithm has received a great attention in MaOP. The Control Dominance Area of Solutions (CDAS) [39] is used with SMPSO and SigmaMOPSO for MaOPS. The indicator-based PSO systems have been proposed to maintain leader's selection using the R2 indicator as presented in H-MOPSO [40] or the hypervolume metric in S-MOPSO [41]. Two-stage strategy and a parallel cell coordinate system are adopted in MaOPSO/2s-pccs [42]. A preference-based method is proposed using PSO system focusing on solutions around the knee point and called knee driven particle swarm optimization (KnPSO) [43]. In [44] the MaPSO method uses leader's selection from a certain number of historical solutions by using scalar projection. In addition, the HGLSS-MOPSO algorithm [45] has adopted the Hybrid Global Leader Selection (HGLSS) using two global leader selection mechanisms the first for exploration and the second for exploitation. A recent published paper [46] has presented an adaptive localized decision variable analysis approach under the decomposition-based framework to solve the Large-Scale Multi-Objective Optimization problems and Multi-Tasking Optimization Problems in MaOPs. As a conclusion, all mentioned Many-Objective Evolutionary Algorithms (MaOEAs) are presented as highly complex and time-consuming systems, essentially when using decomposition-based mechanisms and/or the quality indicators to deal separately with convergence and diversity.

The Crow Search Algorithm (CSA) [47] is a meta-heuristic simulating the social organization of crow folks essentially for food-search procedure. Crows are characterized by their ability to memorize food sources they found but also sources that other members of the flock may hold or hide. The CSA algorithm was first proposed as a mono-objective optimization technique and then extended to solve static Multi-Objective Problem (MOP) and constrained engineering optimization problems, in which the algorithm showed a relative effectiveness in comparison with techniques such as harmony search (HS) [48], the GA [1] and the PSO approaches.

This paper presents a novel Distributed Bi-behaviours Crow Search Algorithm (DB-CSA) for solving both DMOPs and MaOPs. The DB-CSA approach presents two new chasing profiles denoted by Beta Distribution profiles over the large Gaussian Beta-1 function for diversity enhancement, and the narrow Gaussian Beta-2 function for convergence improvement. The proposed approach tends to achieve a dynamic balance between exploitation and exploration at each iteration during the optimization process which makes more suitable for both dynamic multi-objective optimization and many-objective optimization. 
The reminder of this manuscript is organized as follow; Section 2 presents an overview of the most known Dynamic Multi-Objective Optimization methods, the Many-Objective Optimization Approaches and some existing Crow Search Algorithms based-methods. Section 3 presents the proposed Distributed Bi-behaviours Crow Search Algorithm (DB-CSA). Section 4, details the experimental evaluation which is based on two comparative studies: one for DMOPs and the second for MaOPs. Results are presented in term of mean, and standard deviation. Then a comparative of the proposed method toward key state of art methods using the nonparametric Wilcoxon signed rank test. Finally, Section 5 conclude this paper and presents some future work.

\section{State of the Art on Evolutionary multi-objective optimization}

This section presents a set of comparable MOEAs and MaOEAs designed for both Dynamic Multi-Objective Optimization and Many-Objective Optimization are presented in sub-sections 2.1 and 2.2 respectively. In addition, the existing crow search-based methods are in sub-section

\section{3 .}

\subsection{Dynamic Multi-Objective Optimization Methods}

Several Multi-Objective Evolutionary Algorithms (MOEAs) have been designed in the literature to solve DMOPs with time-varying objective, variables or constraints, a set of them are visible Table 1. Among them two variant of the dynamic non-dominated sorting genetic algorithm II (DNSGA-II) [1] are proposed to enhance the diversity of solutions when solving DMOPs. In DNSGA-II, a set of solutions is selected randomly as detectors and re-evaluated iteratively. Then, if a change is detected all selected solutions are re-initialized or hypermutated. The Steady-State and Generational Evolutionary Algorithm (SGEA) [9] is designed to detect and react effectively to the change in a steady-state manner. If a change is detected, a number of good solutions is re-used in the next processing step then a combination of previous and the new solutions are used to approximate the new pareto optimal front. The CompetitiveCooperative Coevolutionary Algorithm (dCOEA) in [49] aims to track the time-varying POF based on the decomposition of the optimization process. However, only the winners of each sub-population are considered to manage the optimal solutions. The population prediction strategy (PPS) [50] is a prediction-based method which divides the non- dominated solutions into a center point and a manifold, then both are used to predict the future center point and manifold respectively. When a change is detected based a population re-initialization is operated. The MOEA/D [16] is a decomposition-based approach aiming to subdivide the 
population into several sub-populations and solving many sub-problems separately and simultaneously making the MOEA/D system lower and timely consuming.

Transfer-learning-based techniques are reliable alternatives for DMOPs based on the MOEA/D as a baseline system. In 2020, the new memory-driven manifold transfer learning was proposed based evolutionary algorithm (MMTL-MOEA/D) [51]. This approach has combined the memory mechanism to preserve the previous best solutions and the manifold transfer learning feature to estimate the best solutions, so that the best solutions are conserved and set as initial population of the next generation.

In addition, a randomly reinitialized mechanism (RI-MOEA/D) [51] is used to $10 \%$ of selected populations after each change to maintain the diversity. A combination between the PPS [50] and the MOEA/D are considered in the PPS-MOEA/D algorithm to solve the DMOP. Also, the support vector regression (SVR) based on evolutionary algorithm (SVR-MOEA/D) is proposed in [52] is designed to solve the nonlinear correlation between two historical optimization process. The SVR, is used to predict a new population after each change in the search space. A transfer learning-based dynamic multi-objective evolutionary algorithm (TrMOEA/D) is proposed in [53], aiming to solve the issue of non-independent and identically distributed data in a dynamic environment. The Tr-MOEA/D system implements a transfer learning mechanism to reuse the past historical population after each change which speed-up the optimization process. In KF-MOEA/D [54] system a Kalman filter (KF) is used to predict a new population prior to perform the convergence concept.

Table 1. Classification of the MOEAs for DMOPs.

\begin{tabular}{|l|l|}
\hline Diversity-based Approaches & DNSGA-II [1] \\
\hline Memory-based Approaches & $\begin{array}{l}\text { SGEA [9] } \\
\text { dCOEA [49] }\end{array}$ \\
\hline Prediction-based methods & PPS [50] \\
\hline Parallel Approaches & MOEA/D [16] \\
\hline & MMTL-MOEA/D [51]. \\
Transfer Learning-based Methods & RI-MOEA/D [51] \\
& SVR-MOEA/D [52] \\
& Tr-MOEA/D [53] \\
& KF-MOEA/D [54] \\
\hline
\end{tabular}

\subsection{Many-Objective Optimization Methods}

Generally speaking, many-objective algorithms are designed to optimally manage the couple of exploitation and exploration concepts. Table 2, presents key Many-Objective Evolutionary 
Algorithms (MaOEAs). The inutility of dominance operator in Pareto-based methods is managed based-on the decomposition of many-objective to single or multi-objectives. The multiple single objective pareto sampling (MSOPS) [14] algorithm generates a set of target vectors, then it undergoes a multiple single objective optimization processes to solve MaOP, such a strategy may return moderated results since it is not managing the multi-objectives of MaOp's correctly. The enhanced MSOPS-II [13] use a set of target vectors to guide the optimization process at each iteration. Then, the aggregation of fitness functions is used to evaluate the performances of the proposed solutions. The MOEA/D [16] algorithm, proceed with a decomposition of the many-objectives into a set of single objectives using a uniformly distributed weight vector. Similar to the weight vectors of the MOEA/D algorithm, the NSGAIII [19] has used a number of well-spread reference points to approximate non-dominated solutions, then it enhances the diversity of the population. Based on the main idea of the NSGAII, the reference vector-guided evolutionary algorithm (RVEA) [17] adopted two reference vectors, one for the selection and the second was for the adaptation. In RVEA system, the concept of convergence and diversity are dynamically managed using the Angle Penalized Distance (APD).

A vector angle-based evolutionary algorithm (VaEA) [55] is proposed for Unconstrained MaOPs. This algorithm uses the maximum-vector-angle as selection mechanism to guarantee a good distribution and approximation to a POF; while the worse solutions are replaced with a new generated one. The $\theta$-DEA [31] system is based on NSGA-III while with a new $\theta$ nondominated concept which is different from the original dominance operator used on the pareto-based methods. It employs a set of reference points to cluster the solutions set in order to enhance the exploration phase. The NSGA-II/SDR is a modified version of the NSGA-II with a Strengthened Dominance Relation (SDR), presented in [56] for solving MaOP. The NSGA-II/SDR adopts the angle and the niching mechanism to select the best converged solutions. MOEA/DD, MOEA dominance and decomposition [20] is a hybridization between the MOEA/D [16] and the NSGA-III [19]; where the many-objectives are decomposed into sub-problems then a dominance criterion is used to aggregate the global solution. Different grid-based criterions like the grid crowding distance (GCD), the grid ranking (GR) and the grid coordinate point distance (GCPD) are integrated in MOEAs to evaluate the fitness function of the MaOP. In addition, the GrEA system [30], is designed to maintain a good balance between convergence and diversity over both the grid dominance and grid difference to evaluate the fitness function and pushing the system toward the best optimal solutions. Two variants of the Pareto-based evolutionary algorithm using the penalty mechanism (PMEA) are presented in 
[57], the MPEA-MP and the MPEA*-MA. The PMEA-MA is developed using the Manhattandistance and the cosine distance as the convergence and distribution metrics, it includes a population preprocessing to enhance the diversity. The second variant, PMEA*-MA, is a simplified one, which do not adopt the preprocessing step.

The AnD algorithm [58] is a non-pareto-based method and maintains the diversity of the population using an angle-based selection technique, then it picks optimized members which are the same search direction as a sorting solution. A hybridization between the Strength Pareto Evolutionary Algorithm (SPEA) and the shift-based density estimation (SDE) strategy in [34] is denoted by (SPEA/SDE) it estimates the density of the population, then individuals who are not converging are eliminated to enhance the diversity among the divergent solutions only. In [59], the SPEAR leverages on reference direction-based density estimator using the standard SPEA algorithm for multi/many objective optimization problems. The knee point-driven evolutionary algorithm (KnEA), proposed in [35], evolves a population then select nondominated solutions based on knee point criterion, which may be assumed to a Pareto strategy. Furthermore, the two-stage evolutionary algorithm (TSEA) is developed in [60], in the first stage several sub-populations are optimized to converge to different regions of the Pareto front, then the nondominated solutions of each sub-population are considered as individuals to optimize in the second stage. In indicator-based methods several quality metrics are used to perform the optimization process, for example the Monto Carlo simulation is used in HypE algorithm [22] to minimize the computation cost and to approximate the results. The preferencebased approaches use different adaptation mechanisms to perform the decision toward the true Pareto front. In [36], the PICEA-g algorithm integrates the coevolution as a posteriori adaptation mechanism with a set of candidate solutions to help decision making and approximate the entire of POF. Two archives are used in the Two_Arch2 [38] system, where the first is considered for convergence (CA) and the second is to maintain diversity (DA). A crossover operator is used between the $\mathrm{CA}$ and DA as selector mechanism and mutation operator is used in CA memory.

Table 2. Classification of the MaOEAs for MaOPs.

\begin{tabular}{|l|l|}
\hline & MSOPS [14] and MSOPS-II [13] \\
& MOEA/D [16] \\
& MOEA/DD [20] \\
Decomposition-based approaches & TSEA [60] \\
& MPEA-MP and MPEA*-MA [57] \\
\hline Indicator-based approaches & HypE [22] \\
\hline
\end{tabular}




\begin{tabular}{|l|l|}
\hline Diversity-based selection criterion & NSGA-III [19] \\
& SPEA/SDE [34] \\
& KnEA [35] \\
& SPEAR [59] \\
\hline \multirow{4}{*}{ Modified dominance relation-based } & GrEA [30] \\
approaches & VaEA [55] \\
& O-DEA [31] \\
& NSGA-II/SDR [56] \\
& AnD [58] \\
\hline \multirow{3}{*}{ Preference-based approaches } & RVEA [17] \\
& VaEA [55] \\
& PICEA-g [36] \\
& Two_Arch2 [38] \\
\hline
\end{tabular}

\subsection{Existing Crow Search-based Methods}

The Crow Search Algorithm (CSA) [47] was first proposed in 2016 to solve constrained engineering optimization problems. In [61], Meriahi et al. published a new overview paper to present all modified version of CSA system. CSA has been extended in a way to solve MOPs as well. A Multi-Objective Crow Search Algorithm (MOCSA) is proposed in [62], for instance in which chaos and orthogonal opposition-based operators are used to hybridize CSA, (M2OCSA) with a focus on solving MOPs. Also, the Multi-objective Taylor Crow Optimization algorithm (MOTCO) is proposed for clustering aware wireless sensor network [63]. Furthermore, two binary version of CSA algorithm are proposed in [64] and [65]. The first one is the BCSA [64] which used a V-shaped transfer function to obtain a binary representation a continuous data with application to feature selection. The second on [65] consists in applying a sigmoid transformation and was applied to solve the 2D bin packing problem. Several modified versions of CSA tended to manage the diversity based on the Gaussian distribution and diversity information of the population such in [66] for electromagnetic optimization, the usability factors hierarchical model for feature extraction and prediction [67], the priority-based technique is used to determine the sufficient flight length amount for each crow to update their position based other crow for economic load dispatch problem [68] and the modification of the CSA parameters like; the awareness probability and the random perturbation of each crow is proposed in [69].

A set of mechanisms has been used to improve the CSA algorithm including search bounds limits management strategy [70], adding an archive component [71], restructuring the awareness probability [72] to enhance the random perturbation and the dynamic probability of 
CSA system. Several operators have been added to achieve a good balance between the convergence and the diversity such as the Roulette wheel selection tool and the inertia weight, the Lévy flight and the adaptive adjustment factors. In addition, a cross-over and a mutation operator was proposed to hybridize CSA intrinsically in [73] with application to a hybrid renewable energy PV/wind/battery system. Many hybridization methods are developed to combine the CSA algorithm with the Grey Wolf Optimizer (GWO) [74], the Cat Swarm Optimization (CSO), the Crow PSO [75] and the Crow Search Mating-based Lion Algorithm [76].

\section{The proposed Distributed Bi-behaviors Crow Search Algorithm}

Different MOEAs are designed to solve the DMOP should be able to detect the problem patterns changes and to response respectively. However, many modified evolutionary approaches are designed for MaOP to deal with a high number of objective functions. The two classes of optimization approaches have been characterized by their complexity in terms of time and resources. This work proposes a new Distributed Bi-behaviours Crow Search Algorithm (DB-CSA) to manage both convergence and diversity concepts dynamically when solving both DMOP and MaOP. The new DB-CSA is classified as a diversity-based approach combined the simplicity of CSA algorithm and the flexibility of the Beta function proposed by [77] to produce several forms and configurations of distributions, including the normal Gaussian one. More details about the proposed DB-CSA are presented in the next sub-section.

\subsection{The Standard Crow Search Algorithm}

The Crow Search Algorithm (CSA) was proposed by Askarzadeh in 2016 [47] as a metaheuristic for solving constrained engineering optimization problems. Crows are known to be social bird with the ability to memorize and use food source positions when needed; those sources may be the result of a personal search or from the crow group social activity. The CSA algorithm mimics the crows flock search mechanisms' and use it for optimization purposes. The search process is detailed in Figure 1 and starts by a random initialization of $N$ crow's positions with $d$ dimensional search space. Each crow $i$ is characterized by a position vector $\mathrm{X}_{\mathrm{i}}$ defined by: $\mathrm{X}_{i}=X_{1}^{i}, X_{2}^{i}, \ldots, X_{d}^{i}$ and their best position $M_{i}$ presenting the food positions. All crows are flying in search space aiming to optimize their fitness function Fit $\left(X_{i}\right)$ based on their positions and memories to attend the best food source. While exploring the search space for new food positions, a crow will keep needs to reminder the location where it hides its own food, and should keep awake if other crows discover. Assuming that the $j$-th crow decides to visit a 
previously memorized position at iteration $(t)\left(M_{j, t}\right)$ and assuming that a congener (i) is following the crow (j), two controversial behaviors, may occur each one represented by a state:

- The first state is when the crow $j$ ignores being followed, so it simply continues searching considering what it previously found $\left(M_{j, t}\right)$.

- The second state is when the crow is aware of being followed; in this case the crow will simply hide its food source and undergo a fully random search.

These two position updates are detailed in equation (1).

$$
\mathrm{X}_{\mathrm{i}}(\mathrm{t}+1)=\left\{\begin{array}{l}
/ / \text { State } 1: \\
\text { If } \mathrm{R}_{\mathrm{j}}(\mathrm{t}) \geq \mathrm{AP}_{\mathrm{j}}(\mathrm{t}) \text { then: } \\
\quad \mathrm{X}_{\mathrm{i}}(\mathrm{t})+\mathrm{R}_{\mathrm{i}}(\mathrm{t}) \times \mathrm{Fl}_{\mathrm{i}}(\mathrm{t}) \times\left(\mathrm{M}_{\mathrm{j}}(\mathrm{t})-\mathrm{X}_{\mathrm{i}}(\mathrm{t})\right) \\
\text { Else: } \\
/ / \text { State } 2: \\
\quad \text { random update }
\end{array}\right.
$$

where; $R_{i}(t)$ is a random number with uniform distribution between the interval $[0,1]$ at iteration $t$ and $F l_{i}(t)$ is the flight length of the crow $i$ and $A P_{j}(t)$ is the awareness probability of the crow $j$.

In CSA algorithm, the balance between exploration and exploitation during the optimization process is achieved by the flight length $(\mathrm{Fl})$ of the $i^{\text {th }}$ crow during the update process of each position. However, the memory $M_{i}(t+1)$ of each crow $i$ is updated using equation (2). All the optimization process is executed until a predefined maximum number of iterations.

$$
M_{i}(t+1)=\left\{\begin{array}{l}
X_{i}(t+1) \quad \text { IF } \quad \text { Fit }\left(X_{i}(t+1)\right) \geq \operatorname{Fit}\left(M_{i}(t)\right) \\
M_{i}(t) \text { Otherwise }
\end{array}\right.
$$

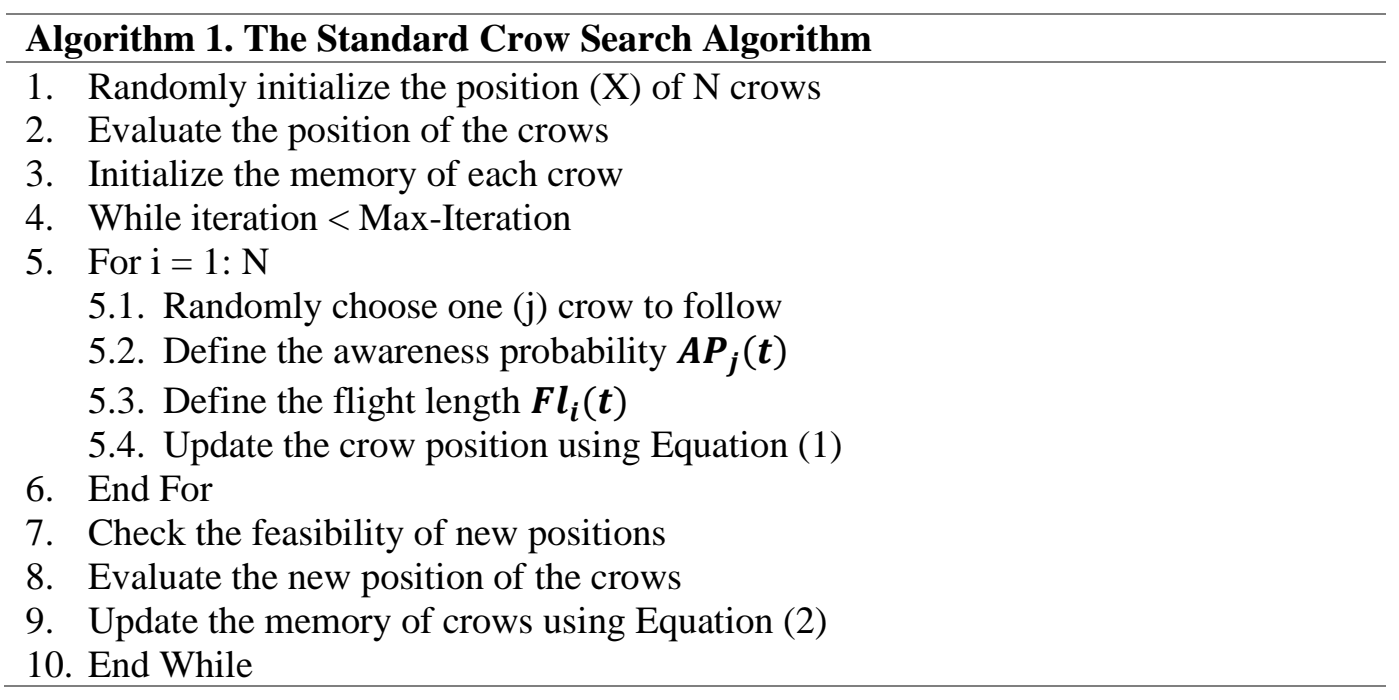

Fig. 1. Pseudo code of the Standard Crow Search Algorithm 


\subsection{A General Presentation of the new DB-CSA Approach}

The Distributed Bi-behaviours Crow Search Algorithm (DB-CSA) is based on the couple of Beta distribution profiles for exploitation and exploration enhancement as presented the flowchart in Figure 2 and detailed in the pseudo code in Figure 3. The new DB-CSA system has the same optimization process as the standard CSA algorithm [47] and the main difference is provided on the convergence and the diversity treatment during the optimization process when updating the position of each crow $i$. In DB-CSA algorithm, each crow $i$ is presented as a potential solution in the search space.

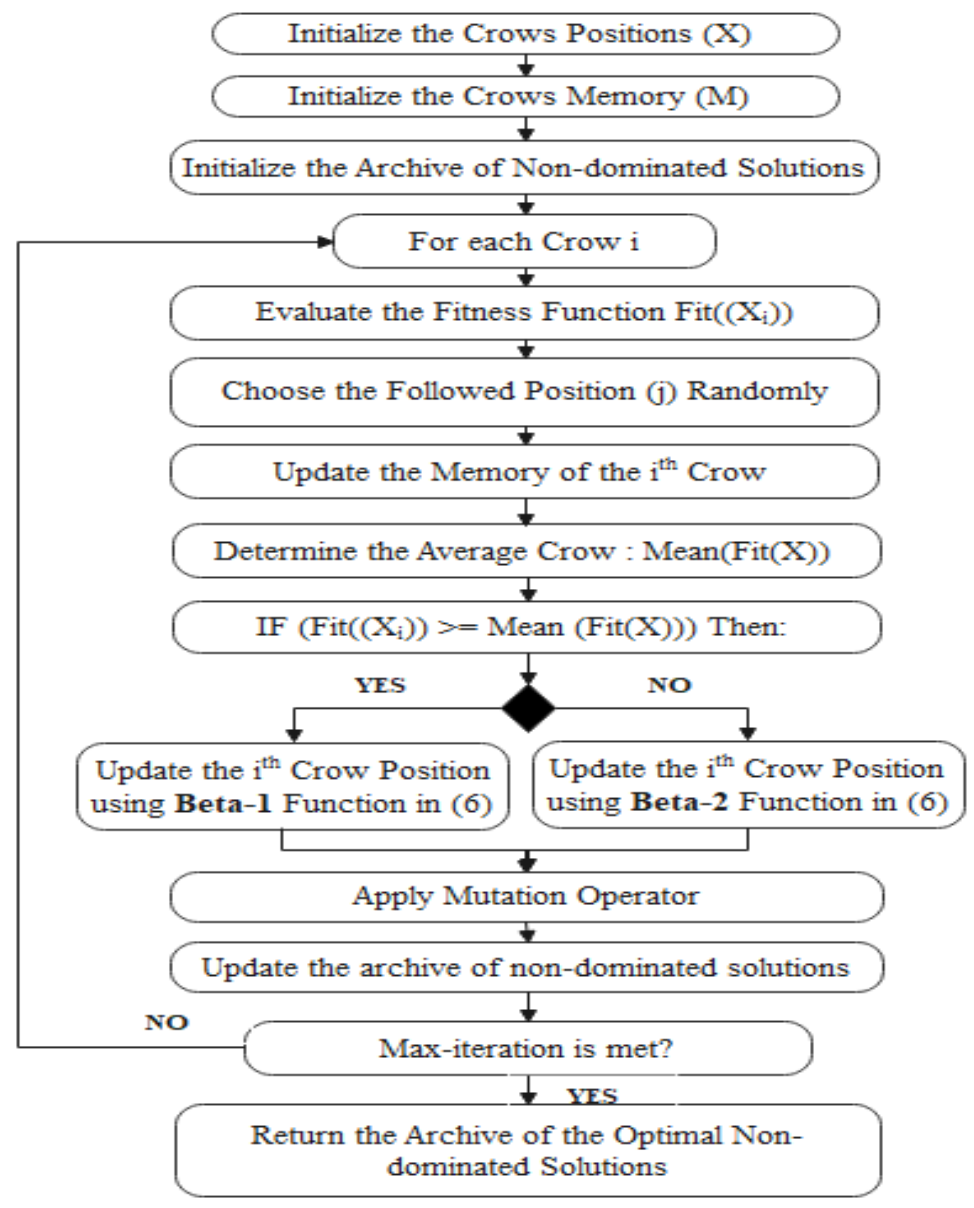

(a)
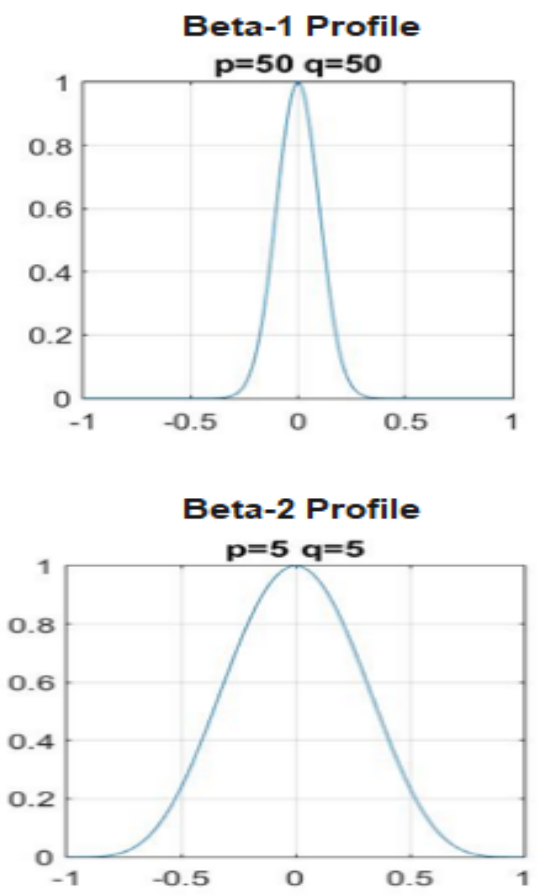

(b)

Fig. 2. The proposed Distributed Bi-behaviours Crow Search Algorithm (DB-CSA). (a) Flow chart of the DB-CSA, (b) Beta profiles, respectively Beta-1 and Beta -2 .

The key processing steps of the proposed approach, see Figure 2, are detailed as follow:

1. Initialization (population positions and their memories): the DB-CSA starts with a random initialization of the position $(X)$ and the memory $(M)$ of the flock of $N$ crows, when each crow $i$ has presented as a potential solution in the search space.

2. Initialization of the archive of the non-dominated solutions: the archive (A) is 
initially created to store all the non-dominated solutions during the optimization process. After that, all the following steps are executed until a predefined number of iterations.

3. Fitness Function Evaluation: for each crow $i$, the fitness function $\left(\right.$ Fit $\left(X_{i}\right)$ ) is evaluated.

4. Determine the followed crow $\mathbf{j}$ : at each iteration, one of the main behaviors of the crow $\mathrm{i}$ is to determine one crow $\mathrm{j}$ to follow by selecting a random position value between zero and the size of the flock of crows.

5. Determine the average crow i: the aggregative value of $K$ objectives are computed as the fitness function $F i t\left(X_{i}(t)\right)$ of each crow $i$, then the average value of all fitness functions is selected to determine the mean solution (crow).

\section{Update the crow position using the bi-behaviours beta distribution profiles}

7. Update the memory (M): the memory of each crow $i$ is updated using Equation (2).

8. Apply the mutation operators

9. Update the archive of non-dominated solutions: at each time $t$ of the optimization procedure, all the non-dominated solutions are stored in the archive (A).

10. Generate OUTPUT $=$ best Pareto solution from Archive (A).

In the standard CSA algorithm, the update of crow position is done according to the Equation (1), while the convergence and the diversity stages are treated separately causing the issue of premature convergence. However, this issue has treated by the new DB-CSA system using a bi-behaviours beta distribution profiles to assume a dynamic and a good balance between both stages. The two beta distribution profiles are presented in equation (6) denoted by Beta1_rand which and Beta2_rand respectively for exploitation and exploration. The couple of beta profiles are used to modify the original equation (1) presenting the update process executed at each iteration for each crow $i$. The two profiles were presented based on the beta function proposed by Alimi [77] and presented in both equations (3), (4) and (5). When, the main advantage in using the beta functions here, is their capacity to produce several forms and configurations of distributions, including the normal Gaussian one. The one-dimensional Beta function is defined in equation (3).

$$
\beta\left(x, p, q, x_{0}, x_{1}\right)=\left\{\begin{array}{c}
\left(\frac{x-x_{0}}{x_{c}-x_{0}}\right)^{p}\left(\frac{x_{1}-x}{x_{1}-x_{c}}\right)^{q} \text { IF } x \in\left[x_{0}, x_{1}\right] \\
0 \quad \text { otherwise }
\end{array}\right.
$$

Where; $\mathrm{p}, \mathrm{q}, x_{0}$ and $x_{1}$ are a real value, with $\left(x_{0}<x_{1}\right) \in \mathbb{R}$ and $x_{c}$ is detailed in equation (4). 


$$
x_{c}=\frac{p \cdot x_{1}+q \cdot x_{0}}{p+q}
$$

However, the multi-dimensional version is provided in the mathematical definition (5) presenting $m$ product of the one-dimensional in (3).

$$
\beta(x)=\prod_{k=1}^{m} \beta\left(x_{k}, p_{k}, q_{k}, x_{0, k}, x_{1, k}\right)
$$

The dynamic switch mechanism between the bi-behaviors Beta-1 and Beta-2 profiles are assumed by a comparison between the fitness function Fit $\left(X_{i}(t)\right)$ of each crow $i$ and the average solution (crow). If the fitness function $F i t\left(X_{i}(t)\right)=\sum_{k=1}^{K} f_{k}$ is greater than the mean value, we assume an exploration stage for the crow optimization process using Beta- 1 behaviour in Equation (6) is used the update the crow position. Otherwise, the second Beta-2 behaviour in Equation (6) is considered pushing each solution to the exploitation stage.

As it can be illustrated in figure 2, the two beta distribution profiles are detailed as follows:

$\checkmark$ The first large Gaussian Beta-1 exploitation profile, which characterized by a large standard deviation pushing the population for a good diversity in the search space with $\mathrm{p}$ and q variables of the Beta function in equation (3) are equals to 50.

$\checkmark$ The second narrow Gaussian Beta-2 exploration profile adapts a limited standard deviation with $\mathrm{p}$ and $\mathrm{q}$ in equation (3) are equals to 5 allowing a good convergence to the optimal solution over the time.

$$
X_{i}(t+1)=\left\{\begin{array}{c}
\text { //Beta } 1 \text { Behaviour for explotation profile: } \\
\text { If Fit }\left(X_{i}(t)\right) \geq \operatorname{Mean}\left(F i t\left(X_{i}(t)\right)\right. \text { then: } \\
X_{i}(t)+\text { Beta1_rand }(\boldsymbol{i}) \times\left(M_{j}(t)-X_{i}(t)\right) \\
\text { Else: } \\
\text { //Beta } 2 \text { Behaviour for exploration profile: } \\
\text { Beta2_rand }()
\end{array}\right.
$$

where; Beta-1 is a beta random distribution over $[0,1]$ which is assimilated to fine search step around the optimal solution, while the Beta-2 is more like a random explore mechanism performed away from the previous optimal solution, $M_{j}(t)$. Both Beta- 1 and Beta-2 values are determined using equation (3) with different configuration of the two properties $\mathrm{p}$ and $\mathrm{q}$.

The mutation operators in [78] is added to maintain more diversity in the flock of $\mathrm{N}$ crows. The nonuniform and the boundary mutation operators in equations (7) and (8) are applied to modify the variables $\mathrm{X}_{i}=X_{1}^{i}, X_{2}^{i}, \ldots, X_{d}^{i}$ of each crow $i$ according to the probability mutation $P_{m}$ equal to $\frac{1}{d}$, where $d$ is the dimensional search space and $X_{i} \in\left[a_{i}, b_{i}\right]$ where: $a_{i}$ and $b_{i}$ are 
the lower and the upper bounds respectively. The nonuniform mutation in equation (7) is applied when the modulo value when dividing the crow position i by three is equal to zero. However, if the remainder is equal to one the boundary mutation in equation (8) is used. Otherwise, all variables are considered without mutation operators.

$$
X_{i}^{\prime}=\left\{\begin{array}{c}
X_{i}+\left(b_{i}-X_{i}\right) \times\left(r_{1} \times\left(1-\frac{\text { iteration }}{\text { Maxiterations }}\right)^{b}, \text { if } r_{1} \leq 0.5, i \bmod 3=0\right. \\
X_{i}+\left(X_{i}-a_{i}\right) \times\left(r_{2} \times\left(1-\frac{\text { iteration }}{\text { Maxiterations }}\right)^{b}, \text { if } r_{2}>0.5, i \bmod 3=0\right. \\
X_{i}, \quad \text { otherwise }
\end{array}\right.
$$

where: $r_{1}$ and $r_{2}$ are a random value between 0 and 1 .

$$
X_{i}^{\prime}=\left\{\begin{array}{c}
a_{i}, \text { if } X_{i}+\left(r-0.5 * P_{m}\right)<a_{i}, i \bmod 3=1 \\
b_{i}, \text { if } X_{i}+\left(r-0.5 * P_{m}\right) \geq b_{i}, i \bmod 3=1 \\
X_{i}+\left(r-0.5 * P_{m}\right), \quad \text { otherwise; where } r=U(0,1)
\end{array}\right.
$$

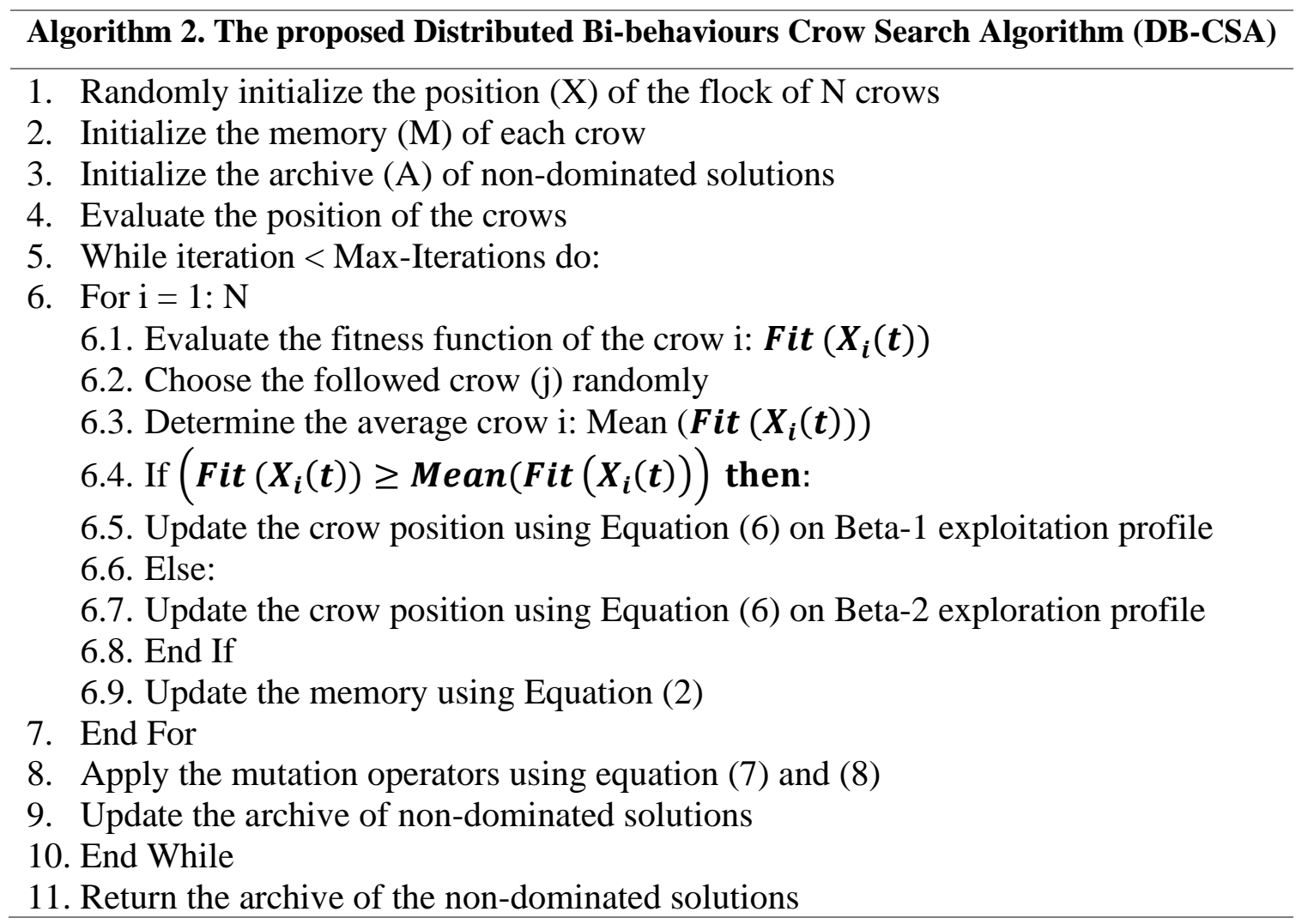

Fig. 3. The pseudo code of the proposed Distributed Bi-behaviours Crow Search Algorithm (DB-CSA). The advantage of the proposed DB-CSA algorithm is proved over their simplicity in terms of complexity which is equal to $O(n \times \log (n))$. When, the dynamic beta distribution profiles are the main properties of the DB-CSA algorithm investigating a high flexibility to produce several forms and configurations of distributions. Using both large Beta-1 and the narrow Beta-2 
functions have given the standard CSA a new mechanism to assume a good distribution of the population toward the best approximated results.

\section{Experimental Study}

The experimental study presented in this section is conducted using personal computer with 8 Go of Ram and a i7 intel processor. A Java implementation of the proposed method is done on the jMetal framework [79]. Results are presented with two comparative studies as detailed in Table 5:

- The first is done to compare the new proposed DB-CSA to a set of MOEAs designed for Dynamic Multi-Objective Optimization Problems (DMOPs).

- The second is for Many-Objective Optimization Problems (MaOPs).

- Algorithm configuration and parameters are listed in Table 4.

\subsection{Quality Indicators}

The performance measurements of all tested systems are done using the minimum values of the three quality indicators (QI), including the Inverted General Distance (IGD), the Mean Inverted General Distance (MIGD) and the Hypervolume Difference (HVD) which are presented respectively in equations (9), (10) and (11) respectively. All those metrics are used to measure both convergence and diversity of the tested MOEAs.

- The Inverted General Distance (IGD) [9] in equation (9) measures a Euclidian distance $d(i, P O F)$ between the ith points in the non-dominated solutions $P O F^{*}$ to the nearest approximated $P O F$ point.

$$
I G D\left(P O F^{*}, P O F\right)=\frac{\sum_{i \in P O F^{*}} d(i, P O F)}{\left|P O F^{*}\right|}
$$

- The Mean Inverted General Distance (MIGD) [9] , is presented in equation (10) presenting the average of IGD values at each iteration $t \in T$.

$$
\operatorname{MIGD}\left(\mathrm{POF}_{t}^{*}, \mathrm{POF}_{t}\right)=\frac{1}{T} \sum_{t \in T} I G D\left(\mathrm{POF}_{t}^{*}, \mathrm{POF}_{t}\right)
$$

- The Hypervolume Difference (HVD) [9], detailed in equation (11) aims to compute the difference between the Hypervolume (HV) of the true $P O F^{*}$ and the approximated POF .

$$
H V D=H V\left(P O F_{t}^{*}\right)-H V\left(P O F_{t}\right)
$$




\subsection{Tested Benchmarks}

Forty-four benchmarks are used to evaluate the relative performances of the proposed method upon the two scenarios. The twenty-one DMOPs test beds are as follows: five FDA [6], three dMOP [49], seven UDF [80] and six F(ZJZ) [81] functions. The twenty-three problems for MaOPs are composed of: seven MaF test suite MaF1-7, seven DTLZ1-7 functions and nine WFG1-9 problems. Test configurations detailed in Table 4 according to the number of variables (D) and objectives (M).

For dynamic multi-objective optimization, Farina et al.[6] has presented three types of DMOPs classified into three categories according to the time-varying POF and POS. In type I, the POS change and the POF remains the same, in type II both POS and POF are changed. However, type III of DMOP presents a time-varying POF and POS is unchanged. The main properties of all tested problems are reported in Table 3 presenting the variation of both POS and POF.

Table 3. Properties of the tested benchmarks: DMOPs and MaOPs.

\begin{tabular}{|c|c|c|c|c|}
\hline \multicolumn{2}{|c|}{ Problems } & $\mathbf{D}$ & $\mathbf{M}$ & Properties \\
\hline \multirow{17}{*}{$\begin{array}{l}\text { Dynamic Multi- } \\
\text { Objective } \\
\text { Optimization } \\
\text { Problems } \\
\text { (DMOPs) }\end{array}$} & FDA1 & 20 & 2 & Type I, convex, POS: sinusoidal and vertical shift \\
\hline & FDA2 & 15 & 2 & $\begin{array}{l}\text { Type II, POF: convex to concave, dynamic density, POS: sinusoidal and } \\
\text { vertical shift }\end{array}$ \\
\hline & FDA3 & 30 & 2 & $\begin{array}{l}\text { Type II, POF: convex, dynamic spread, POS: sinusoidal and vertical } \\
\text { shift }\end{array}$ \\
\hline & FDA4 & 12 & 3 & $\begin{array}{l}\text { Type I, POF: concave, dynamic spread, POS: sinusoidal and vertical } \\
\text { shift }\end{array}$ \\
\hline & FDA5 & 12 & 3 & $\begin{array}{l}\text { Type II, POF: concave, dynamic spread, POS: sinusoidal and vertical } \\
\text { shift }\end{array}$ \\
\hline & dMOP1 & 10 & 2 & Type III, POF: convex to concave, POS: no change \\
\hline & dMOP2 & 10 & 2 & Type II, POF: convex to concave, POS: sinusoidal and vertical shift \\
\hline & dMOP3 & 10 & 2 & Type I, POF: convex, dynamic spread, POS: sinusoidal and vertical shift \\
\hline & F5, F6, F7, F9, F10 & 20 & 2 & Type II, POF: convex to concave, POS: trigonometric and vertical shift \\
\hline & F8 & 20 & 3 & \\
\hline & UDF1 & 10 & 2 & Type I, POF: linear continuous, POS: trigonometric and vertical shift \\
\hline & UDF2 & 10 & 2 & Type I, POF: linear continuous, POS: polynomial and vertical shift \\
\hline & UDF3 & 10 & 2 & Type III, POF: discontinuous, POS: trigonometric and no variation \\
\hline & UDF4 & 10 & 2 & Type II, convex to concave, POS: trigonometric and horizontal shift \\
\hline & UDF5 & 10 & 2 & Type II, convex to concave, POS: polynomial + vertical shift \\
\hline & UDF6 & 10 & 2 & Type III, discontinuous, POS: trigonometric and no variation \\
\hline & UDF7 & 10 & 3 & Type III, POF :3D radius concave, POS: trigonometric and no variation \\
\hline \multirow{12}{*}{$\begin{array}{l}\text { Many-Objective } \\
\text { Optimization } \\
\text { Problems } \\
\text { (MaOPs) }\end{array}$} & MaF1 & \multirow{6}{*}{$\begin{array}{l}11 \\
12 \\
16\end{array}$} & \multirow{6}{*}{$\begin{array}{l}2 \\
3 \\
7\end{array}$} & Linear \\
\hline & $\mathrm{MaF} 2$ & & & Concave \\
\hline & MaF3 & & & Convex, multimodal \\
\hline & MaF4 & & & Concave, multimodal \\
\hline & MaF5 & & & Convex, biased \\
\hline & MaF6 & & & Concave, degenerate \\
\hline & \multirow{3}{*}{ MaF7 } & 21 & 2 & Mixed \\
\hline & & 22 & 3 & Disconnected \\
\hline & & 26 & 7 & Multimodal \\
\hline & WFG1 & 11 & 2 & Convex, unimodal \\
\hline & WFG2 & 12 & 3 & Convex, disconnected \\
\hline & WFG3 & 16 & 7 & Linear, unimodal \\
\hline
\end{tabular}




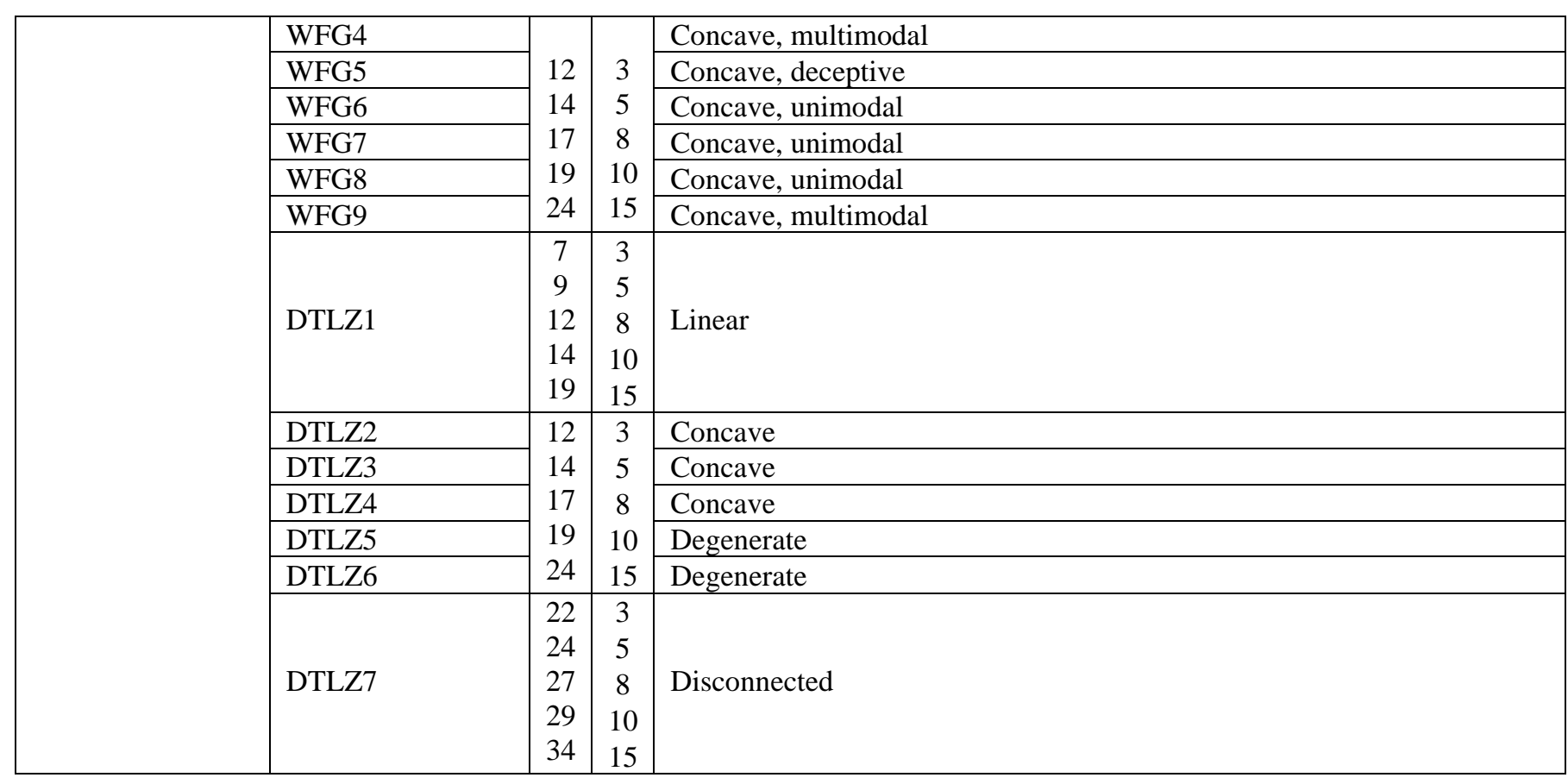

\subsection{Experimental Settings}

\section{A- Comparative study (1) for DMOPs:}

The first comparative test is done for DMOPs using FDA, dMOP, UDF and F(ZJZ) benchmarks with 2 and 3 objectives. Five standard MOEAs [9] and the six-transfer learningbased methods [51] are compared to the new proposal DB-CSA system. All compared algorithms have the same parameters settings referring to the original publications [9] and [51]. However, all DMOPs are characterized by a dynamic POS or/and POF according to the timevarying property $t$ that change at each instance as in equation (12).

$$
t=\frac{1}{n_{t}}\left|\frac{\tau}{\tau_{t}}\right|
$$

where: $n_{t}, \tau$ and $\tau_{t}$ are the severity of change, the iteration counter and the frequency of the change respectively. Three categories of environmental change are considered in this study and differentiated according to the values of $n_{t}$ fixed to 10 and the variation of the frequency $\tau_{t}$. The property $\tau_{t}$ is equal to 5,10 and 20 for severe, moderate and slight environmental changes respectively.

As resumed in Table 4, the swarm and the archive size are equal to 100 as fixed in [9] and [51]. All MOEAs are executed 30 times independently and each run is stopped when the maximum number of iterations is reached and computed as follow; Maxiter $=3 \times n_{t} \times \tau_{t}+$ 50. For each DMOP the number of variables (D) and objectives (M) are such in Table 3.

\section{B- Comparative study (2) for MaOPs:}


The second experimental test is done for many-objective optimization referring to the contributions [57] and [58] to compare the proposed DB-CSA approach to seven and thirteen Many Objective Evolutionary Algorithms (MaOEAs) respectively. As mentioned in Table 4, the population size is fixed according to the number of objectives (M). The seven and thirteen MaOEAs are executed during 30 and 31 independent runs respectively.

Each run is stopped when the maximum number of iterations $\left(\right.$ Max $\left._{i t e r}\right)$ is reached. As per the recommendations in [58], the number of objectives (M) for both MaF and WFG test suites is set to 2, 3 and 7 and the number of variables (D) is computed as follow; $D=M+K-1$, where $\mathrm{k}$ is set to 10 for MaF1-MaF6 and 20 for MaF7. However, the WFG test suite has characterized by three parameters including; the number of decision variables (D) equal to $D=$ $M+9$ the number of position related variables (K) equal to $K=M-1$ and the number of distance related variables (L) set as $L=D-k$. Furthermore, in [57] both WGF and DTLZ functions are tested with 3, 5, 8, 10 and 15 objectives.

Table 4. Parameters Settings

\begin{tabular}{|c|c|c|c|c|}
\hline Reference & Nb. Objectives (M) & Population size & Max-Iteration $\left(\right.$ Max $\left._{\text {iter }}\right)$ & Independent runs \\
\hline$[9]$ & 2 and 3 & 100 & $3 \times n_{t} \times \tau_{t}+50$ & 30 \\
\hline$[58]$ & 2,3 and 7 & 100 & 25000 & 31 \\
& 3 & 92 & 300 WFG1-7 and DTLZ 2,4,5,7 & 30 \\
{$[57]$} & 5 & 224 & $1000:$ DTLZ 1,3,6 & \\
& 8 & 164 & & \\
& 10 & 280 & & \\
& 15 & 152 & & \\
\hline
\end{tabular}

Table 5. MOEAs and MaOEAs Solvers used for the comparative study

\begin{tabular}{|c|c|c|c|c|}
\hline & \multicolumn{2}{|c|}{ Comparative study (1) for DMOPs } & \multicolumn{2}{|c|}{ Comparative study (2) for MaOPs } \\
\hline & Five MOEAs [9] & $\begin{array}{l}\text { Six transfer learning- } \\
\text { based methods [51] }\end{array}$ & Thirteen MaOEAs [58] & Seven MaOEAs [57] \\
\hline $\begin{array}{c}\text { Tested } \\
\text { MOEAs and } \\
\text { MaOEAs }\end{array}$ & $\begin{array}{l}\text { DNSGA-II [1] } \\
\text { SGEA [9] } \\
\text { dCOEA [49] } \\
\text { PPS [50] } \\
\text { MOEA/D [16] }\end{array}$ & $\begin{array}{l}\text { MMTL-MOEA/D [51] } \\
\text { RI-MOEA/D [51] } \\
\text { PPS-MOEA/D [51] } \\
\text { SVR-MOEA/D [52] } \\
\text { Tr-MOEA/D [53] } \\
\text { KF-MOEA/D [54] }\end{array}$ & $\begin{array}{l}\text { MSOPS-II [15] } \\
\text { MOEA/D [16] } \\
\text { HypE [22] } \\
\text { PICEA-g [36] } \\
\text { SPEA/SDE [34] } \\
\text { GrEA [30] } \\
\text { NSGA-III [19] } \\
\text { KnEA [35] } \\
\text { RVEA [17] } \\
\text { Two_Arch2 [38] } \\
\theta \text {-DEA [31] } \\
\text { MOEA/DD [20] } \\
\text { AnD [58] }\end{array}$ & $\begin{array}{l}\text { PMEA-MA [57] } \\
\text { PMEA*-MA[57] } \\
\text { SPEA2/SDE [34] } \\
\text { NSGA-II/SDR [56] } \\
\text { MaOEA/IGD [26] } \\
\text { VaEA [55] } \\
\text { SPEA [59] }\end{array}$ \\
\hline QI & IGD and HVD & MIGD & IGD & IGD \\
\hline Benchmarks & FDA, dMOP, UDF, F & FDA, dMOP & WFG, MaF & WFG, DTLZ \\
\hline $\begin{array}{c}\text { Number of } \\
\text { Objectives } \\
\text { (M) }\end{array}$ & 2 and 3 & 2 and 3 & 2,3 and 7 & $3,5,8,10$, and 15 \\
\hline
\end{tabular}




\subsection{Results Analysis and Discussion}

In this sub-section, comparative result analysis is conducted for the experimental studies of DMOPs and MaOPS, using the nonparametric Wilcoxon sign rank test [82], while some qualitative results are performed over the box plot of the one-way ANOVA test [83]. The statistical analysis methods are used to estimate the $p$-value property to determine the statistically significant difference between the compared methods. If the $p$-value is less or equal to 0.05 , the statistical results are considered significantly important. All quantitative results are presented in the appendices section including Tables 9, 10, 11, 12, 13, 14, 15, 16 and 17.

\section{A- Analysis of the comparative study (1) for FDA and dMOP problems}

The comparative study (1) is firstly considered to compare the proposed DB-CSA to six transfer learning-based methods for solving FDA and dMOP problems with severe $\left(\tau_{t}=\right.$ $\left.5, n_{t}=10\right)$, moderate $\left(\tau_{t}=n_{t}=10\right)$ and slight $\left(\tau_{t}=20, n_{t}=10\right)$ environmental changes. Based on the reported results over MIGD metric in Table 9, it is remarkable the efficiency of the new DB-CSA system having the best mean and standard deviations values for all test suites with different environmental changes compared to six transfer learning-based approaches. Based on the statistical results over the Wilcoxon signed rank test on Table 6 , we can determine the importance of the new DB-CSA with a $p$-value less than 0.05 defining a significant difference compared to MMTL-MOEA/D, KF-MOEA/D, PPS-MOEA/D, SVR-MOEA/D, TrMOEA/D, and RI-MOEA/D approaches. Also, Figure 4 determines the importance of DB-CSA compared to six transfer learning-based methods over the one-way ANOVA test.

Table 6. Nonparametric statistical analysis based on Wilcoxon signed rank test of DB-CSA vs. Six peer transfer-learning based approaches over MIGD metric for FDA and dMOP functions.

\begin{tabular}{|c|c|c|c|c|c|c|}
\hline DB-CSA Vs. & QI & Prob. & R- & $\mathbf{R}+$ & P-value & Best method \\
\hline MMTL-MOEA/D & \multirow{6}{*}{ MIGD } & \multirow{6}{*}{ FDA \& dMOP } & 300 & 0 & 0.000018 & DB-CSA \\
\hline KF-MOEA/D & & & 300 & 0 & 0.000018 & DB-CSA \\
\hline PPS-MOEA/D & & & 300 & 0 & 0.000018 & DB-CSA \\
\hline SVR-MOEA/D & & & 300 & 0 & 0.000018 & DB-CSA \\
\hline Tr-MOEA/D & & & 300 & 0 & 0.000018 & DB-CSA \\
\hline RI-MOEA/D & & & 300 & 0 & 0.000018 & DB-CSA \\
\hline
\end{tabular}

Secondly, the five standard MOEAs (DNSGA-II, dCOEA, PPS, MOEA/D, and SGEA) are compared to the new DB-CSA. The average and the standard deviation values for both FDA and dMOP test suites over the IGD and HVD metrics respectively can be seen in Tables 10 and 11. Based on IGD metric on Table 10, we can argue the superiority of DB-CSA method compared to five standard MOEAs designed for dynamic multi-objective optimization. The results based on Wilcoxon signed rank test are presented in Table 7, indicating that DB-CSA is the best method over IGD at 0.05 statistically significance level compared to other MOEAs. 
While, the same conclusion is confirmed using the box plot over one-way ANOVA test in Figure 5.

Table 11 reports the quantitative results over HVD quality indicator. We can conclude that the proposed DB-CSA is the winner for solving different types of DMOPs including FDA1 in type I with dynamic POS and static POF, FDA3, FDA5 and dMOP2 in type II with time-varying POS and POF and dMOP1 in type III with unchangeable POS and dynamic POF respecting to all category of environmental changes. Meanwhile the DB-CSA has a closed result to the SGEA system for solving FDA2 function in type II characterized by a dynamic density of the solutions set as well as a cyclic change of the POF from convex to concave and the FDA4 in type I with time-varying spread of solutions and severe search space. In addition, the dCOEA algorithm has a closed mean value for solving dMOP3 function characterized by a static curvature of the estimated POF and dynamic spread of the solution set compared to the proposed DB-CSA.

Based on Table 7 and comparing the negative and positive ranks, the DB-CSA is the best method over HVD quality indicator. While, this importance does not determine as statistically significant with a p-value greater than 0.05. The one-way ANOVA results in Figure 6 assume the competitive importance of DNSGA-II, dCOEA, PPS, MOEA/D, and SGEA for solving FDA and dMOPs test functions with 2 and 3 objective including different environmental changes when using the HVD metric.

\section{B- Analysis of the comparative study (1) for UDF and F problems}

Considering the quantitative results for the Unconstrained Dynamic Functions (UDF1UDF7) in Table 12, it appears that the DB-CSA has the greatest values for all UDF functions. Furthermore, we can resume the stability of the new DB-CSA algorithm when solving the triobjective problem (F8) and the bi-objectives function (F10) over IGD metrics compared to the Population Prediction Strategy (PPS) approach which is performed only for solving F5, F6, F7 and F9 test functions. However, the $\mathrm{F}(\mathrm{ZJZ})$ problems are a complex benchmark including a time-varying POF and POS with a nonlinear correlation between the decision variables. Based on the Wilcoxon sign rank in Table 7, we can resume that the DB-CSA is the best method, however this importance does not present a high statistically significance with a p-values greater than 0.05 compared to the five MOEAs over the IGD metric.

Based on HVD results reported in Table 13, the DB-CSA has a good result for the majority of UDF benchmarks, and fails only for solving the disconnected UDF6 compared to the DNSGA-II system. However, we can resume the importance of the PPS system for solving F5, F7 and F10 and the SGEA for F6 and F9. Also, the Wilcoxon signed rank test detailed in Table 7 presents the importance of DNSGA-II, dCOEA, PPS, MOEA/D and SGEA with a $p$-value 
exceeding 0.05 significance level. Figure 7 has reported the one-way ANOVA results in a box plot of the six MOEAs over IGD and HVD metrics.

Table 7. Nonparametric statistical analysis based on Wilcoxon signed rank test of DB-CSA vs. five peer MOEAs over IGD, HVD metrics for FDA, dMOP, UDF and F functions

\begin{tabular}{|c|c|c|c|c|c|c|c|c|c|c|c|c|}
\hline DB-CSA Vs. & Prob. & QI & R- & $\mathbf{R}+$ & P-value & Best method & Prob. & QI & R- & $\mathbf{R}+$ & P-value & Best method \\
\hline DNSGA-II & \multirow{10}{*}{$\begin{array}{c}\text { FDA } \\
\& \\
\text { dMOP }\end{array}$} & \multirow{5}{*}{ IGD } & 300 & 0 & 0.000018 & DB-CSA & \multirow{10}{*}{$\begin{array}{c}\text { UDF } \\
\& \\
\text { F }\end{array}$} & \multirow{5}{*}{ IGD } & 56 & 35 & 0,463071 & DB-CSA \\
\hline dCOEA & & & 300 & 0 & 0.000018 & DB-CSA & & & 61 & 30 & 0,278707 & DB-CSA \\
\hline PPS & & & 300 & 0 & 0.000018 & DB-CSA & & & 56 & 35 & 0,463071 & DB-CSA \\
\hline MOEA/D & & & 300 & 0 & 0.000018 & DB-CSA & & & 55 & 36 & 0,506746 & DB-CSA \\
\hline SGEA & & & 300 & 0 & 0.000018 & DB-CSA & & & 55 & 36 & 0,506746 & DB-CSA \\
\hline DNSGA-II & & \multirow{5}{*}{ HVD } & 181 & 119 & 0,375772 & DB-CSA & & \multirow{5}{*}{ HVD } & 35 & 56 & 0,463071 & DNSGA-II \\
\hline dCOEA & & & 170 & 130 & 0,567709 & DB-CSA & & & 36 & 55 & 0,506746 & dCOEA \\
\hline PPS & & & 173 & 127 & 0,511089 & DB-CSA & & & 36 & 55 & 0,506746 & PPS \\
\hline MOEA/D & & & 181 & 119 & 0,375772 & DB-CSA & & & 36 & 55 & 0,506746 & MOEA/D \\
\hline SGEA & & & 163 & 137 & 0,710318 & DB-CSA & & & 35 & 56 & 0,463071 & SGEA \\
\hline
\end{tabular}

\section{1) Analysis of the comparative study (2) for MaF and WFG problems with 2, 3 and 7} objectives

For the second comparative study (2), thirteen many-objectives evolutionary approaches (MSOPS-II, MOEA/D, HypE, PICEA-g, SPEA/SDE, GrEA, NSGA-III, KnEA, RVEA, two_Arch2, $\theta$-DEA, MOEA/DD, AnD) are firstly compared to the new proposed DB-CSA system based on a set of many-objective optimization problems denoted by MaF and WFG test suites with 2, 3 and 7 objectives including different numbers of decision variables as detailed in Table 3. Results reported in Table 14, shown the IGD results of the 14 compared ManyObjective Evolutionary Algorithms for solving nine MaOPs (WFG1-WFG9) characterized by a dynamic shape of the POF that change from convex to concave. The DB-CSA has ranked as the first system for solving seven WFG test suites from nine thus including; WFG1, WFG3, WFG4, WFG5, WFG6, WFG8 and WFG9 and fails only for WFG2 compared to HypE and $\theta$ DEA having almost the same mean values of the IGD metric for WFG7 when the number of objectives is equal to 2. By increasing the number of objectives to 3 and 7 the WFG becomes more complex and the issue of the lack of convergence and diversity presents the challenging task. Based on the reported IGD values of the tri-objectives WFG functions in Table 14, we can conclude the efficiency of the new proposed DB-CSA approach to deal with the increasing number of objectives. Also, Table 14 has shown the best values for MaOPS with 7 objectives.

In addition, Table 15 has showing the mean and the standard deviation values over IGD metric for solving the MaF test suite (MaF1-MaF7) with 2, 3 and 7 objectives functions. Figure 12, has presented the approximated POF for the MaF test suite. The new DB-CSA is presented a good method for solving the MaF test suite compared to the thirteen state of the art MaOEAs. Table 8, has shown the importance of DB-CSA over the Wilcoxon signed rank test, while all 
computed p-values are less than 0.05 assuming the statistically significance difference of DBCSA compared to the thirteen MaOEAs thus including; MSOPS-II, MOEA/D, HypE, PICEAg, SPEA/SDE, GrEA, NSGA-III, KnEA, RVEA, two_Arch2, $\theta$-DEA, MOEA/DD, AnD for solving the MaF test suite with 2,3 and 7 objectives compared. The dynamic treatment of both convergence and diversity concepts is very useful when solving a set of complex MaOPs with high number of objectives.

\section{2) Analysis of the comparative study (2) for DTLZ and WFG problems with 3, 5, 8, 10 and 15 objectives}

In the second part the comparative study (2), seven MaOEAs (PMEA-MA, PMEA*-MA, SPEA2/SDE, NSGA-II/SDR, MaOEA/IGD, VaEA, SPEA) are compared to the new DB-CSA approach for solving a set of complex DTLZ and WFG test suites with 3, 5, 8, 10 and 15 objectives. Some qualitative results are presented in Figures 13 and 14 to present the estimated POF to the true optimal solutions for both WFG and DTLZ with 10 and 15 objectives respectively. However, all quantitative results are given in Tables 16 and 17 presenting the efficiency of new DB-CSA approach over IGD metric for solving the complex set of tested nine WFG1-9 problems and seven DTLZ1-7 functions respectively. However, this difference is reported as statistically very significant when using the Wilcoxon signed rank test with 0.05 significance level as detailed in Table 8 , when all computed $p$-values are less than 0.05. Figure 8, has presented the boxplot over the one-way ANOVA test for solving a set of WFG test suit with 3, 5 and 15 objectives, when the DB-CSA is the best method.

Table 8. Nonparametric statistical analysis based on Wilcoxon signed rank test of DB-CSA vs. thirteen peer MAOEAs over IGD metric for WFG, MaF and DTLZ functions.

\begin{tabular}{|c|c|c|c|c|c|c|c|c|c|c|c|c|}
\hline DB-CSA Vs. & QI & Prob. & R- & $\mathbf{R +}$ & P-value & $\begin{array}{c}\text { Best } \\
\text { method }\end{array}$ & QI & Prob. & R- & $\mathbf{R +}$ & P-value & $\begin{array}{c}\text { Best } \\
\text { method }\end{array}$ \\
\hline MSOPS-II & \multirow{20}{*}{ IGD } & \multirow{13}{*}{ WFG } & 378 & 0 & 0,000006 & DB-CSA & & \multirow{13}{*}{ MaF } & 231 & 0 & 0,000060 & DB-CSA \\
\hline MOEA/D & & & 378 & 0 & 0,000006 & DB-CSA & & & 231 & 0 & 0,000060 & DB-CSA \\
\hline HypE & & & 374 & 4 & 0,000009 & DB-CSA & & & 231 & 0 & 0,000060 & DB-CSA \\
\hline PICEA-g & & & 378 & 0 & 0,000006 & DB-CSA & & & 231 & 0 & 0,000060 & DB-CSA \\
\hline SPEA/SDE & & & 376 & 2 & 0,000007 & DB-CSA & & & 231 & 0 & 0,000060 & DB-CSA \\
\hline GrEA & & & 378 & 0 & 0,000006 & DB-CSA & & & 231 & 0 & 0,000060 & DB-CSA \\
\hline NSGA-III & & & 373 & 5 & 0,000010 & DB-CSA & & & 231 & 0 & 0,000060 & DB-CSA \\
\hline KnEA & & & 378 & 0 & 0,000006 & DB-CSA & & & 231 & 0 & 0,000060 & DB-CSA \\
\hline RVEA & & & 378 & 0 & 0,000006 & DB-CSA & & & 231 & 0 & 0,000060 & DB-CSA \\
\hline Two_Arch2 & & & 374 & 4 & 0,000009 & DB-CSA & ICD & & 231 & 0 & 0,000060 & DB-CSA \\
\hline$\theta$-DEA & & & 376.5 & 1.5 & 0,000007 & DB-CSA & IGD & & 231 & 0 & 0,000060 & DB-CSA \\
\hline MOEA/DD & & & 377 & 1 & 0,000006 & DB-CSA & & & 231 & 0 & 0,000060 & DB-CSA \\
\hline AnD & & & 378 & 0 & 0,000006 & DB-CSA & & & 231 & 0 & 0,000060 & DB-CSA \\
\hline PMEA-MA & & \multirow{7}{*}{ WFG } & 1035 & 0 & $5,179 \mathrm{E}-9$ & DB-CSA & & \multirow{7}{*}{ DTLZ } & 629 & 1 & $2,70 \mathrm{E}-7$ & DB-CSA \\
\hline PMEA*-MA & & & 1035 & 0 & 5,179E-9 & DB-CSA & & & 629 & 1 & $2,70 \mathrm{E}-7$ & DB-CSA \\
\hline SPEA2/SDE & & & 1035 & 0 & $5,179 \mathrm{E}-9$ & DB-CSA & & & 630 & 0 & $2,48 \mathrm{E}-7$ & DB-CSA \\
\hline $\begin{array}{l}\text { NSGA- } \\
\text { II/SDR }\end{array}$ & & & 1035 & 0 & $5,179 \mathrm{E}-9$ & DB-CSA & & & 630 & 0 & $2,48 \mathrm{E}-7$ & DB-CSA \\
\hline MaOEA/IGD & & & 1035 & 0 & $5,179 \mathrm{E}-9$ & DB-CSA & & & 630 & 0 & $2,48 \mathrm{E}-7$ & DB-CSA \\
\hline VaEA & & & 1035 & 0 & $5,179 \mathrm{E}-9$ & DB-CSA & & & 629 & 1 & $2,70 \mathrm{E}-7$ & DB-CSA \\
\hline SPEA & & & 1035 & 0 & $5,179 \mathrm{E}-9$ & DB-CSA & & & 630 & 0 & $2,48 \mathrm{E}-7$ & DB-CSA \\
\hline
\end{tabular}


One-way ANOVA Results in a Boxplot of Seven MOEAs over MIGD for FDA, dMOP Functions with $\left(\tau_{t}=5, n_{t}=10\right)$.

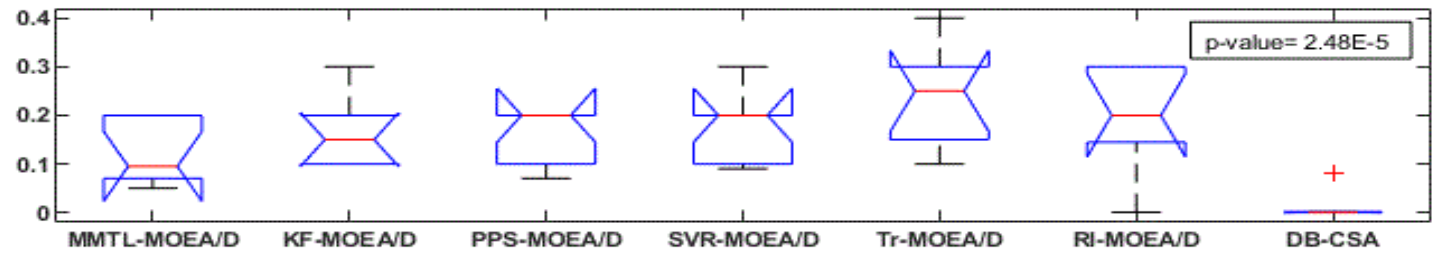

(a)

One-way ANOVA Results in a Boxplot of Seven MOEAs over MIGD for FDA, dMOP Functions with $\left(\tau_{t}=10, n_{t}=10\right)$.

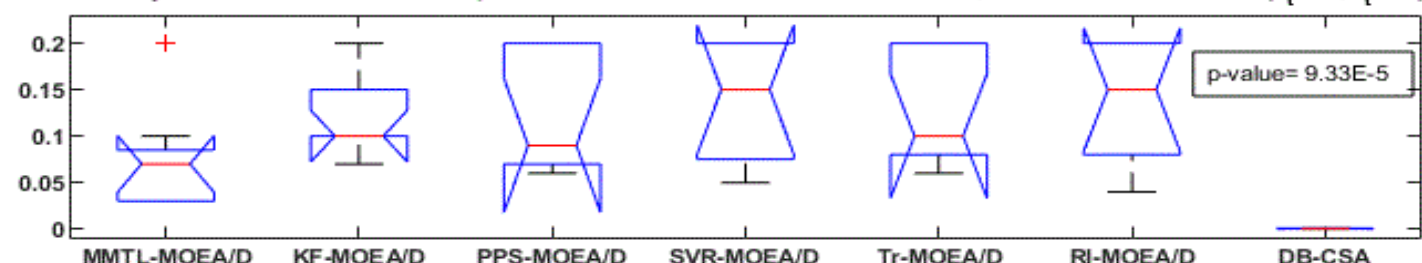

(b)

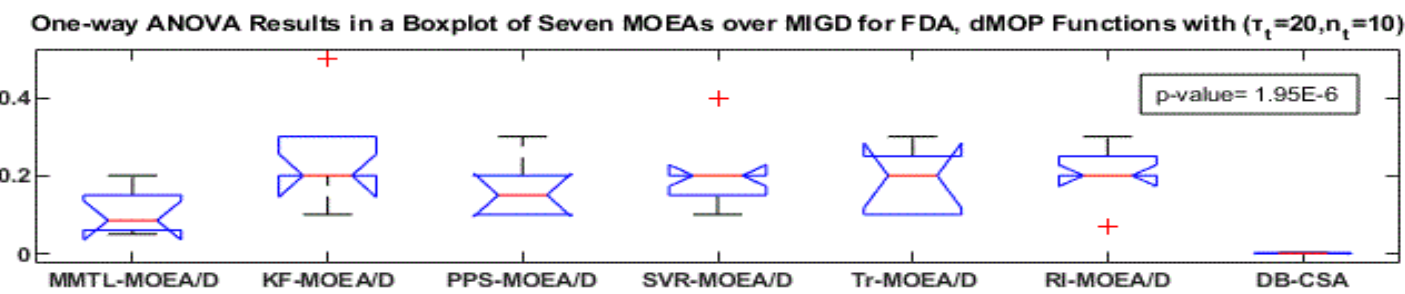

(c)

Fig. 4. One-way ANOVA Results in a Boxplot of 7 MOEAs over MIGD of FDA, dMOP Functions for (a) severe with $\left(\tau_{t}=5, n_{t}=10\right)$, (b) moderate with $\left(\tau_{t}=10, n_{t}=10\right)$, and (c) slight with $\left(\tau_{t}=20, n_{t}=10\right)$ environmental changes respectively.

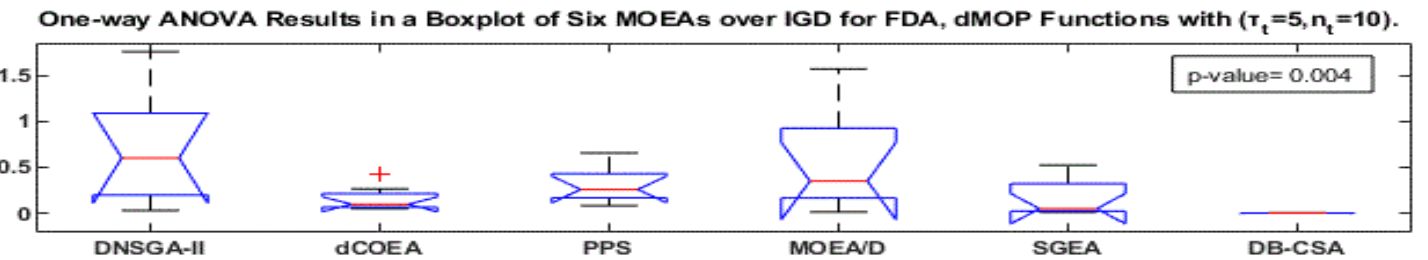

(a)

One-way ANOVA Results in a Boxplot of Six MOEAs over IGD for FDA, dMOP Functions with $\left(r_{t}=10, n_{t}=10\right)$.

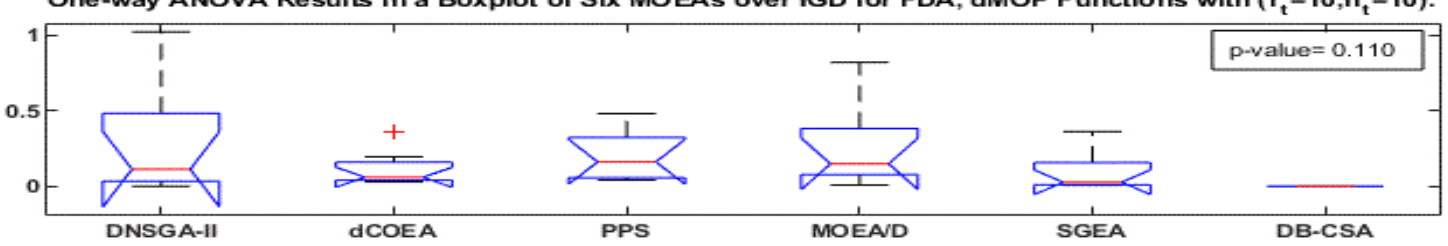

(b)

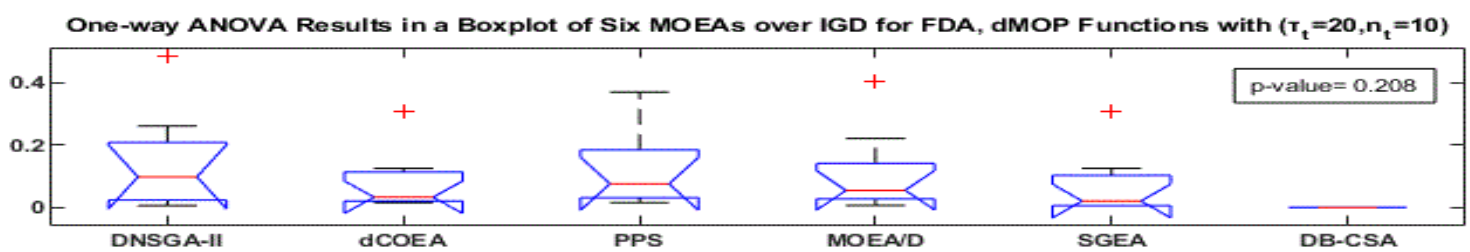

(c)

Fig. 5 One-way ANOVA Results in a Boxplot of 6 MOEAs over IGD of FDA, dMOP for (a) severe with $\left(\tau_{t}=5, n_{t}=10\right)$, (b) moderate $\left(\tau_{t}=10, n_{t}=10\right)$, and (c) slight $\left(\tau_{t}=20, n_{t}=10\right)$ environmental changes respectively. 


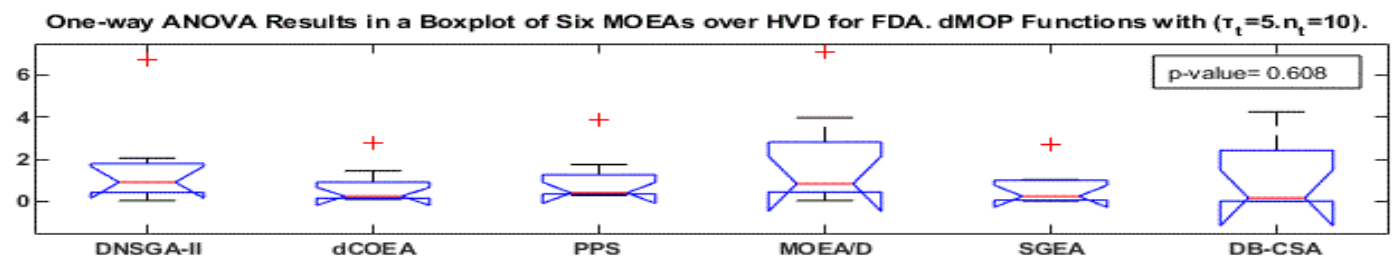

(a)

One-way ANOVA Results in a Boxplot of Six MOEAs over HVD for FDA, dMOP Functions with $\left(\tau_{t}=10 . n_{t}=10\right)$.

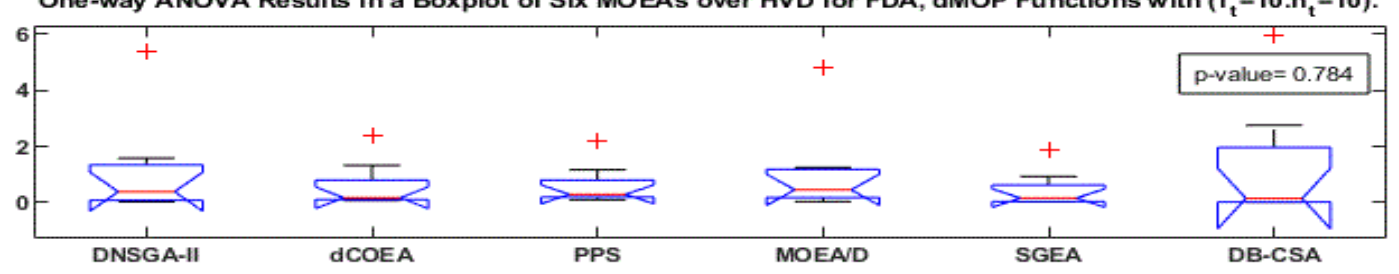

(b)

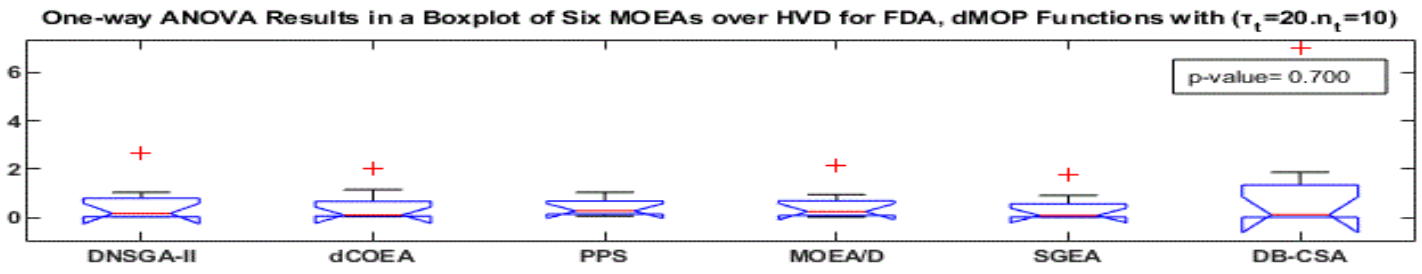

(c)

Fig. 6. One-way ANOVA Results in a Boxplot of 6 MOEAs over HVD of FDA, dMOP for (a) severe $\left(\tau_{t}=5, n_{t}=10\right)$, (b) moderate $\left(\tau_{t}=10, n_{t}=10\right)$, and (c) slight $\left(\tau_{t}=20, n_{t}=10\right)$ environmental changes respectively.

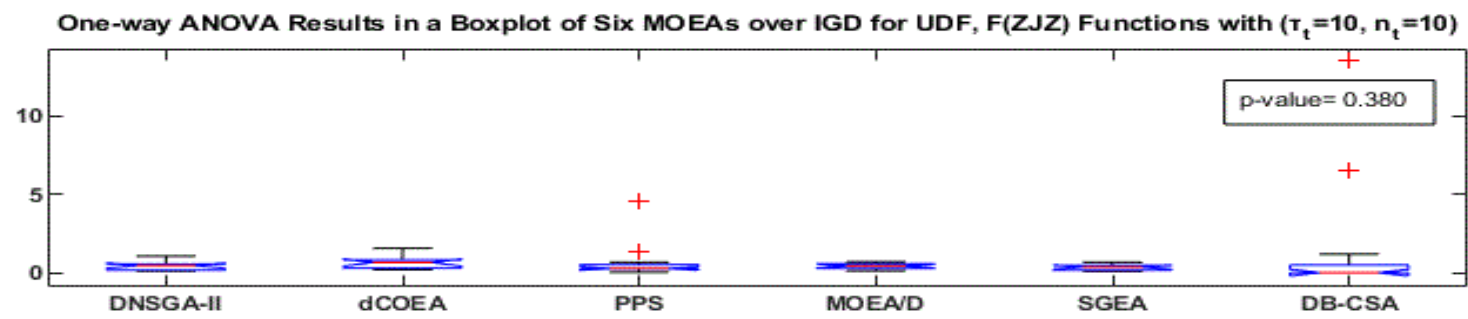

(a)

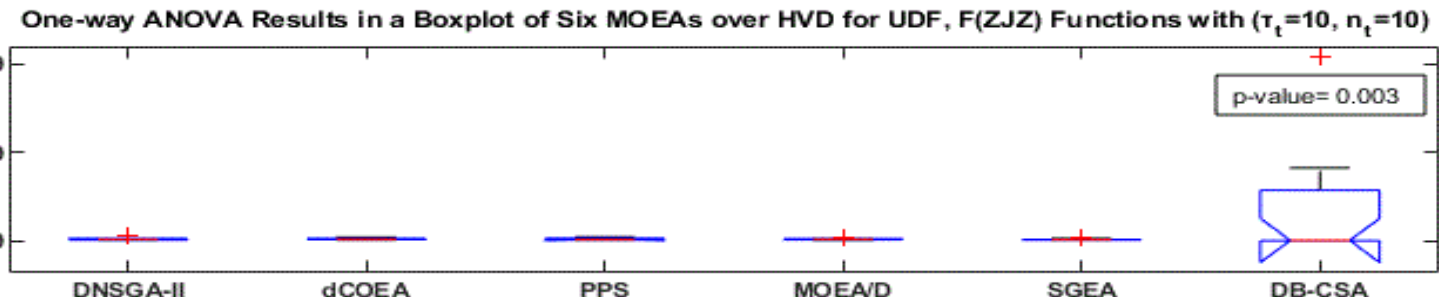

(b)

Fig. 7 One-way ANOVA Results in a Boxplot of 6 MOEAs over (a) IGD and (b) HVD of UDF, F functions for moderate $\left(\tau_{t}=10, n_{t}=10\right)$ environmental changes. 


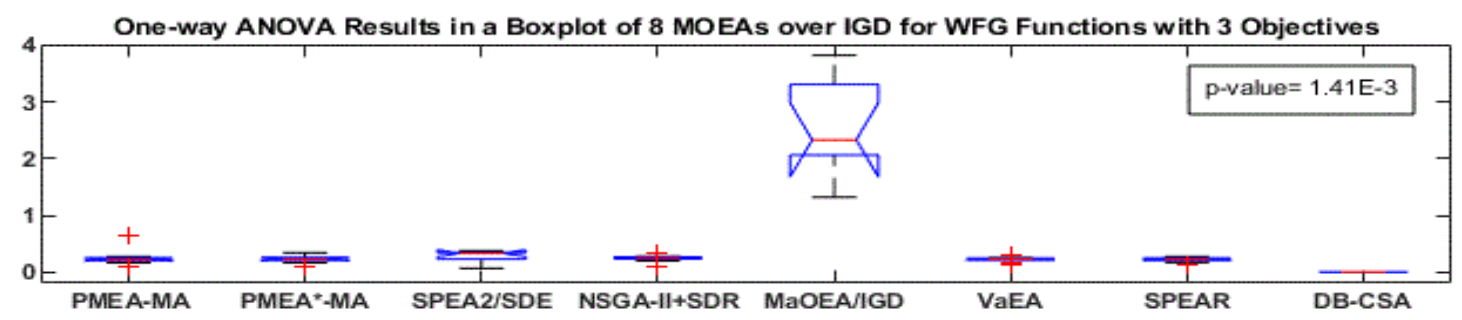

(a)

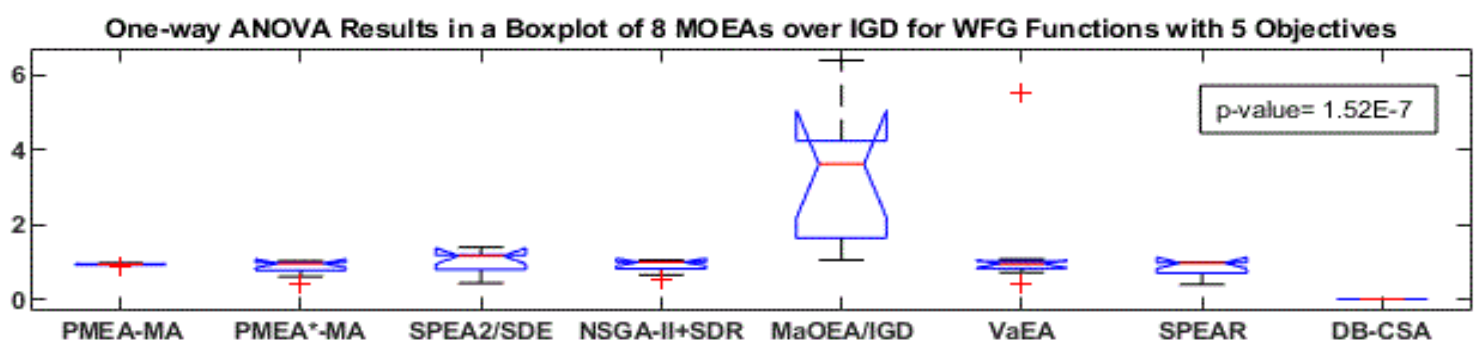

(b)

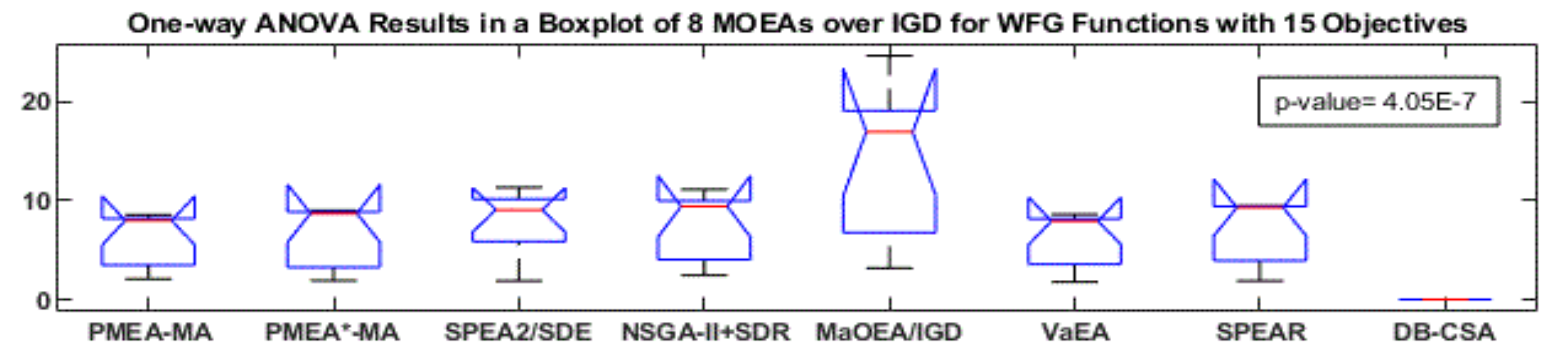

(c)

Fig. 8 One-way ANOVA Results in a Boxplot of 8 MOEAs over IGD for WFG functions with (a) 3, (b) 5 and (c) 15 objectives.

As a global conclusion and based on both comparative studies (1) and (2), all quantitative results have shown the efficiency of DB-CSA system and its flexibility for solving eight DMOPs (FDA and dMOP) with 2 and 3 objectives including several types of time-varying POF and POS compared to seven transfer-learning based methods (MMTL-MOEA/D, KFMOEA/D, PPS-MOEA/D, SVR-MOEA/D, Tr-MOEA/D, and RI-MOEA/D) using the MIGD metric. Considering the plot of MIGD, IGD and HVD values in Figures 9, 10 and 11 during 30 independent runs, we can determine the importance of DB-CSA for solving DMOPs in types I (FDA1, FDA4, dMOP3), II (dMOP2) and III (dMOP1). By analyzing the perturbation of MIGD, IGD and HVD plots, we can see the challenging results when solving FDA1, FDA4, dMOP1, dMOP2 and dMOP3 compared to FDA5 and FDA3 in type II with time-varying POF and POS in both severe and moderate search space and FDA5, FDA3 and FDA2 in a slight change.

Also, this efficiency of DB-CSA is demonstrated when solving a dynamic tri-objective FDA4 with dynamic POS. However, the proposed DB-CSA algorithm has assumed a 
competitive importance compared to the five standard MOEAs (DNSGA-II, dCOEA, PPS, MOEA/D and SGEA) when solving five FDA functions, three dMOP problems over IGD metric including different type of environmental changes. Contradictory to the HVD metric when all results are not statistically significant at a level of 0.05 . Furthermore, the importance of DB-CSA does not assume a high significance level compared to the five standard MOEAs when solving seven UDF and six F problems in type II with a time-varying POF and POS in a moderate environmental change.

Last but not least, we can resume the importance of the DB-CSA system compared to 13 algorithms thus including; MSOPS-II, MOEA/D, HypE, PICEA-g, SPEA/SDE, GrEA, NSGAIII, KnEA, RVEA, Two_Arch2, $\theta$-DEA, MOEA/DD, AnD for solving a set of many-objective optimization problems ( $9 \mathrm{WFG}$ and $7 \mathrm{MaF}$ ) with 2, 3 and 7 objectives as well as the more complex DTLZ and WFG test suites with 3, 5, 8, 10 and 15 objectives compared to the seven MaOEAs (PMEA-MA, PMEA*-MA，SPEA2/SDE，NSGA-II/SDR，MaOEA/IGD，VaEA, SPEA).
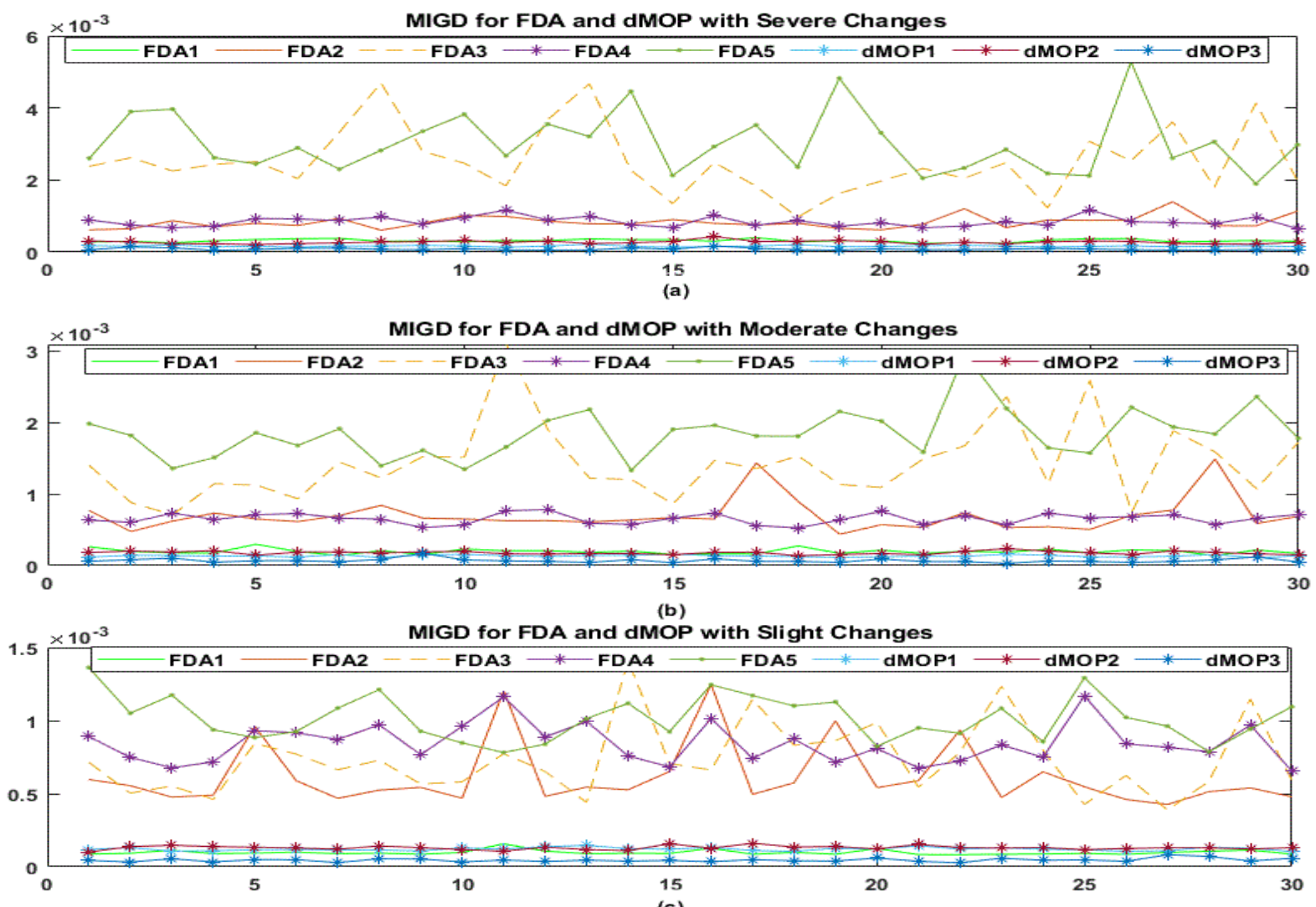

(c)

Fig. 9. MIGD Plot for FDA, dMOP functions with (a) severe, (b) moderate and (c) slight environmental changes using DB-CSA algorithm. 


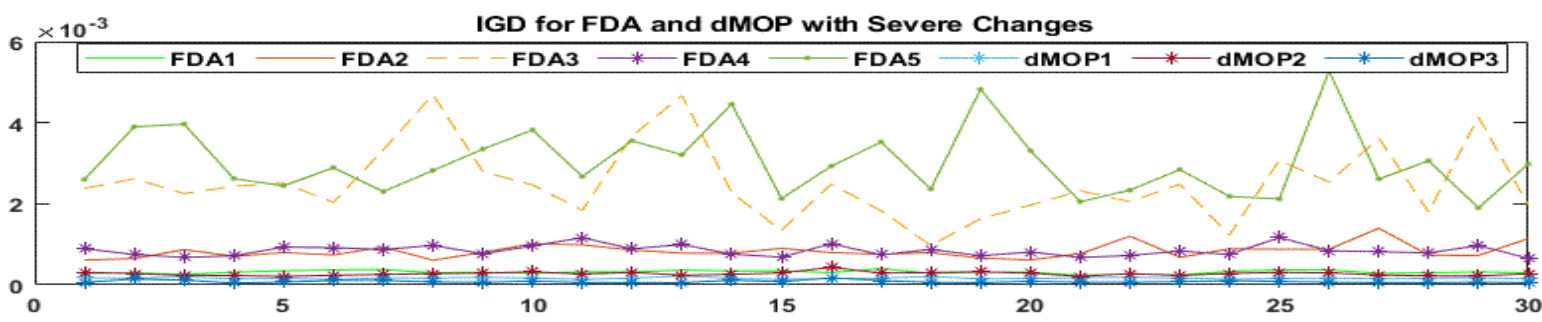

(a)

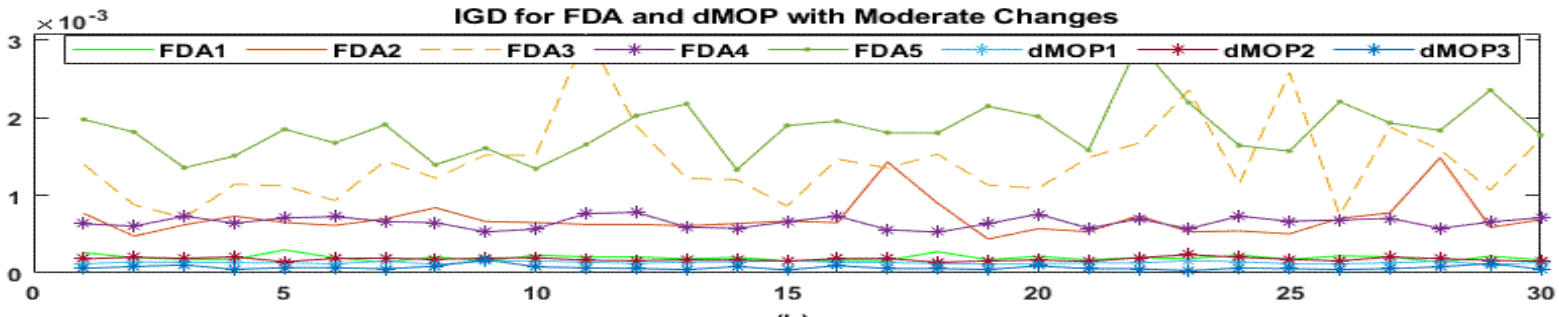

(b)

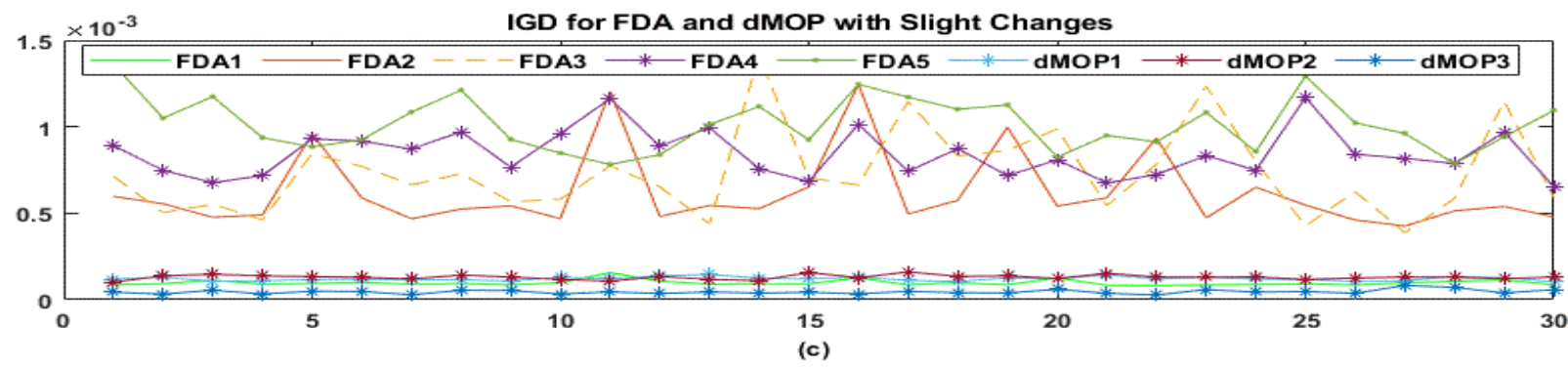

Fig. 10. IGD Plot for FDA, dMOP functions with (a) severe, (b) moderate and (c) slight environmental changes using DB-CSA algorithm.

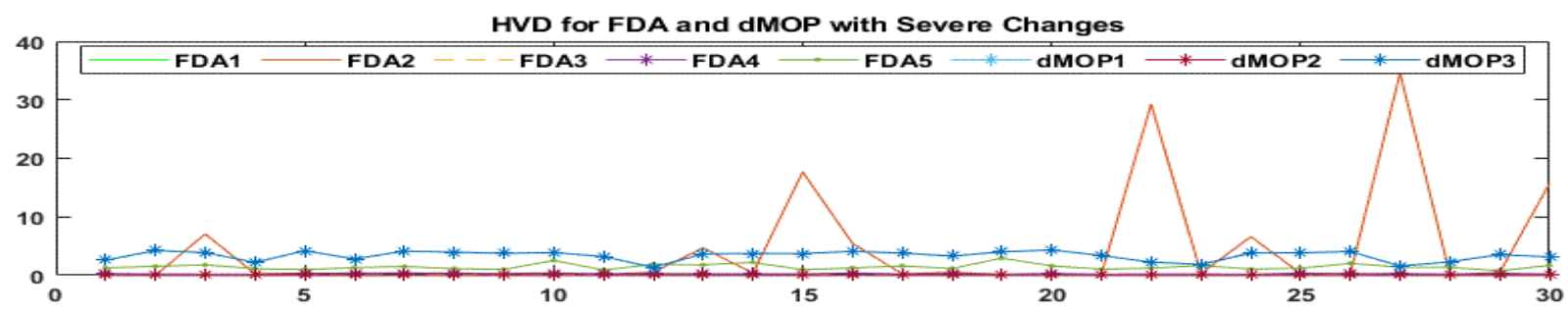

(a)

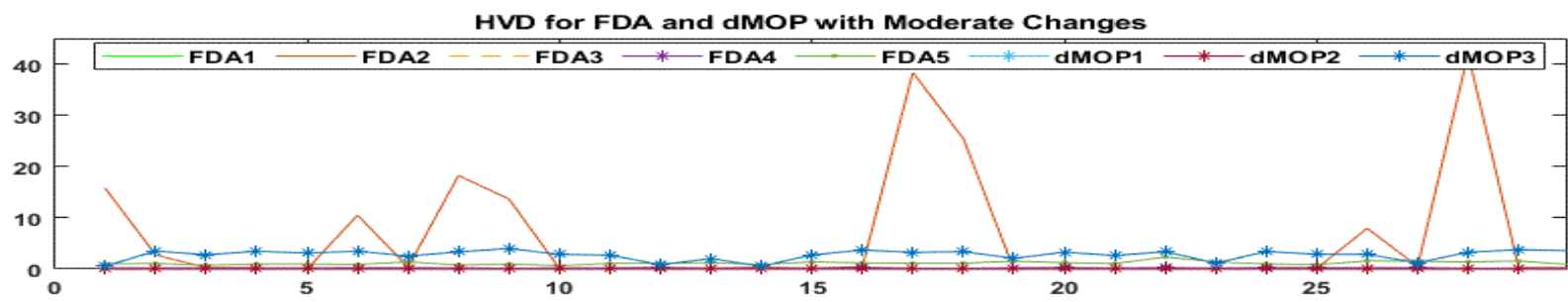

(b)

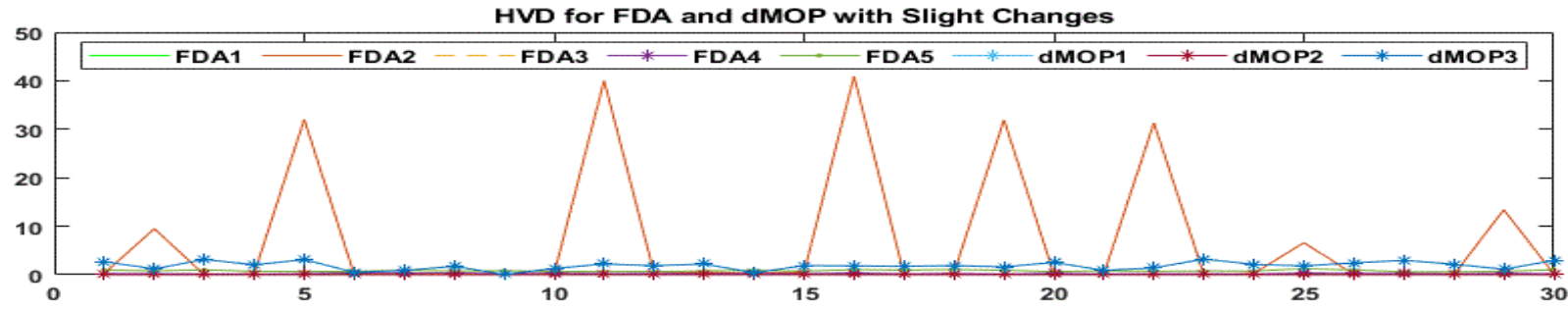

(c)

Fig. 11. HVD Plot for FDA, dMOP functions with (a) severe, (b) moderate and (c) slight environmental changes using DB-CSA algorithm. 

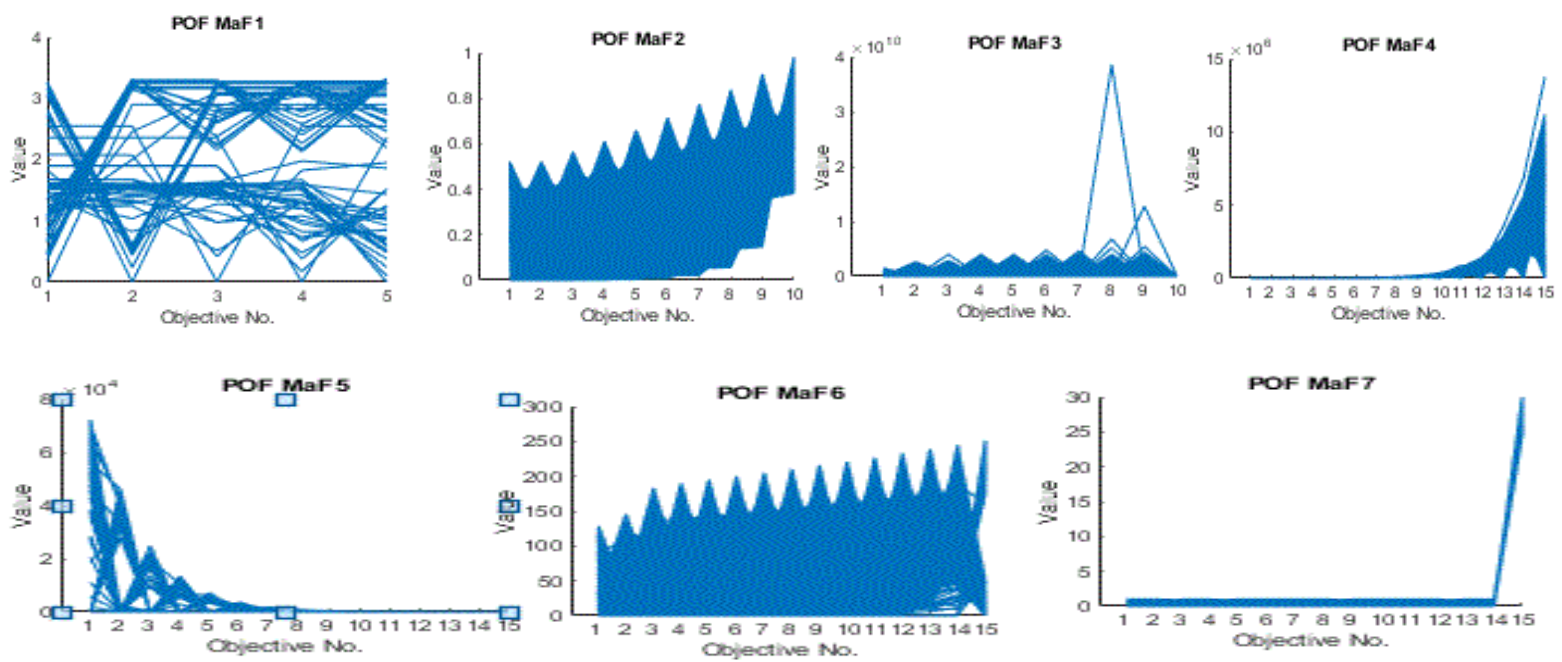

Fig. 12. POF for MaF1-7 functions with 7 objectives using DB-CSA algorithm.
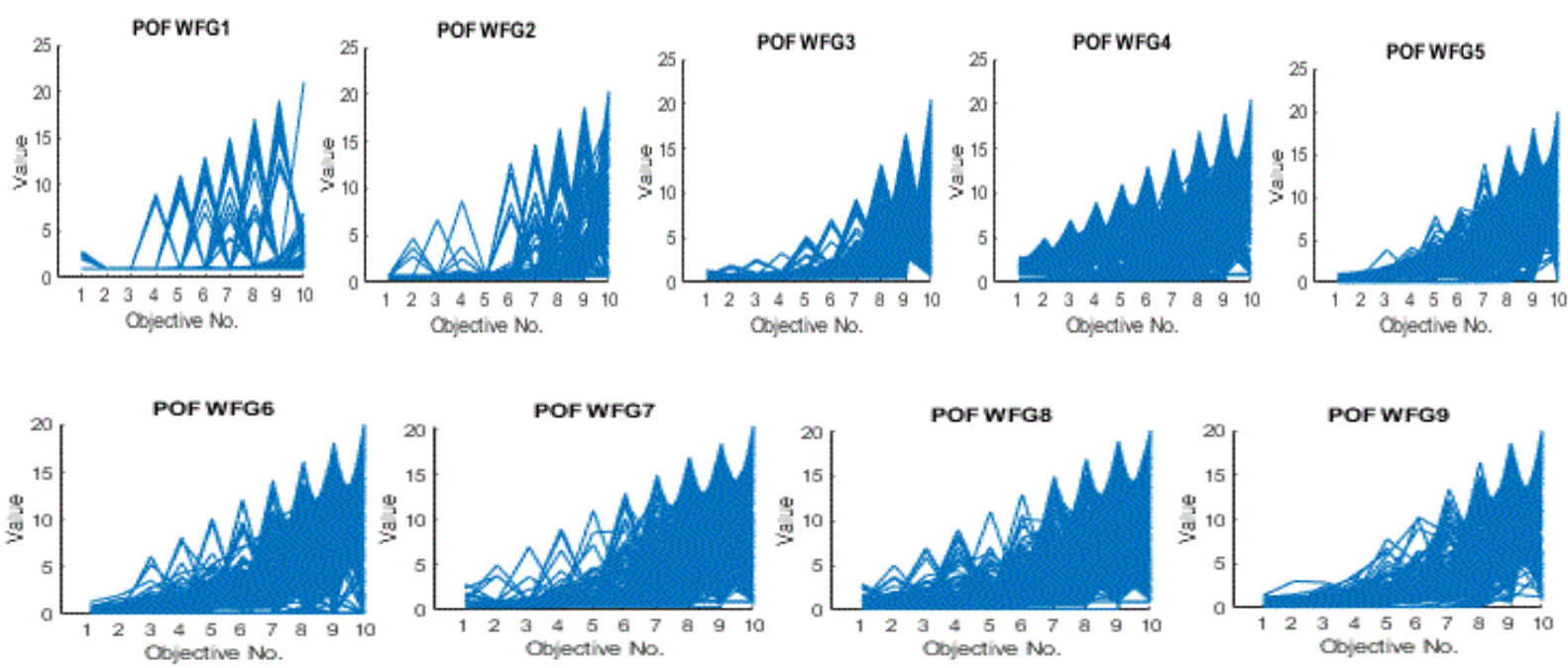

Fig. 13. POF for WFG1-9 functions with 10 objectives using DB-CSA algorithm.
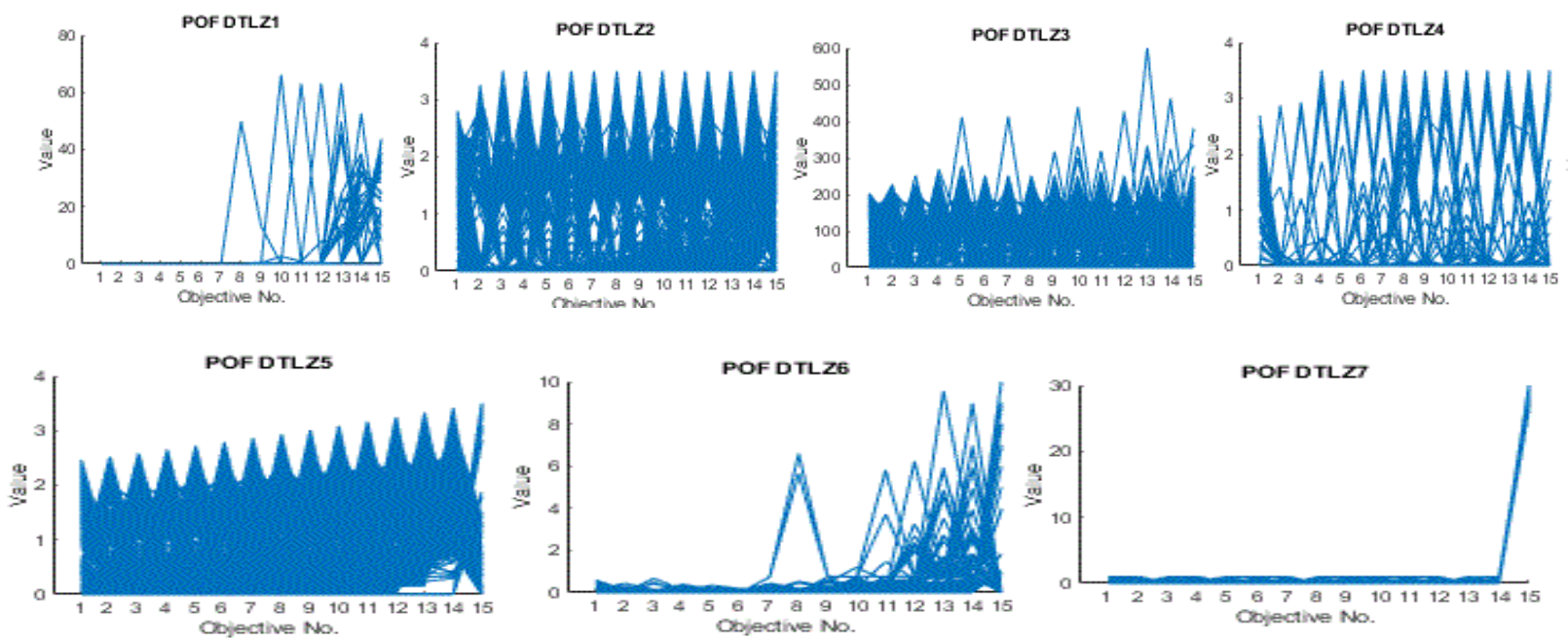

Fig. 14. POF for DTLZ1-7 functions with 15 objectives using DB-CSA algorithm. 


\section{Conclusions and perspectives}

In this paper, a new Distributed Bi-behaviors Crow Search Algorithm (DB-CSA) is proposed for dynamic treatment of both convergence and diversity concepts, which is based on two new mechanisms: distributed bi-behaviors profiles characterized by a large gaussian Beta-1 and narrow gaussian Beta-2 functions for exploitation and exploration enhancement respectively. All quantitative results are analyzed using the nonparametric Wilcoxon signed rank test with 0.05 significance level. The experiments showed that the proposed DB-CSA is significantly better than the key similar techniques used in this paper for comparisons. DB-CSA is found to be more effective in solving dynamic multi-objective problem characterized by different timevarying of both POS and POF with 2 and 3 objectives. It is also a powerful solver for the manyobjectives optimizations problems with $2,3,5,7,8,10$ and 15 objectives characterized by a dynamic shift of the POF from convex to concave and multimodal, unimodal, disconnected and deceptive geometric forms. The comparative study (1) including seven transfer-learning based methods (MMTL-MOEA/D, KF-MOEA/D, PPS-MOEA/D, SVR-MOEA/D, Tr-MOEA/D, and RI-MOEA/D) using MIGD metric and the five popular MOEAs (DNSGA-II, dCOEA, PPS, MOEA/D and SGEA) for solving twenty-one DMOPs with different types of changes on both POF and POS over IGD and HVD quality indicators. Confirmed that the proposal relative results are better for all test beds. Based on the comparative study (2), we can resume the efficiency of DB-CSA system compared to thirteen MaOEAs (MSOPS-II, MOEA/D, HypE, PICEA-g, SPEA/SDE, GrEA, NSGA-III, KnEA, RVEA, Two_Arch2, $\theta$-DEA, MOEA/DD , AnD) for solving sixteen many-objective optimization problems ( 9 WFG and $7 \mathrm{MaF}$ ) with 2 , 3 and 7 objectives as well as the more complex DTLZ and WFG test suites with 3, 5, 8, 10 and 15 objectives compared to seven MaOEAs (PMEA-MA, PMEA*-MA, SPEA2/SDE, NSGAII/SDR, MaOEA/IGD, VaEA, SPEA). All results confirmed the relevance of the proposed DBCSA and its capacity to correctly manage convergence and diversity concepts when solving DMOPs and MaOPS. For future works, it is recommended to investigate the impact of the beta profiles on performances when solving a DMOP characterized by a time-varying POS and POF, a dynamic spread or dynamic density of the approximated solution set with a nonlinear correlation between the decision variables. The DB-CSA method is worthy of consideration to solve a set of Evolutionary Transfer Multi/Many-objective Optimization Problems.

\section{Acknowledgment}

The research leading to these results has received funding from the Ministry of Higher Education and Scientific Research of Tunisia under the grant agreement number LR11ES48. 


\section{Appendices}

Table 9. MIGD results (Mean and Standard Deviation) for FDA and dMOP functions.

\begin{tabular}{|c|c|c|c|c|c|c|c|c|}
\hline \multirow[b]{2}{*}{ Prob. } & \multirow[b]{2}{*}{$\left(\tau_{t}, n_{t}\right)$} & \multicolumn{6}{|c|}{ Reference: [51] } & \multirow[b]{2}{*}{ DB-CSA } \\
\hline & & $\begin{array}{l}\text { MMTL- } \\
\text { MOEA/D }\end{array}$ & KF-MOEA/D & PPS-MOEA/D & $\begin{array}{c}\text { SVR- } \\
\text { MOEA/D }\end{array}$ & Tr-MOEA/D & RI-MOEA/D & \\
\hline FDA1 & $\begin{array}{l}(5,10) \\
(10,10) \\
(20,10) \\
\end{array}$ & $\begin{array}{l}0.1214_{(1.07 \mathrm{E}-1)}- \\
0.1199_{(7.93 \mathrm{E}-2)}- \\
0.0658_{(3.64 \mathrm{E}-2)}\end{array}$ & $\begin{array}{l}0.4670_{(3.38 \mathrm{E}-1)}- \\
0.2659_{(1.23 \mathrm{E}-1)}- \\
0.1635_{(9.12 \mathrm{E}-2)}-\end{array}$ & $\begin{array}{l}0.2485_{(1.40 \mathrm{E}-1)}- \\
0.2141_{(1.22 \mathrm{E}-1)}- \\
0.1018_{(1.25 \mathrm{E}-1)}-\end{array}$ & $\begin{array}{l}0.3745_{(3.12 \mathrm{E}-1)}- \\
0.2332_{(1.66 \mathrm{E}-1)} \\
0.2168_{(2.03 \mathrm{E}-1)-}\end{array}$ & $\begin{array}{l}0.3381_{(2.14 \mathrm{E}-1)}- \\
0.3592_{(3.41 \mathrm{E}-1)}- \\
0.1778_{(2.47 \mathrm{E}-1)-}\end{array}$ & $\begin{array}{l}0.3166_{(3.58 \mathrm{E}-1)}- \\
0.2733_{(1.83 \mathrm{E}-1)}- \\
0.1959_{(2.36 \mathrm{E}-1)}\end{array}$ & $\begin{array}{l}3.15 \mathrm{E}-4_{(4.0 \mathrm{E}-5)} \\
1.96 \mathrm{E}-4_{(3.7 \mathrm{E}-5)} \\
9.73 \mathrm{E}-5_{(1.6 \mathrm{E}-5)}\end{array}$ \\
\hline FDA2 & $\begin{array}{l}(5,10) \\
(10,10) \\
(20,10) \\
\end{array}$ & $\begin{array}{l}0.0740_{(3.53 \mathrm{E}-2)}- \\
0.0842_{(3.34 \mathrm{E}-2)}- \\
0.0662_{(3.63 \mathrm{E}-2)}\end{array}$ & $\begin{array}{l}0.1695_{(6.51 \mathrm{E}-2)}- \\
0.1906_{(7.00 \mathrm{E}-2)}- \\
0.1335_{(4.02 \mathrm{E}-2)}\end{array}$ & $\begin{array}{l}0.1023_{(1.09 \mathrm{E}-1)}- \\
0.1200_{(2.00 \mathrm{E}-1)}- \\
0.0719_{(9.86 \mathrm{E}-2)}\end{array}$ & $\begin{array}{l}0.2062_{(1.66 \mathrm{E}-1)}- \\
0.1965_{(1.31 \mathrm{E}-1)}- \\
0.1810_{(1.88 \mathrm{E}-1)-}\end{array}$ & $\begin{array}{l}0.1241_{(4.72 \mathrm{E}-2)}- \\
0.1243_{(4.27 \mathrm{E}-2)}- \\
0.0785_{(3.37 \mathrm{E}-2)}\end{array}$ & $\begin{array}{l}0.2127_{(1.49 \mathrm{E}-1)-} \\
0.2528_{(1.34 \mathrm{E}-1)}- \\
0.1678_{(1.44 \mathrm{E}-1)-}\end{array}$ & $\begin{array}{l}8.31 E-4_{(1.8 E-4)} \\
6.98 E-4_{(2.3 E-4)} \\
6.18 E-4_{(2.1 E-4)}\end{array}$ \\
\hline FDA3 & $\begin{array}{l}(5,10) \\
(10,10) \\
(20,10) \\
\end{array}$ & $\begin{array}{l}0.1428_{(1.11 \mathrm{E}-1)}- \\
0.0914_{(9.77 \mathrm{E}-2)}- \\
0.0749_{(5.08 \mathrm{E}-2)}\end{array}$ & $\begin{array}{l}0.2685_{(2.66 \mathrm{E}-1)}- \\
0.1429_{(7.49 \mathrm{E}-2)}- \\
0.1349_{(1.02 \mathrm{E}-1)}\end{array}$ & $\begin{array}{l}0.3142_{(2.14 \mathrm{E}-1)}- \\
0.2072_{(1.38 \mathrm{E}-1)}- \\
0.2286_{(1.76 \mathrm{E}-1)-}\end{array}$ & $\begin{array}{l}0.2250_{(1.81 \mathrm{E}-1)}- \\
0.1994_{(1.93 \mathrm{E}-1)}- \\
0.1409_{(1.94 \mathrm{E}-1)-}\end{array}$ & $\begin{array}{c}0.2925_{(2.44 \mathrm{E}-1)}- \\
0.252_{(2.75 \mathrm{E}-1)}- \\
0.1442_{(8.24 \mathrm{E}-2)}\end{array}$ & $\begin{array}{l}0.3493_{(4.27 \mathrm{E}-1)}- \\
0.2530_{(3.05 \mathrm{E}-1)}- \\
0.1361_{(7.58 \mathrm{E}-2)-}\end{array}$ & $\begin{array}{l}2.51 \mathrm{E}-3_{(9.0 \mathrm{E}-4)} \\
1.43 \mathrm{E}-3_{(5.2 \mathrm{E}-4)} \\
7.32 \mathrm{E}-4_{(2.4 \mathrm{E}-4)}\end{array}$ \\
\hline FDA4 & $\begin{array}{l}(5,10) \\
(10,10) \\
(20,10) \\
\end{array}$ & $\begin{array}{l}0.1523_{(9.67 \mathrm{E}-2)}- \\
0.1594_{(5.77 \mathrm{E}-2)}- \\
0.1336_{(3.89 \mathrm{E}-2)}-\end{array}$ & $\begin{array}{c}0.1578_{(7.21 \mathrm{E}-2)}- \\
0.1311_{(4.03 \mathrm{E}-2)}- \\
0.125_{(4.06 \mathrm{E}-2)}-\end{array}$ & $\begin{array}{l}0.2114_{(1.48 \mathrm{E}-1)}- \\
0.1848_{(1.75 \mathrm{E}-1)}- \\
0.1765_{(2.02 \mathrm{E}-1)}-\end{array}$ & $\begin{array}{l}0.1866_{(7.83 \mathrm{E}-2)}- \\
0.1709_{(5.15 \mathrm{E}-2)}- \\
0.1234_{(2.36 \mathrm{E}-2)}-\end{array}$ & $\begin{array}{l}0.2335_{(1.21 \mathrm{E}-1)}- \\
0.2180_{(1.05 \mathrm{E}-1)}- \\
0.1998_{(9.90 \mathrm{E}-2)-}\end{array}$ & $\begin{array}{l}0.1702_{(4.11 \mathrm{E}-2)}- \\
0.1787_{(8.33 \mathrm{E}-2)}- \\
0.1253_{(2.66 \mathrm{E}-2)}-\end{array}$ & $\begin{array}{l}8.43 E-4_{(1.3 E-4)} \\
6.53 E-4_{(7.2 E-5)} \\
5.33 E-4_{(6.6 E-5)}\end{array}$ \\
\hline FDA5 & $\begin{array}{r}(5,10) \\
(10,10) \\
(20,10) \\
\end{array}$ & $\begin{array}{l}0.2081_{(6.47 \mathrm{E}-2)}- \\
0.1892_{(5.19 \mathrm{E}-2)}- \\
0.1642_{(6.06 \mathrm{E}-2)}\end{array}$ & $\begin{array}{l}0.2683_{(8.65 \mathrm{E}-2)}- \\
0.2369_{(7.79 \mathrm{E}-2)}- \\
0.1818_{(5.76 \mathrm{E}-2)-}\end{array}$ & $\begin{array}{l}0.2036_{(7.28 \mathrm{E}-2)-} \\
0.2305_{(1.04 \mathrm{E}-1)}- \\
0.1895_{(8.11 \mathrm{E}-2)-}\end{array}$ & $\begin{array}{l}0.2120_{(1.05 \mathrm{E}-1)}- \\
0.1862_{(9.43 \mathrm{E}-2)}- \\
0.1729_{(9.00 \mathrm{E}-2)-}\end{array}$ & $\begin{array}{l}0.1737_{(4.19 \mathrm{E}-2)}- \\
0.1752_{(4.89 \mathrm{E}-2)}- \\
0.1879_{(4.56 \mathrm{E}-2)}\end{array}$ & $\begin{array}{l}0.2184_{(1.01 \mathrm{E}-1)}- \\
0.2140_{(1.01 \mathrm{E}-1)}- \\
0.1968_{(7.64 \mathrm{E}-2)-}\end{array}$ & $\begin{array}{l}3.03 E-3_{(8.3 E-4)} \\
1.84 E-3_{(3.4 E-4)} \\
1.01 E-3_{(1.5 E-4)}\end{array}$ \\
\hline dMOP1 & $\begin{array}{l}(5,10) \\
(10,10) \\
(20,10) \\
\end{array}$ & $\begin{array}{l}0.0589_{(3.82 \mathrm{E}-2)}- \\
0.0543_{(5.52 \mathrm{E}-2)}- \\
0.0252_{(9.00 \mathrm{E}-3)}\end{array}$ & $\begin{array}{l}0.1857_{(9.13 \mathrm{E}-2)}- \\
0.1565_{(7.39 \mathrm{E}-2)}- \\
0.1145_{(5.03 \mathrm{E}-2)}\end{array}$ & $\begin{array}{l}0.1269_{(2.37 \mathrm{E}-1)}- \\
0.0965_{(2.18 \mathrm{E}-1)}- \\
0.0690_{(1.95 \mathrm{E}-1)}\end{array}$ & $\begin{array}{l}0.2237_{(8.15 \mathrm{E}-2)}- \\
0.3266_{(1.99 \mathrm{E}-1)}- \\
0.1938_{(1.25 \mathrm{E}-1)-}\end{array}$ & $\begin{array}{l}0.2345_{(6.53 \mathrm{E}-2)}- \\
0.2507_{(8.15 \mathrm{E}-2)}- \\
0.1204_{(9.13 \mathrm{E}-2)-}\end{array}$ & $\begin{array}{l}0.2421_{(1.33 \mathrm{E}-1)}- \\
0.2734_{(1.46 \mathrm{E}-1)}- \\
0.1606_{(1.63 \mathrm{E}-1)-}\end{array}$ & $\begin{array}{l}1.65 \mathrm{E}-4_{(2.0 \mathrm{E}-5)} \\
1.34 \mathrm{E}-4_{(1.4 \mathrm{E}-5)} \\
1.21 \mathrm{E}-4_{(1.1 \mathrm{E}-5)}\end{array}$ \\
\hline dMOP2 & $\begin{array}{l}(5,10) \\
(10,10) \\
(20,10) \\
\end{array}$ & $\begin{array}{l}0.0494_{(1.59 \mathrm{E}-2)}- \\
0.0717_{(4.20 \mathrm{E}-2)}- \\
0.0261_{(8.53 \mathrm{E}-3)}\end{array}$ & $\begin{array}{c}0.2258_{(1.31 \mathrm{E}-1)}- \\
0.1646_{(8.01 \mathrm{E}-2)}- \\
0.120_{(8.70 \mathrm{E}-2)} \\
\end{array}$ & $\begin{array}{l}0.1265_{(1.34 \mathrm{E}-1)}- \\
0.1102_{(1.00 \mathrm{E}-1)}- \\
0.0771_{(1.12 \mathrm{E}-1)}\end{array}$ & $\begin{array}{l}0.1302_{(8.99 \mathrm{E}-2)}- \\
0.1142_{(8.98 \mathrm{E}-2)}- \\
0.0541_{(4.82 \mathrm{E}-2)}\end{array}$ & $\begin{array}{l}0.1311_{(6.02 \mathrm{E}-2)}- \\
0.1157_{(6.03 \mathrm{E}-2)}- \\
0.0795_{(4.89 \mathrm{E}-2)}\end{array}$ & $\begin{array}{l}0.1505_{(1.58 \mathrm{E}-1)}- \\
0.1586_{(1.33 \mathrm{E}-1)}- \\
0.0609_{(4.64 \mathrm{E}-2)-}\end{array}$ & $\begin{array}{l}2.73 \mathrm{E}-4_{(4.5 \mathrm{E}-5)} \\
1.77 \mathrm{E}-4_{(2.2 \mathrm{E}-5)} \\
1.30 \mathrm{E}-4_{(1.3 \mathrm{E}-5)}\end{array}$ \\
\hline dMOP3 & $\begin{array}{l}(5,10) \\
(10,10) \\
(20,10)\end{array}$ & $\begin{array}{l}0.0593_{(3.10 \mathrm{E}-2)}- \\
0.0683_{(4.26 \mathrm{E}-2)}- \\
0.0260_{(5.56 \mathrm{E}-3)}\end{array}$ & $\begin{array}{l}0.1132_{(8.72 \mathrm{E}-2)}{ }^{-} \\
\left.0.1431_{(5.58 \mathrm{E}-2)}\right)^{-} \\
0.0730_{(4.91 \mathrm{E}-2)}-\end{array}$ & $\begin{array}{l}0.1136_{(8.84 \mathrm{E}-2)}{ }^{-} \\
0.0736_{(6.38 \mathrm{E}-2)}{ }^{-} \\
0.0563_{(6.87 \mathrm{E}-2)^{-}}\end{array}$ & $\begin{array}{l}0.0987_{(7.16 \mathrm{E}-2)}- \\
0.0897_{(4.56 \mathrm{E}-2)}- \\
0.0510_{(3.52 \mathrm{E}-2)}-\end{array}$ & $\begin{array}{l}0.1203_{(4.29 \mathrm{E}-2)}- \\
0.1057_{(5.18 \mathrm{E}-2)}- \\
0.0575_{(3.22 \mathrm{E}-2)-}\end{array}$ & $\begin{array}{l}0.0729_{(3.87 \mathrm{E}-2)}- \\
0.0850_{(5.68 \mathrm{E}-2)}- \\
0.0401_{(2.57 \mathrm{E}-2)}\end{array}$ & $\begin{array}{l}8.09 \mathrm{E}-5_{(2.9 \mathrm{E}-5)} \\
6.80 \mathrm{E}-5_{(2.8 \mathrm{E}-5)} \\
4.54 \mathrm{E}-5_{(1.2 \mathrm{E}-5)}\end{array}$ \\
\hline$+1-1=$ & & & & & & $0 / 24$ & & \\
\hline
\end{tabular}

The symbols "+", “ $\approx$ " and "-" denote that the performance of the compared algorithm is statistically better than, equivalent to, and worse than DB-CSA.

Table 10. IGD results (Mean and Standard Deviation) for FDA and dMOP functions.

\begin{tabular}{|c|c|c|c|c|c|c|c|}
\hline \multirow[b]{2}{*}{ Prob. } & \multirow[b]{2}{*}{$\left(\tau_{t}, n_{t}\right)$} & \multicolumn{5}{|c|}{ Reference: [9] } & \multirow[b]{2}{*}{ DB-CSA } \\
\hline & & DNSGA-II & dCOEA & PPS & MOEA/D & SGEA & \\
\hline \multirow{3}{*}{ FDA1 } & $(5,10)$ & $6.40 \mathrm{E}-1_{(9.8 \mathrm{E}-2)}-$ & $6.36 \mathrm{E}-2_{(1.1 \mathrm{E}-2)}-$ & $2.08 \mathrm{E}-1_{(8.4 \mathrm{E}-2)}-$ & $3.56 \mathrm{E}-1_{(4.9 \mathrm{E}-2)}-$ & $3.41 \mathrm{E}-2_{(8.0 \mathrm{E}-3)}-$ & $3.15 \mathrm{E}-4_{(4.0 \mathrm{E}-5)}$ \\
\hline & $(10,10)$ & $5.82 \mathrm{E}-2_{(3.8 \mathrm{E}-3)}$ & $4.13 \mathrm{E}-2(6.5 \mathrm{E}-3)-$ & $4.27 \mathrm{E}-2_{(1.9 \mathrm{E}-2)}-$ & $1.21 \mathrm{E}-1_{(1.1 \mathrm{E}-2)}-$ & $1.48 \mathrm{E}-2_{(2.0 \mathrm{E}-3)}-$ & $1.96 \mathrm{E}-4_{(3.7 \mathrm{E}-5)}$ \\
\hline & $(20,10)$ & $4.14 \mathrm{E}-2_{(4.2 \mathrm{E}-3)}-$ & $2.39 \mathrm{E}-2_{(2.2 \mathrm{E}-3)}-$ & $1.62 \mathrm{E}-2_{(7.9 \mathrm{E}-3)-}$ & $4.04 \mathrm{E}-2_{(2.2 \mathrm{E}-3)-}$ & $7.55 \mathrm{E}-3_{(1.4 \mathrm{E}-3)}$ & $9.73 E-5_{(1.6 \mathrm{E}-5)}$ \\
\hline \multirow{3}{*}{ FDA2 } & $(5,10)$ & $2.85 \mathrm{E}-2_{(2.4 \mathrm{E}-3)}-$ & $7.28 \mathrm{E}-2_{(3.8 \mathrm{E}-2)-}$ & $8.13 \mathrm{E}-2_{(3.0 \mathrm{E}-2)}-$ & $8.40 \mathrm{E}-2_{(1.3 \mathrm{E}-2)}-$ & $1.50 \mathrm{E}-2_{(1.6 \mathrm{E}-3)}-$ & $8.31 \mathrm{E}-4_{(1.8 \mathrm{E}-4)}$ \\
\hline & $(10,10)$ & $1.68 \mathrm{E}-3_{(9.0 \mathrm{E}-4)}-$ & $4.73 \mathrm{E}-2_{(3.3 \mathrm{E}-2)-}$ & $6.35 \mathrm{E}-2_{(1.0 \mathrm{E}-2)}-$ & $3.38 \mathrm{E}-2_{(8.8 \mathrm{E}-3)}-$ & $9.11 \mathrm{E}-3_{(6.3 \mathrm{E}-4)}-$ & $6.98 \mathrm{E}-4_{(2.3 \mathrm{E}-4)}$ \\
\hline & $(20,10)$ & $6.51 \mathrm{E}-3_{(5.3 \mathrm{E}-4)-}$ & $3.24 \mathrm{E}-2_{(4.6 \mathrm{E}-2)}-$ & $6.27 \mathrm{E}-2_{(9.1 \mathrm{E}-3)}-$ & $1.64 \mathrm{E}-2_{(4.9 \mathrm{E}-3)}-$ & $6.32 \mathrm{E}-3_{(4.1 \mathrm{E}-4)}$ & $6.18 \mathrm{E}-4_{(2.1 \mathrm{E}-4)}$ \\
\hline \multirow{3}{*}{ FDA3 } & $(5,10)$ & $2.63 \mathrm{E}-1_{(6.0 \mathrm{E}-2)}-$ & $2.63 \mathrm{E}-1_{(3.5 \mathrm{E}-2)}-$ & $4.43 \mathrm{E}-1_{(1.1 \mathrm{E}-1)}-$ & $2.47 \mathrm{E}-1_{(2.3 \mathrm{E}-2)}-$ & $6.25 \mathrm{E}-2_{(3.8 \mathrm{E}-2)}$ & $2.51 \mathrm{E}-3_{(9.0 \mathrm{E}-4)}$ \\
\hline & $(10,10)$ & $1.08 \mathrm{E}-1_{(3.3 \mathrm{E}-2)}-$ & $1.95 \mathrm{E}-1_{(3.2 \mathrm{E}-2)}-$ & $2.19 \mathrm{E}-1_{(1.8 \mathrm{E}-2)}-$ & $1.30 \mathrm{E}-1_{(2.5 \mathrm{E}-2)}-$ & $4.03 \mathrm{E}-2_{(2.9 \mathrm{E}-2)}-$ & $1.43 \mathrm{E}-3_{(5.2 \mathrm{E}-4)}$ \\
\hline & $(20,10)$ & $9.03 \mathrm{E}-2_{(2.8 \mathrm{E}-3)-}$ & $1.26 \mathrm{E}-1_{(3.1 \mathrm{E}-2)}-$ & $1.92 \mathrm{E}-1_{(2.4 \mathrm{E}-2)}-$ & $5.45 \mathrm{E}-2_{(8.3 \mathrm{E}-3)-}$ & $3.52 \mathrm{E}-2_{(2.9 \mathrm{E}-2)}-$ & $7.32 \mathrm{E}-4_{(2.4 \mathrm{E}-4)}$ \\
\hline \multirow{3}{*}{ FDA4 } & $(5,10)$ & $1.49 \mathrm{E}+0_{(1.2 \mathrm{E}-1)}$ & $1.62 \mathrm{E}-1_{(6.1 \mathrm{E}-3)}-$ & $3.07 \mathrm{E}-1_{(1.9 \mathrm{E}-2)}-$ & $1.36 \mathrm{E}+0_{(1.6 \mathrm{E}-1)}$ & $4.60 \mathrm{E}-1_{(6.6 \mathrm{E}-2)}-$ & $8.43 E-4_{(1.3 E-4)}$ \\
\hline & $(10,10)$ & $7.63 \mathrm{E}-1_{(4.4 \mathrm{E}-2)}-$ & $1.24 \mathrm{E}-1_{(4.5 \mathrm{E}-3)}-$ & $2.11 \mathrm{E}-1_{(2.0 \mathrm{E}-2)}-$ & $5.77 \mathrm{E}-1_{(5.4 \mathrm{E}-2)}-$ & $1.83 \mathrm{E}-1_{(6.6 \mathrm{E}-3)}-$ & $6.53 \mathrm{E}-4_{(7.2 \mathrm{E}-5)}$ \\
\hline & $(20,10)$ & $2.62 \mathrm{E}-1_{(1.6 \mathrm{E}-2)}-$ & $1.03 \mathrm{E}-1_{(1.7 \mathrm{E}-3)-}$ & $1.79 \mathrm{E}-1_{(3.0 \mathrm{E}-3)}-$ & $2.22 \mathrm{E}-1_{(1.3 \mathrm{E}-2)}-$ & $1.26 \mathrm{E}-1_{(1.5 \mathrm{E}-3)}-$ & $5.33 \mathrm{E}-4_{(6.6 \mathrm{E}-5)}$ \\
\hline \multirow{3}{*}{ FDA5 } & $(5,10)$ & $1.76 \mathrm{E}+0_{(1.0 \mathrm{E}-1)}$ & $4.33 \mathrm{E}-1_{(4.6 \mathrm{E}-2)}-$ & $6.55 \mathrm{E}-1_{(3.1 \mathrm{E}-2)-}$ & $1.57 \mathrm{E}+0_{(1.3 \mathrm{E}-1)}$ & $5.23 \mathrm{E}-1_{(3.3 \mathrm{E}-2)}-$ & $3.03 E-3_{(8.3 E-4)}$ \\
\hline & $(10,10)$ & $1.02 \mathrm{E}+0_{(5.4 \mathrm{E}-2)}-$ & $3.62 \mathrm{E}-1_{(4.0 \mathrm{E}-2)}-$ & $4.80 \mathrm{E}-1_{(3.5 \mathrm{E}-2)}-$ & $8.19 \mathrm{E}-1_{(6.0 \mathrm{E}-2)}-$ & $3.62 \mathrm{E}-1_{(8.5 \mathrm{E}-3)}-$ & $1.84 \mathrm{E}-3_{(3.4 \mathrm{E}-4)}$ \\
\hline & $(20,10)$ & $4.88 \mathrm{E}-1_{(1.2 \mathrm{E}-2)}-$ & $3.10 \mathrm{E}-1_{(2.7 \mathrm{E}-2)-}$ & $3.71 \mathrm{E}-1_{(1.2 \mathrm{E}-2)}-$ & $4.07 \mathrm{E}-1_{(1.4 \mathrm{E}-2)}-$ & $3.09 \mathrm{E}-1_{(2.2 \mathrm{E}-3)}-$ & $1.01 E-3_{(1.5 E-4)}$ \\
\hline \multirow{3}{*}{ dMOP1 } & $(5,10)$ & $1.31 \mathrm{E}-1_{(1.1 \mathrm{E}-2)}-$ & $6.95 \mathrm{E}-2_{(1.4 \mathrm{E}-2)}-$ & $4.15 \mathrm{E}-1_{(7.4 \mathrm{E}-1)}-$ & $1.36 \mathrm{E}-2_{(9.0 \mathrm{E}-3)}-$ & $1.12 \mathrm{E}-2_{(8.1 \mathrm{E}-3)}-$ & $1.65 \mathrm{E}-4_{(2.0 \mathrm{E}-5)}$ \\
\hline & $(10,10)$ & $8.83 \mathrm{E}-3_{(5.0 \mathrm{E}-3)}-$ & $3.93 \mathrm{E}-2(6.2 \mathrm{E}-3)-$ & $5.09 \mathrm{E}-2_{(9.3 \mathrm{E}-2)}-$ & $9.39 \mathrm{E}-3_{(4.3 \mathrm{E}-3)}-$ & $8.24 \mathrm{E}-3_{(5.3 \mathrm{E}-3)}-$ & $1.34 \mathrm{E}-4_{(1.4 \mathrm{E}-5)}$ \\
\hline & $(20,10)$ & 7.39E-3(3.2E-3) - & $1.88 \mathrm{E}-2_{(2.3 \mathrm{E}-3)-}$ & $4.39 \mathrm{E}-2_{(8.4 \mathrm{E}-2)}$ & $7.17 \mathrm{E}-3_{(2.7 \mathrm{E}-3)-}$ & $6.54 \mathrm{E}-3_{(3.0 \mathrm{E}-3)-}$ & $1.21 \mathrm{E}-4_{(1.1 \mathrm{E}-5)}$ \\
\hline \multirow{3}{*}{ dMOP2 } & $(5,10)$ & $6.87 \mathrm{E}-1_{(7.5 \mathrm{E}-2)}-$ & $1.20 \mathrm{E}-1_{(2.0 \mathrm{E}-2)}$ & $1.56 \mathrm{E}-1_{(1.8 \mathrm{E}-2)}-$ & $4.91 \mathrm{E}-1_{(4.1 \mathrm{E}-2)}-$ & $3.02 \mathrm{E}-2_{(3.4 \mathrm{E}-3)}-$ & $2.73 \mathrm{E}-4_{(4.5 \mathrm{E}-5)}$ \\
\hline & $(10,10)$ & $1.18 \mathrm{E}-1_{(9.4 \mathrm{E}-3)}-$ & $7.32 \mathrm{E}-2_{(8.9 \mathrm{E}-3)-}$ & $4.28 \mathrm{E}-1_{(1.7 \mathrm{E}-2)}-$ & $1.88 \mathrm{E}-1_{(1.9 \mathrm{E}-2)}-$ & $1.21 \mathrm{E}-2_{(5.7 \mathrm{E}-4)}-$ & $1.77 \mathrm{E}-4_{(2.2 \mathrm{E}-5)}$ \\
\hline & $(20,10)$ & $1.57 \mathrm{E}-1_{(6.70 \mathrm{E}-4)}-$ & $3.46 \mathrm{E}-2_{(4.3 \mathrm{E}-3)-}$ & $2.02 \mathrm{E}-2_{(2.5 \mathrm{E}-3)-}$ & $5.63 \mathrm{E}-2_{(3.9 \mathrm{E}-3)-}$ & $6.32 \mathrm{E}-3_{(1.8 \mathrm{E}-4)}$ & $1.30 \mathrm{E}-4_{(1.3 \mathrm{E}-5)}$ \\
\hline \multirow{3}{*}{ dMOP3 } & $(5,10)$ & $5.62 \mathrm{E}-1_{(3.9 \mathrm{E}-2)-}$ & $4.95 \mathrm{E}-2_{(4.8 \mathrm{E}-3)}-$ & $1.76 \mathrm{E}-1_{(8.0 \mathrm{E}-2)}-$ & $3.42 \mathrm{E}-1_{(1.9 \mathrm{E}-2)}-$ & $1.81 \mathrm{E}-1_{(9.6 \mathrm{E}-2)}$ & $8.09 \mathrm{E}-5_{(2.9 \mathrm{E}-5)}$ \\
\hline & $(10,10)$ & $2.00 \mathrm{E}-1_{(1.5 \mathrm{E}-2)}-$ & $2.95 \mathrm{E}-2_{(2.4 \mathrm{E}-3)}-$ & $1.13 \mathrm{E}-1_{(1.2 \mathrm{E}-2)}-$ & $1.68 \mathrm{E}-1_{(1.0 \mathrm{E}-2)}-$ & $1.32 \mathrm{E}-1_{(1.3 \mathrm{E}-2)}-$ & $6.80 \mathrm{E}-5_{(2.8 \mathrm{E}-5)}$ \\
\hline & $(20,10)$ & $1.07 \mathrm{E}-1_{(8.5 \mathrm{E}-3)-}$ & $1.63 \mathrm{E}-2(1.7 \mathrm{E}-3)-$ & $8.99 \mathrm{E}-2_{(6.7 \mathrm{E}-3)-}$ & $6.27 \mathrm{E}-2_{(4.4 \mathrm{E}-3)-}$ & $8.15 \mathrm{E}-2_{(1.3 \mathrm{E}-2)}$ & $4.54 \mathrm{E}-5_{(1.2 \mathrm{E}-5)}$ \\
\hline$+/-/ \approx$ & & $0 / 24 / 0$ & $0 / 24 / 0$ & $0 / 24 / 0$ & $0 / 24 / 0$ & $0 / 24 / 0$ & \\
\hline
\end{tabular}

The symbols “+”, “ $\approx$ " and "-" denote that the performance of the compared algorithm is statistically better than, equivalent to, and worse than DB-CSA. 
Table 11. HVD results (Mean and Standard Deviation) for FDA and dMOP functions

\begin{tabular}{|c|c|c|c|c|c|c|c|}
\hline \multirow[b]{2}{*}{ Prob. } & \multirow[b]{2}{*}{$\left(\tau_{t}, n_{t}\right)$} & \multicolumn{5}{|c|}{ Reference: [9] } & \multirow[b]{2}{*}{ DB-CSA } \\
\hline & & DNSGA-II & dCOEA & PPS & MOEA/D & SGEA & \\
\hline \multirow{3}{*}{ FDA1 } & $(5,10)$ & $8.70 \mathrm{E}-1_{(7.5 \mathrm{E}-2)}-$ & $1.25 \mathrm{E}-1_{(2.4 \mathrm{E}-2)}-$ & $3.87 \mathrm{E}-1_{(1.0 \mathrm{E}-1)}-$ & $7.70 \mathrm{E}-1_{(9.4 \mathrm{E}-2)}-$ & $8.14 \mathrm{E}-2_{(2.0 \mathrm{E}-2)}-$ & $1.36 \mathrm{E}-2_{(2.2 \mathrm{E}-3)}$ \\
\hline & $(10,10)$ & $1.36 \mathrm{E}-1_{(1.7 \mathrm{E}-2)}-$ & $8.52 \mathrm{E}-2_{(2.0 \mathrm{E}-2)}-$ & $2.97 \mathrm{E}-1_{(1.6 \mathrm{E}-2)}-$ & $2.88 \mathrm{E}-1_{(2.9 \mathrm{E}-2)}-$ & $3.81 \mathrm{E}-2_{(1.4 \mathrm{E}-2)}-$ & $9.28 \mathrm{E}-3_{(1.4 \mathrm{E}-3)}$ \\
\hline & $(20,10)$ & $3.55 \mathrm{E}-2_{(1.3 \mathrm{E}-2)}-$ & $5.46 \mathrm{E}-2_{(1.6 \mathrm{E}-2)}-$ & $2.84 \mathrm{E}-1_{(1.5 \mathrm{E}-2)}-$ & $1.34 \mathrm{E}-1_{(9.2 \mathrm{E}-3)-}$ & $2.02 \mathrm{E}-2_{(1.2 \mathrm{E}-2)}$ & $5.29 \mathrm{E}-3_{(6.8 \mathrm{E}-4)}$ \\
\hline \multirow{3}{*}{ FDA2 } & $(5,10)$ & $4.71 \mathrm{E}-2_{(1.4 \mathrm{E}-2)}+$ & $1.85 \mathrm{E}-1_{(6.4 \mathrm{E}-2)}+$ & $3.21 \mathrm{E}-1_{(6.7 \mathrm{E}-2)}+$ & $1.30 \mathrm{E}-1_{(2.5 \mathrm{E}-2)+}$ & $2.54 \mathrm{E}-2_{(1.3 \mathrm{E}-2)+}$ & $4.25 \mathrm{E}+0_{(8.6 \mathrm{E}+0)}$ \\
\hline & $(10,10)$ & $2.05 \mathrm{E}-2_{(1.4 \mathrm{E}-2)}+$ & $1.24 \mathrm{E}-1_{(4.6 \mathrm{E}-2)}+$ & $2.66 \mathrm{E}-1_{(1.4 \mathrm{E}-2)}+$ & $6.29 \mathrm{E}-2_{(1.8 \mathrm{E}-2)+}$ & $1.67 E-2_{(1.4 E-2)+}$ & $5.97 \mathrm{E}+0_{(1.1 \mathrm{E}+1)}$ \\
\hline & $(20,10)$ & $1.33 \mathrm{E}-2_{(1.4 \mathrm{E}-2)}+$ & $8.64 \mathrm{E}-2_{(7.0 \mathrm{E}-2)}+$ & $2.55 \mathrm{E}-1_{(9.4 \mathrm{E}-3)+}$ & $3.24 \mathrm{E}-2_{(1.4 \mathrm{E}-2)+}$ & $1.23 \mathrm{E}-2_{(1.4 \mathrm{E}-2)+}$ & $6.99 \mathrm{E}+0_{(1.3 \mathrm{E}+1)}$ \\
\hline \multirow{3}{*}{ FDA3 } & $(5,10)$ & $1.54 \mathrm{E}+0_{(1.6 \mathrm{E}-1)}-$ & $1.45 \mathrm{E}+0_{(8.5 \mathrm{E}-2)}-$ & $1.75 \mathrm{E}+0_{(1.8 \mathrm{E}-1)}-$ & $1.66 \mathrm{E}+0_{(7.8 \mathrm{E}-2)}-$ & $9.80 \mathrm{E}-1_{(1.0 \mathrm{E}-1)}-$ & $8.29 \mathrm{E}-2_{(3.2 \mathrm{E}-2)}$ \\
\hline & $(10,10)$ & $1.09 \mathrm{E}+0_{(9.9 \mathrm{E}-2)}-$ & $1.32 \mathrm{E}+0_{(7.7 \mathrm{E}-2)}-$ & $1.16 \mathrm{E}+0_{(4.6 \mathrm{E}-2)}-$ & $1.12 \mathrm{E}+0_{(9.3 \mathrm{E}-2)}-$ & $9.24 \mathrm{E}-1_{(8.2 \mathrm{E}-2)}-$ & $5.46 \mathrm{E}-2_{(2.1 \mathrm{e}-2)}$ \\
\hline & $(20,10)$ & $1.04 \mathrm{E}+0_{(7.9 \mathrm{E}-2)}-$ & $1.15 \mathrm{E}+0_{(6.6 \mathrm{E}-2)}-$ & $1.03 \mathrm{E}+0_{(7.4 \mathrm{E}-2)}-$ & $9.47 \mathrm{E}-1_{(2.2 \mathrm{E}-2)}-$ & $9.11 \mathrm{E}-1_{(8.1 \mathrm{E}-2)}-$ & $3.20 \mathrm{E}-2_{(1.0 \mathrm{E}-2)}$ \\
\hline \multirow{3}{*}{ FDA4 } & $(5,10)$ & $2.05 \mathrm{E}+0_{(2.0 \mathrm{E}-1)}-$ & $3.80 \mathrm{E}-1_{(2.6 \mathrm{E}-2)}-$ & $7.77 \mathrm{E}-1_{(6.8 \mathrm{E}-2)^{-}}$ & $3.97 \mathrm{E}+0_{(1.6 \mathrm{E}+0)}-$ & $1.03 \mathrm{E}+0_{(1.3 \mathrm{E}-1)}-$ & $2.59 \mathrm{E}-1_{(7.1 \mathrm{E}-2)}$ \\
\hline & $(10,10)$ & $1.58 \mathrm{E}+0_{(6.6 \mathrm{E}-2)}-$ & $2.70 \mathrm{E}-1_{(3.5 \mathrm{E}-2)}-$ & $4.34 \mathrm{E}-1_{(7.2 \mathrm{E}-2)}-$ & $1.24 \mathrm{E}+0_{(1.3 \mathrm{E}-1)}-$ & $2.74 \mathrm{E}-1_{(2.4 \mathrm{E}-2)}-$ & $2.24 \mathrm{E}-1_{(4.6 \mathrm{E}-2)}$ \\
\hline & $(20,10)$ & $5.48 \mathrm{E}-1_{(5.7 \mathrm{E}-2)}-$ & $1.80 \mathrm{E}-1_{(2.4 \mathrm{E}-2)}+$ & $3.34 \mathrm{E}-1_{(8.3 \mathrm{E}-3)}-$ & $4.34 \mathrm{E}-1_{(5.0 \mathrm{E}-2)}$ & $1.44 \mathrm{E}-1_{(2.0 \mathrm{E}-2)+}$ & $1.90 \mathrm{E}-1_{(4.5 \mathrm{E}-2)}$ \\
\hline \multirow{3}{*}{ FDA5 } & $(5,10)$ & $6.75 \mathrm{E}+0_{(1.9 \mathrm{E}-1)}-$ & $2.76 \mathrm{E}+0_{(2.8 \mathrm{E}-1)}-$ & $3.88 \mathrm{E}+0_{(3.1 \mathrm{E}-1)}-$ & $7.08 \mathrm{E}+0_{(1.0 \mathrm{E}+0)}-$ & $2.70 \mathrm{E}+0_{(2.2 \mathrm{E}-1)}-$ & $1.47 \mathrm{E}+0_{(4.9 \mathrm{E}-1)}$ \\
\hline & $(10,10)$ & $5.41 \mathrm{E}+0_{(1.6 \mathrm{E}-1)}-$ & $2.37 \mathrm{E}+0_{(2.7 \mathrm{E}-1)}-$ & $2.19 \mathrm{E}+0_{(3.9 \mathrm{E}-1)}-$ & $4.80 \mathrm{E}+0_{(2.6 \mathrm{E}-1)}-$ & $1.88 \mathrm{E}+0_{(9.3 \mathrm{E}-2)}-$ & $1.17 \mathrm{E}+\mathbf{0}_{(3.4 \mathrm{E}-1)}$ \\
\hline & $(20,10)$ & $2.64 \mathrm{E}+0_{(1.1 \mathrm{E}-1)}-$ & $2.02 \mathrm{E}+0_{(1.8 \mathrm{E}-1)}-$ & $1.04 \mathrm{E}+0_{(1.1 \mathrm{E}-1)}-$ & $2.15 \mathrm{E}+0_{(1.0 \mathrm{E}-1)-}$ & $1.78 \mathrm{E}+0_{(7.1 \mathrm{E}-2)}-$ & $8.28 \mathrm{E}-1_{(1.7 \mathrm{E}-1)}$ \\
\hline \multirow{3}{*}{ dMOP1 } & $(5,10)$ & $3.93 \mathrm{E}-2_{(3.81 \mathrm{E}-2)}-$ & $1.73 \mathrm{E}-1_{(3.3 \mathrm{E}-2)^{-}}$ & $2.86 \mathrm{E}-1_{(3.6 \mathrm{E}-1)^{-}}$ & $4.64 \mathrm{E}-2_{(3.6 \mathrm{E}-2)}$ & $3.75 \mathrm{E}-2_{(2.5 \mathrm{E}-2)-}$ & 8.07E-3 ${ }_{(9.2 E-4)}$ \\
\hline & $(10,10)$ & $2.28 \mathrm{E}-2_{(2.0 \mathrm{E}-2)}-$ & $1.12 \mathrm{E}-1_{(2.0 \mathrm{E}-2)}-$ & $9.27 \mathrm{E}-2_{(1.3 \mathrm{E}-1)}-$ & $2.57 \mathrm{E}-2_{(1.5 \mathrm{E}-2)}-$ & $1.90 \mathrm{E}-2_{(1.4 \mathrm{E}-2)}$ & $7.03 E-3_{(7.0 E-4)}$ \\
\hline & $(20,10)$ & $1.71 \mathrm{E}-2_{(1.4 \mathrm{E}-2)}-$ & $5.65 \mathrm{E}-2_{(8.1 \mathrm{E}-3)}-$ & $6.02 \mathrm{E}-2_{(8.1 \mathrm{E}-2)-}$ & $1.59 \mathrm{E}-2(7.9 \mathrm{E}-3)-$ & $1.80 \mathrm{E}-2_{(1.3 \mathrm{E}-2)-}$ & $6.59 \mathrm{E}-3_{(5.1 \mathrm{E}-4)}$ \\
\hline \multirow{3}{*}{ dMOP2 } & $(5,10)$ & $8.06 \mathrm{E}-1_{(1.1 \mathrm{E}-1)^{-}}$ & $\left.3.03 \mathrm{E}-1_{(4.9 \mathrm{E}-2)}\right)^{-}$ & $3.95 \mathrm{E}-1_{(3.9 \mathrm{E}-2)}-$ & $9.04 \mathrm{E}-1_{(7.3 \mathrm{E}-2)}-$ & $8.71 \mathrm{E}-2_{(1.9 \mathrm{E}-2)}-$ & $1.15 \mathrm{E}-2_{(1.5 \mathrm{E}-3)}$ \\
\hline & $(10,10)$ & $2.90 \mathrm{E}-1_{(2.5 \mathrm{E}-2)^{-}}$ & $2.07 \mathrm{E}-1_{(2.4 \mathrm{E}-2)}{ }^{-}$ & $1.17 \mathrm{E}-1_{(4.3 \mathrm{E}-2)^{-}}$ & $4.46 \mathrm{E}-1_{(4.2 \mathrm{E}-2)}-$ & $3.59 \mathrm{E}-2_{(1.1 \mathrm{E}-2)}-$ & $8.62 \mathrm{E}-3_{(1.0 \mathrm{E}-3)}$ \\
\hline & $(20,10)$ & $4.50 \mathrm{E}-2_{(1.2 \mathrm{E}-2)}-$ & $1.09 \mathrm{E}-1_{(1.5 \mathrm{E}-2)}-$ & $5.65 \mathrm{E}-2_{(6.2 \mathrm{E}-3)}-$ & $1.98 \mathrm{E}-1_{(1.4 \mathrm{E}-2)-}$ & $1.85 \mathrm{E}-2_{(1.1 \mathrm{E}-2)}-$ & $6.89 \mathrm{E}-3_{(6.6 \mathrm{E}-4)}$ \\
\hline \multirow{3}{*}{ dMOP3 } & $(5,10)$ & $9.51 \mathrm{E}-1_{(3.4 \mathrm{E}-2)}+$ & 1.05E-1 $_{(1.6 \mathrm{E}-2)}+$ & $4.22 \mathrm{E}-1_{(1.5 \mathrm{E}-2)}+$ & $7.61 \mathrm{E}-1_{(5.3 \mathrm{E}-2)+}$ & $4.07 \mathrm{E}-1_{(2.4 \mathrm{E}-2)+}$ & $3.36 \mathrm{E}+0_{(8.3 \mathrm{E}-1)}$ \\
\hline & $(10,10)$ & $4.74 \mathrm{E}-1_{(2.8 \mathrm{E}-2)}+$ & $6.57 \mathrm{E}-2_{(1.3 \mathrm{E}-2)}+$ & $2.79 \mathrm{E}-1_{(2.7 \mathrm{E}-2)}+$ & $4.54 \mathrm{E}-1_{(2.8 \mathrm{E}-2)+}$ & $3.18 \mathrm{E}-1_{(2.9 \mathrm{E}-2)+}$ & $2.75 \mathrm{E}+0_{(9.6 \mathrm{E}-1)}$ \\
\hline & $(20,10)$ & $2.76 \mathrm{E}-1_{(2.5 \mathrm{E}-2)}+$ & 3.63E-2 ${ }_{(1.3 \mathrm{E}-2)}+$ & $2.21 \mathrm{E}-1_{(1.5 \mathrm{E}-2)}+$ & $2.87 \mathrm{E}-1_{(2.0 \mathrm{E}-2)+}$ & $2.15 \mathrm{E}-1_{(3.0 \mathrm{E}-2)+}$ & $1.87 \mathrm{E}+0_{(8.2 \mathrm{E}-1)}$ \\
\hline$+/-/ \approx$ & & $6 / 18 / 0$ & $7 / 17 / 1$ & $6 / 18 / 0$ & $6 / 18 / 0$ & $7 / 17 / 0$ & - \\
\hline
\end{tabular}

The symbols "+", “ $\approx$ " and "-" denote that the performance of the compared algorithm is statistically better than, equivalent to, and worse than DB-CSA.

Table 12. IGD results (Mean and Standard Deviation) for UDF and F(ZJZ) functions with $\left(\tau_{t}=n_{t}=10\right)$.

\begin{tabular}{|c|c|c|c|c|c|c|}
\hline \multicolumn{6}{|c|}{ Reference: [9] } & \multirow[b]{2}{*}{ DB-CSA } \\
\hline Prob. & DNSGA-II & dCOEA & PPS & MOEA/D & SGEA & \\
\hline UDF1 & $1.07 \mathrm{E}-1_{(2.4 \mathrm{E}-2)}-$ & $2.91 \mathrm{E}-1_{(2.3 \mathrm{E}-2)}-$ & $2.67 \mathrm{E}-1_{(2.2 \mathrm{E}-2)}-$ & $1.70 \mathrm{E}-1_{(5.1 \mathrm{E}-2)}-$ & $1.24 \mathrm{E}-1_{(3.3 \mathrm{E}-2)}{ }^{-}$ & $3.16 \mathrm{E}-4_{(3.1 \mathrm{E}-5)}$ \\
\hline UDF2 & $1.12 \mathrm{E}-1_{(1.0 \mathrm{E}-2)}-$ & $1.83 \mathrm{E}-1_{(2.0 \mathrm{E}-2)^{-}}-$ & $2.54 \mathrm{E}-2_{(5.0 \mathrm{E}-3)^{-}}-$ & $1.16 \mathrm{E}-1_{(9.5 \mathrm{E}-3)}-$ & $8.95 \mathrm{E}-2_{(1.3 \mathrm{E}-2)}-$ & $3.21 \mathrm{E}-4_{(2.1 \mathrm{E}-5)}$ \\
\hline UDF3 & $6.06 \mathrm{E}-1_{(3.3 \mathrm{E}-6)^{-}}-$ & $6.51 \mathrm{E}-1_{(7.7 \mathrm{E}-2)}-$ & $4.55 \mathrm{E}+0_{(1.1 \mathrm{E}+0)}-$ & $6.06 \mathrm{E}-1_{(6.3 \mathrm{E}-5)^{-}}-$ & $6.06 \mathrm{E}-1_{(7.4 \mathrm{E}-6)}-$ & $6.36 \mathrm{E}-5_{(4.8 \mathrm{E}-6)}$ \\
\hline UDF4 & $1.70 \mathrm{E}-1_{(4.7 \mathrm{E}-2)^{-}}$ & $2.87 \mathrm{E}-1_{(2.8 \mathrm{E}-2)^{-}}$ & $1.85 \mathrm{E}-1_{(8.2 \mathrm{E}-3)^{-}}$ & $3.19 \mathrm{E}-1_{(1.3 \mathrm{E}-1)}-$ & $1.68 \mathrm{E}-1_{(4.4 \mathrm{E}-2)^{-}}$ & $2.76 \mathrm{E}-5_{(2.7 \mathrm{E}-6)}$ \\
\hline UDF5 & $\left.1.18 \mathrm{E}-1_{(1.2 \mathrm{E}-2)}\right)^{-}$ & $2.05 \mathrm{E}-1_{(3.5 \mathrm{E}-2)}-$ & $2.89 \mathrm{E}-2_{(1.3 \mathrm{E}-2)}-$ & $1.61 \mathrm{E}-1_{(1.4 \mathrm{E}-2)}-$ & $1.00 \mathrm{E}-1_{(1.1 \mathrm{E}-2)}-$ & $3.00 \mathrm{E}-5_{(2.5 \mathrm{E}-6)}$ \\
\hline UDF6 & $4.57 \mathrm{E}-1_{(8.7 \mathrm{E}-2)^{-}}$ & $8.04 \mathrm{E}-1_{(1.0 \mathrm{E}-1)^{-}}$ & $1.34 \mathrm{E}+0_{(7.1 \mathrm{E}-2)}-$ & $5.31 \mathrm{E}-1_{(1.6 \mathrm{E}-1)^{-}}$ & $6.68 \mathrm{E}-1_{(2.0 \mathrm{E}-1)}{ }^{-}$ & $1.20 \mathrm{E}-2_{(3.9 \mathrm{E}-3)}$ \\
\hline UDF7 & $5.24 \mathrm{E}-1_{(2.2 \mathrm{E}-2)}-$ & $8.40 \mathrm{E}-1_{(6.4 \mathrm{E}-2)}-$ & $6.68 \mathrm{E}-1_{(4.4 \mathrm{E}-2)}-$ & $5.08 \mathrm{E}-1_{(1.4 \mathrm{E}-1)}-$ & $5.08 \mathrm{E}-1_{(4.2 \mathrm{E}-2)}-$ & $5.04 \mathrm{E}-5_{(9.4 \mathrm{E}-6)}$ \\
\hline F5 & $7.82 \mathrm{E}-1_{(3.9 \mathrm{E}-2)}+$ & $8.01 \mathrm{E}-1_{(2.2 \mathrm{E}-1)}+$ & $2.69 \mathrm{E}-1_{(4.3 \mathrm{E}-2)}+$ & $6.88 \mathrm{E}-1_{(4.1 \mathrm{IE}-2)}+$ & $4.41 \mathrm{E}-1_{(4.5 \mathrm{E}-2)}+$ & $6.54 \mathrm{E}+0_{(2.1 \mathrm{E}+1)}$ \\
\hline F6 & $3.02 \mathrm{E}-1_{(2.1 \mathrm{E}-2)}+$ & $6.57 \mathrm{E}-1_{(1.3 \mathrm{E}-1)}+$ & $2.60 \mathrm{E}-1_{(6.5 \mathrm{E}-2)}+$ & $3.44 \mathrm{E}-1_{(5.6 \mathrm{E}-2)}+$ & $2.90 \mathrm{E}-1_{(1.3 \mathrm{E}-2)}+$ & $1.36 \mathrm{E}+1_{(1.7 \mathrm{E}+1)}$ \\
\hline F7 & $4.19 \mathrm{E}-1_{(6.9 \mathrm{E}-3)}-$ & $1.56 \mathrm{E}+0_{(6.0 \mathrm{E}-1)}-$ & $2.63 \mathrm{E}-1_{(7.1 \mathrm{E}-2)}+$ & $4.18 \mathrm{E}-1_{(6.0 \mathrm{E}-2)}-$ & $4.47 \mathrm{E}-1_{(1.0 \mathrm{E}-2)}-$ & $2.70 \mathrm{E}-1_{(5.4 \mathrm{E}-2)}$ \\
\hline F8 & $4.86 \mathrm{E}-1_{(1.3 \mathrm{E}-2)^{-}}$ & $4.00 \mathrm{E}-1_{(6.7 \mathrm{E}-2)^{-}}$ & $4.56 \mathrm{E}-1_{(3.1 \mathrm{E}-2)^{-}}$ & $5.49 \mathrm{E}-1_{(2.3 \mathrm{E}-2)^{-}}$ & $2.51 \mathrm{E}-1_{(1.4 \mathrm{E}-1)^{-}}$ & $3.76 \mathrm{E}-3_{(3.1 \mathrm{E}-4)}$ \\
\hline F9 & $4.74 \mathrm{E}-1_{(2.1 \mathrm{E}-2)}+$ & $8.87 \mathrm{E}-1_{(3.3 \mathrm{E}-1)}+$ & $3.59 \mathrm{E}-1_{(4.4 \mathrm{E}-2)}+$ & $4.29 \mathrm{E}-1_{(2.4 \mathrm{E}-2)}+$ & $3.65 \mathrm{E}-1_{(3.4 \mathrm{E}-2)}+$ & $1.18 \mathrm{E}+0_{(2.2 \mathrm{E}-1)}$ \\
\hline F10 & $1.05 \mathrm{E}+0_{(1.5 \mathrm{E}-1)}-$ & $5.76 \mathrm{E}-1_{(8.1 \mathrm{E}-2)}-$ & $\left.3.79 \mathrm{E}-1_{(8.7 \mathrm{E}-2)}\right)^{-}$ & $6.39 \mathrm{E}-1_{(8.6 \mathrm{E}-2)-}$ & $3.80 \mathrm{E}-1_{(1.3 \mathrm{E}-2)}-$ & $1.42 \mathrm{E}-1_{(1.9 \mathrm{E}-0)}$ \\
\hline$+/-/ \approx$ & $3 / 10 / 0$ & $3 / 10 / 0$ & $4 / 9 / 0$ & $3 / 10 / 0$ & $3 / 10 / 0$ & \\
\hline
\end{tabular}

The symbols "+", “ $\approx$ " and "-" denote that the performance of the compared algorithm is statistically better than, equivalent to, and worse than DB-CSA

Table 13. HVD results (Mean and Standard Deviation) for UDF and F(ZJZ) functions with $\left(\tau_{t}=n_{t}=10\right)$.

\begin{tabular}{|c|c|c|c|c|c|c|}
\hline \multicolumn{6}{|c|}{ Reference: [9] } & \multirow[b]{2}{*}{ DB-CSA } \\
\hline Prob. & DNSGA-II & dCOEA & PPS & MOEA/D & SGEA & \\
\hline UDF1 & $5.14 \mathrm{E}-1_{(3.2 \mathrm{E}-2)}-$ & $7.47 \mathrm{E}-1_{(3.8 \mathrm{E}-2)^{-}}$ & $7.97 \mathrm{E}-1_{(5.2 \mathrm{E}-2)^{-}}$ & $6.12 \mathrm{E}-1_{(9.4 \mathrm{E}-2)}-$ & $5.18 \mathrm{E}-1_{(5.0 \mathrm{E}-2)}-$ & $2.25 \mathrm{E}-2_{(6.3 \mathrm{E}-3)}$ \\
\hline UDF2 & $5.51 \mathrm{E}-1_{(2.4 \mathrm{E}-2)}-$ & $6.13 \mathrm{E}-1_{(2.8 \mathrm{E}-2)}-$ & $4.32 \mathrm{E}-1_{(1.9 \mathrm{E}-2)}-$ & $5.42 \mathrm{E}-1_{(1.7 \mathrm{E}-2)}-$ & $5.10 \mathrm{E}-1_{(2.5 \mathrm{E}-2)}-$ & $2.47 \mathrm{E}-2_{(6.7 \mathrm{E}-3)}$ \\
\hline UDF3 & $1.22 \mathrm{E}+0_{(1.9 \mathrm{E}-3)}-$ & $1.23 \mathrm{E}+0_{(7.0 \mathrm{E}-2)}-$ & $1.73 \mathrm{E}+0_{(3.1 \mathrm{E}-4)}-$ & $1.22 \mathrm{E}+0_{(2.4 \mathrm{E}-3)}-$ & $1.22 \mathrm{E}+0_{(2.4 \mathrm{E}-3)}-$ & $4.59 \mathrm{E}-3_{(3.0 \mathrm{E}-4)}$ \\
\hline UDF4 & $3.47 \mathrm{E}-1_{(8.3 \mathrm{E}-2)}-$ & $5.06 \mathrm{E}-1_{(3.7 \mathrm{E}-2)}-$ & $3.77 \mathrm{E}-1_{(2.1 \mathrm{E}-2)}-$ & $6.41 \mathrm{E}-1_{(1.9 \mathrm{E}-1)}-$ & $3.32 \mathrm{E}-1_{(7.1 \mathrm{E}-2)}-$ & $6.88 \mathrm{E}-3_{(5.4 \mathrm{E}-4)}$ \\
\hline UDF5 & $2.78 \mathrm{E}-1_{(2.5 \mathrm{E}-2)}-$ & $3.98 \mathrm{E}-1_{(3.3 \mathrm{E}-2)}-$ & $2.70 \mathrm{E}-1_{(1.5 \mathrm{E}-2)}-$ & $3.65 \mathrm{E}-1_{(2.7 \mathrm{E}-2)}-$ & $2.72 \mathrm{E}-1_{(1.8 \mathrm{E}-2)}-$ & $6.96 \mathrm{E}-3_{(3.9 \mathrm{E}-4)}$ \\
\hline UDF6 & 9.34E-1 ${ }_{(1.5 \mathrm{E}-1)}+$ & $1.26 \mathrm{E}+0_{(7.2 \mathrm{E}-2)}-$ & $1.83 \mathrm{E}+0_{(1.0 \mathrm{E}-2)}-$ & $1.21 \mathrm{E}+0_{(1.4 \mathrm{E}-1)}-$ & $9.77 \mathrm{E}-1_{(2.0 \mathrm{E}-1)}+$ & $1.10 \mathrm{E}+0_{(1.8 \mathrm{E}+0)}$ \\
\hline UDF7 & $2.40 \mathrm{E}+0_{(7.4 \mathrm{E}-2)}-$ & $1.91 \mathrm{E}+0_{(1.7 \mathrm{E}-1)}-$ & $2.06 \mathrm{E}+0_{(5.4 \mathrm{E}-2)}-$ & $2.32 \mathrm{E}+0_{(2.4 \mathrm{E}-1)}-$ & $2.06 \mathrm{E}+0_{(1.2 \mathrm{E}-1)}-$ & $1.80 \mathrm{E}-1_{(1.2 \mathrm{E}-1)}$ \\
\hline F5 & $1.25 \mathrm{E}+0_{(2.5 \mathrm{E}-2)}+$ & $1.10 \mathrm{E}+0_{(1.6 \mathrm{E}-1)}+$ & $4.01 \mathrm{E}-1_{(9.9 \mathrm{E}-2)}+$ & $1.19 \mathrm{E}+0_{(2.9 \mathrm{E}-2)}+$ & $7.16 \mathrm{E}-1_{(8.2 \mathrm{E}-2)}+$ & $2.08 \mathrm{E}+1_{(4.1 \mathrm{E}+1)}$ \\
\hline F6 & $4.76 \mathrm{E}-1_{(3.7 \mathrm{E}-2)}+$ & $9.22 \mathrm{E}-1_{(1.0 \mathrm{E}-1)}+$ & $4.92 \mathrm{E}-1_{(1.5 \mathrm{E}-1)}+$ & $5.75 \mathrm{E}-1_{(7.5 \mathrm{E}-2)}+$ & $3.60 \mathrm{E}-1_{(2.5 \mathrm{E}-2)}+$ & $4.11 \mathrm{E}+1_{(7.6 \mathrm{E}+1)}$ \\
\hline F7 & $6.49 \mathrm{E}-1_{(1.0 \mathrm{E}-2)}+$ & $1.22 \mathrm{E}+0_{(1.5 \mathrm{E}-1)}+$ & $4.49 \mathrm{E}-1_{(1.4 \mathrm{E}-1)}+$ & $6.50 \mathrm{E}-1_{(2.8 \mathrm{E}-2)}+$ & $6.05 \mathrm{E}-1_{(1.5 \mathrm{E}-2)}+$ & $1.04 \mathrm{E}+2_{(1.9 \mathrm{E}+1)}$ \\
\hline F8 & $1.06 \mathrm{E}+0_{(4.6 \mathrm{E}-2)}-$ & $8.85 \mathrm{E}-1_{(1.2 \mathrm{E}-1)}{ }^{-}$ & $1.34 \mathrm{E}+0_{(1.0 \mathrm{E}-1)}-$ & $1.06 \mathrm{E}+0_{(6.6 \mathrm{E}-2)}-$ & $\left.4.57 \mathrm{E}-1_{(3.2 \mathrm{E}-2)}\right)^{-}$ & 1.19E-1 $_{(9.7 \mathrm{E}-2)}$ \\
\hline F9 & $8.87 \mathrm{E}-1_{(3.4 \mathrm{E}-2)}+$ & $1.07 \mathrm{E}+0_{(1.9 \mathrm{E}-1)}+$ & $6.88 \mathrm{E}-1_{(7.7 \mathrm{E}-2)}+$ & $8.58 \mathrm{E}-1_{(4.6 \mathrm{E}-2)}+$ & $5.76 E-1_{(7.0 \mathrm{E}-2)}+$ & $3.61 \mathrm{E}+1_{(6.3 \mathrm{E}+1)}$ \\
\hline F10 & $1.22 \mathrm{E}+0_{(5.0 \mathrm{E}-2)}+$ & $8.58 \mathrm{E}-1_{(8.8 \mathrm{E}-2)}+$ & $5.38 \mathrm{E}-1_{(1.2 \mathrm{E}-1)}+$ & $1.05 \mathrm{E}+0_{(5.9 \mathrm{E}-2)}+$ & $5.77 \mathrm{E}-1_{(2.3 \mathrm{E}-2)}+$ & $2.61 \mathrm{E}+1_{(3.4 \mathrm{E}+1)}$ \\
\hline$+/-/ \approx$ & $6 / 7 / 0$ & $5 / 8 / 0$ & $5 / 8 / 0$ & $5 / 8 / 0$ & $6 / 7 / 0$ & \\
\hline
\end{tabular}

The symbols "+", " $\approx$ " and "--" denote that the performance of the compared algorithm is statistically better than, equivalent to, and worse than DB-CSA 
Table 14. IGD results (Mean and Standard Deviation) of the 13 MOEAs [58] compared to DB-CSA on the 2, 3 and 7 objectives WFG problems.

\begin{tabular}{|c|c|c|c|c|c|c|c|c|c|c|c|}
\hline MOEAs & M & WFG1 & WFG2 & WFG3 & WFG4 & WFG5 & WFG6 & WFG7 & WFG8 & WFG9 & $+/-/ \approx$ \\
\hline \multirow{3}{*}{ MSOPS-II } & 2 & $2.11 \mathrm{E}-1_{(9.19 \mathrm{E}-2)^{-}}$ & $2.68 \mathrm{E}-2_{(3.18 \mathrm{E}-3)^{-}}$ & $1.68 \mathrm{E}-2_{(9.57 \mathrm{E}-3)^{-}}$ & $1.80 \mathrm{E}-2_{(1.16 \mathrm{E}-3)^{-}}$ & $6.61 \mathrm{E}-2_{(4.58 \mathrm{E}-4)^{-}}^{-}$ & $7.66 \mathrm{E}-2_{(2.14 \mathrm{E}-2)^{-}}$ & $1.91 \mathrm{E}-2_{(1.42 \mathrm{E}-3)^{-}}$ & $1.13 \mathrm{E}-1_{(2.64 \mathrm{E}-3)^{-}}$ & $4.76 \mathrm{E}-2_{(7.28 \mathrm{E}-2)^{-}}$ & \multirow{3}{*}{$0 / 27 / 0$} \\
\hline & 3 & $3.86 \mathrm{E}-1_{(7.13 \mathrm{E}-2)}-$ & $2.73 \mathrm{E}-1_{(3.40 \mathrm{E}-2)^{-}}$ & $9.79 \mathrm{E}-2_{(244 \mathrm{E}-2)}-$ & $2.60 \mathrm{E}-1_{(9.62 \mathrm{E}-3)^{-}}$ & $2.80 \mathrm{E}-1_{(9.31 \mathrm{E}-3)^{-}}$ & $3.20 \mathrm{E}-1_{(1.71 \mathrm{E}-2)^{-}}$ & $2.71 \mathrm{E}-1_{(1.35 \mathrm{E}-2)}-$ & $3.91 \mathrm{E}-1_{(1.25 \mathrm{E}-2)^{-}}$ & $2.56 \mathrm{E}-1_{(3.01 \mathrm{E}-2)^{-}}$ & \\
\hline & 7 & $1.17 \mathrm{E}+0_{(9.67 \mathrm{E}-2)}-$ & $3.14 \mathrm{E}+0_{(7.86 \mathrm{E}-1)^{-}}$ & $1.85 \mathrm{E}-1_{(4.01 \mathrm{E}-2)}-$ & $2.78 \mathrm{E}+0_{(3.14 \mathrm{E}-2)^{-}}$ & $2.92 \mathrm{E}+0_{(8.1 \mathrm{E}-2)^{-}}$ & $2.92 \mathrm{E}+0_{(5.6 \mathrm{E}-2)^{-}}$ & $2.92 \mathrm{E}+0_{(6.22 \mathrm{E}-2)}-$ & $2.99 \mathrm{E}+0_{(4.0 \mathrm{E}-2)^{-}}$ & $2.75 \mathrm{E}+0_{(3.9 \mathrm{E}-2)^{-}}$ & \\
\hline \multirow{3}{*}{ MOEA/D } & 2 & $\left.5.28 \mathrm{E}-1_{(5.95 \mathrm{E}-2)}\right)^{-}$ & $1.09 \mathrm{E}-1_{(6.86 \mathrm{E}-2)}-$ & $2.68 \mathrm{E}-2_{(4.89 \mathrm{E}-3)^{-}}$ & $3.60 \mathrm{E}-2_{(4.78 \mathrm{E}-3)^{-}}$ & $7.23 \mathrm{E}-2_{(1.45 \mathrm{E}-3)^{-}}$ & $9.55 \mathrm{E}-2_{(2.32 \mathrm{E}-2)^{-}}$ & $3.35 \mathrm{E}-2_{(3.34 \mathrm{E}-3)^{-}}$ & $1.27 \mathrm{E}-1_{(5.63 \mathrm{E}-3)^{-}}$ & $7.41 \mathrm{E}-2_{(5.48 \mathrm{E}-2)^{-}}$ & \multirow{3}{*}{$0 / 27 / 0$} \\
\hline & 3 & $6.52 \mathrm{E}-1_{(9.52 \mathrm{E}-2)}-$ & $1.02 \mathrm{E}+0_{(3.31 \mathrm{E}-2)^{-}}$ & $2.05 \mathrm{E}-1_{(5.78 \mathrm{E}-2)}-$ & $2.63 \mathrm{E}-1_{(5.94 \mathrm{E}-3)}-$ & $2.51 \mathrm{E}-1_{(3.69 \mathrm{E}-3)^{-}}$ & $2.99 \mathrm{E}-1_{(8.25 \mathrm{E}-3)^{-}}$ & $3.73 \mathrm{E}-1_{(4.54 \mathrm{E}-2)}-$ & $3.25 \mathrm{E}-1_{(1.10 \mathrm{E}-2)^{-}}$ & $3.03 \mathrm{E}-1_{(3.76 \mathrm{E}-2)^{-}}$ & \\
\hline & 7 & $2.12 \mathrm{E}+0_{(2.52 \mathrm{E}-1)}-$ & $1.06 \mathrm{E}+1_{(1.18 \mathrm{E}-1)^{-}}$ & $3.05 \mathrm{E}+0_{(1.7 \mathrm{E}-1)}-$ & $6.00 \mathrm{E}+0_{(1.65 \mathrm{E}-1)^{-}}$ & $5.73 \mathrm{E}+0_{(1.3 \mathrm{E}-1)^{-}}$ & $6.18 \mathrm{E}+0_{(1.4 \mathrm{E}-1)^{-}}$ & $6.10 \mathrm{E}+0_{(1.34 \mathrm{E}-1)-}-$ & $5.37 \mathrm{E}+0_{(1.5 \mathrm{E}-1)^{-}}$ & $5.57 \mathrm{E}+0_{(4.4 \mathrm{E}-1)^{-}}$ & \\
\hline \multirow{3}{*}{ HypE } & 2 & $7.27 \mathrm{E}-1_{(1.53 \mathrm{E}-1)}{ }^{-}$ & $1.08 E-2_{(2.8 E-4)}+$ & $1.12 \mathrm{E}-2_{(3.48 \mathrm{E}-4)}-$ & $1.78 \mathrm{E}-2_{(1.24 \mathrm{E}-3)^{-}}$ & $6.69 \mathrm{E}-2_{(1.48 \mathrm{E}-3)^{-}}$ & $8.11 \mathrm{E}-2_{(2.09 \mathrm{E}-2)^{-}}$ & $1.79 \mathrm{E}-2_{(8.14 \mathrm{E}-4)^{-}}$ & $1.11 \mathrm{E}-1_{(3.79 \mathrm{E}-3)^{-}}$ & $2.07 \mathrm{E}-2_{(1.00 \mathrm{E}-3)^{-}}$ & \multirow{3}{*}{$1 / 26 / 0$} \\
\hline & 3 & $1.33 \mathrm{E}+0_{(1.22 \mathrm{E}-1)}-$ & $2.71 \mathrm{E}-1_{(4.30 \mathrm{E}-2)}-$ & $3.72 \mathrm{E}-2_{(3.53 \mathrm{E}-3)^{-}}$ & $3.33 \mathrm{E}-1_{(1.48 \mathrm{E}-2)}-$ & $3.62 \mathrm{E}-1_{(1.19 \mathrm{E}-2)^{-}}$ & $3.72 \mathrm{E}-1_{(2.28 \mathrm{E}-2)^{-}}$ & $3.83 \mathrm{E}-1_{(1.44 \mathrm{E}-2)}-$ & $3.72 \mathrm{E}-1_{(1.41 \mathrm{E}-2)^{-}}$ & $3.62 \mathrm{E}-1_{(1.31 \mathrm{E}-2)^{-}}$ & \\
\hline & 7 & $2.53 \mathrm{E}+0_{(1.31 \mathrm{E}-1)}-$ & $3.89 \mathrm{E}+0_{(6.24 \mathrm{E}-1)^{-}}$ & $9.29 \mathrm{E}-2_{(9.16 \mathrm{E}-3)}-$ & $4.43 \mathrm{E}+0_{(5.97 \mathrm{E}-1)^{-}}$ & $2.91 \mathrm{E}+0_{(7.70 \mathrm{E}-2)}$ & $2.95 \mathrm{E}+0_{(1.3 \mathrm{E}-1)^{-}}$ & $3.21 \mathrm{E}+0_{(2.53 \mathrm{E}-1)}-$ & $3.39 \mathrm{E}+0_{(1.9 \mathrm{E}-1)^{-}}$ & $2.89 \mathrm{E}+0_{(2.0 \mathrm{E}-1)^{-}}$ & \\
\hline \multirow{3}{*}{ PICEA-g } & 2 & $2.04 \mathrm{E}-1_{(3.63 \mathrm{E}-2)}-$ & $2.59 \mathrm{E}-2_{(4.83 \mathrm{E}-2)}-$ & $1.81 \mathrm{E}-2_{(1.67 \mathrm{E}-3)^{-}}$ & $1.85 \mathrm{E}-2_{(1.97 \mathrm{E}-3)^{-}}$ & $6.59 \mathrm{E}-2_{(2.22 \mathrm{E}-3)^{-}}$ & $9.55 \mathrm{E}-2_{(1.99 \mathrm{E}-2)^{-}}$ & $1.60 \mathrm{E}-2_{(9.18 \mathrm{E}-4)^{-}}$ & $1.20 \mathrm{E}-1_{(4.01 \mathrm{E}-3)^{-}}$ & $4.25 \mathrm{E}-2_{(5.09 \mathrm{E}-2)^{-}}$ & \multirow{3}{*}{$0 / 27 / 0$} \\
\hline & 3 & $9.78 \mathrm{E}-1_{(1.07 \mathrm{E}-1)}-$ & $1.54 \mathrm{E}-1_{(9.67 \mathrm{E}-3)^{-}}$ & $1.25 \mathrm{E}-1_{(1.04 \mathrm{E}-2)}-$ & $2.23 \mathrm{E}-1_{(3.05 \mathrm{E}-3)}-$ & $2.28 \mathrm{E}-1_{(3.29 \mathrm{E}-3)^{-}}$ & $2.63 \mathrm{E}-1_{(2.14 \mathrm{E}-2)^{-}}$ & $2.18 \mathrm{E}-1_{(3.58 \mathrm{E}-3)}-$ & $3.09 \mathrm{E}-1_{(4.52 \mathrm{E}-3)^{-}}$ & $2.21 \mathrm{E}-1_{(1.10 \mathrm{E}-2)^{-}}$ & \\
\hline & 7 & $2.46 \mathrm{E}+0_{(5.1 \mathrm{E}-2)}-$ & $2.04 \mathrm{E}+0_{(3.88 \mathrm{E}-1)^{-}}$ & $8.76 \mathrm{E}-1_{(8.43 \mathrm{E}-2)}-$ & $2.52 \mathrm{E}+0_{(1.51 \mathrm{E}-1)^{-}}$ & $2.46 \mathrm{E}+0_{(1.9 \mathrm{E}-2)^{-}}$ & $2.50 \mathrm{E}+0_{(1.7 \mathrm{E}-2)^{-}}$ & $2.47 \mathrm{E}+0_{(1.69 \mathrm{E}-2)}-$ & $2.70 \mathrm{E}+0_{(1.3 \mathrm{E}-1)^{-}}$ & $2.54 \mathrm{E}+0_{(4.7 \mathrm{E}-2)^{-}}$ & \\
\hline \multirow{3}{*}{ SPEA2/SDE } & 2 & $1.93 \mathrm{E}-1_{(4.81 \mathrm{E}-2)}-$ & $1.25 \mathrm{E}-2_{(7.4 \mathrm{E}-4)}+$ & $1.37 \mathrm{E}-2_{(3.66 \mathrm{E}-4)^{-}}$ & $3.18 \mathrm{E}-2_{(5.11 \mathrm{E}-3)^{-}}$ & $7.82 \mathrm{E}-2_{(4.69 \mathrm{E}-3)^{-}}$ & $9.44 \mathrm{E}-2_{(1.88 \mathrm{E}-2)^{-}}$ & $3.54 \mathrm{E}-2_{(5.56 \mathrm{E}-3)^{-}}$ & $1.18 \mathrm{E}-1_{(3.46 \mathrm{E}-3)^{-}}$ & $3.55 \mathrm{E}-2_{(5.90 \mathrm{E}-3)^{-}}$ & \multirow{3}{*}{$1 / 26 / 0$} \\
\hline & 3 & $2.94 \mathrm{E}-1_{(5.17 \mathrm{E}-2)}-$ & $2.47 \mathrm{E}-1_{(5.53 \mathrm{E}-2)}-$ & $6.64 \mathrm{E}-2_{(5.31 \mathrm{E}-3)}-$ & $3.28 \mathrm{E}-1_{(1.37 \mathrm{E}-2)}-$ & $3.34 \mathrm{E}-1_{(1.60 \mathrm{E}-2)^{-}}$ & $3.55 \mathrm{E}-1_{(1.97 \mathrm{E}-2)^{-}}$ & $3.27 \mathrm{E}-1_{(1.41 \mathrm{E}-2)}-$ & $3.61 \mathrm{E}-1_{(1.11 \mathrm{E}-2)^{-}}$ & $3.12 \mathrm{E}-1_{(1.39 \mathrm{E}-2)^{-}}$ & \\
\hline & 7 & $1.13 \mathrm{E}+0_{(9.70 \mathrm{E}-2)}-$ & $6.15 \mathrm{E}+0_{(1.3 \mathrm{E}+0)^{-}}$ & $1.25 \mathrm{E}+0_{(4.5 \mathrm{E}-1)}-$ & $2.76 \mathrm{E}+0_{(3.53 \mathrm{E}-2)^{-}}$ & $2.75 \mathrm{E}+0_{(4.2 \mathrm{E}-2)^{-}}$ & $2.87 \mathrm{E}+0_{(4.9 \mathrm{E}-2)^{-}}$ & $2.79 \mathrm{E}+0_{(4.18 \mathrm{E}-2)}-$ & $2.83 \mathrm{E}+0_{(3.6 \mathrm{E}-2)^{-}}$ & $2.67 \mathrm{E}+0_{(3.1 \mathrm{E}-2)^{-}}$ & \\
\hline \multirow{3}{*}{ GrEA } & 2 & $1.92 \mathrm{E}-1_{(9.01 \mathrm{E}-2)}-$ & $3.14 \mathrm{E}-2_{(2.06 \mathrm{E}-3)}-$ & $2.38 \mathrm{E}-2_{(3.33 \mathrm{E}-4)}-$ & $2.60 \mathrm{E}-2_{(1.42 \mathrm{E}-3)^{-}}$ & $7.41 \mathrm{E}-2_{(2.13 \mathrm{E}-3)^{-}}$ & $8.08 \mathrm{E}-2_{(2.56 \mathrm{E}-2)^{-}}$ & $2.98 \mathrm{E}-2_{(1.90 \mathrm{E}-3)^{-}}$ & $1.12 \mathrm{E}-1_{(9.73 \mathrm{E}-4)^{-}}$ & $3.03 \mathrm{E}-2_{(2.65 \mathrm{E}-3)^{-}}$ & \multirow{3}{*}{$0 / 27 / 0$} \\
\hline & 3 & $3.04 \mathrm{E}-1_{(4.41 \mathrm{E}-2)}-$ & $2.61 \mathrm{E}-1_{(2.64 \mathrm{E}-2)^{-}}$ & $\left.9.10 \mathrm{E}-2_{(8.78 \mathrm{E}-3)}\right)$ & $2.41 \mathrm{E}-1_{(2.99 \mathrm{E}-3)}-$ & $2.61 \mathrm{E}-1_{(4.44 \mathrm{E}-3)^{-}}$ & $2.72 \mathrm{E}-1_{(9.51 \mathrm{E}-3)^{-}}$ & $2.55 \mathrm{E}-1_{(9.13 \mathrm{E}-3)}-$ & $3.02 \mathrm{E}-1_{(8.89 \mathrm{E}-3)^{-}}$ & $2.39 \mathrm{E}-1_{(5.39 \mathrm{E}-3)^{-}}$ & \\
\hline & 7 & $1.31 \mathrm{E}+0_{(1.90 \mathrm{E}-1)^{-}}$ & $3.00 \mathrm{E}+0_{(6.88 \mathrm{E}-1)^{-}}$ & $8.82 \mathrm{E}-1_{(1.37 \mathrm{E}-1)}-$ & $2.47 \mathrm{E}+0_{(1.66 \mathrm{E}-2)^{-}}$ & $2.47 \mathrm{E}+0_{(2.1 \mathrm{E}-2)^{-}}$ & $2.52 \mathrm{E}+0_{(2.3 \mathrm{E}-2)^{-}}$ & $2.51 \mathrm{E}+0_{(1.22 \mathrm{E}-2)}-$ & $2.59 \mathrm{E}+0_{(2.5 \mathrm{E}-2)^{-}}$ & $2.43 \mathrm{E}+0_{(1.5 \mathrm{E}-2)^{-}}$ & \\
\hline \multirow{3}{*}{ NSGA-III } & 2 & $2.70 \mathrm{E}-1_{(5.03 \mathrm{E}-2)}-$ & $1.52 \mathrm{E}-2_{(6.3 \mathrm{E}-4)}+$ & $1.35 \mathrm{E}-2_{(8.46 \mathrm{E}-4)^{-}}$ & $1.39 \mathrm{E}-2_{(1.13 \mathrm{E}-3)^{-}}$ & $6.44 \mathrm{E}-2_{(1.01 \mathrm{E}-3)^{-}}$ & $8.64 \mathrm{E}-2_{(2.42 \mathrm{E}-2)^{-}}$ & $1.27 \mathrm{E}-2_{(2.4 \mathrm{E}-4)}+$ & $1.13 \mathrm{E}-1_{(1.70 \mathrm{E}-3)^{-}}$ & $2.30 \mathrm{E}-2_{(1.97 \mathrm{E}-3)^{-}}$ & \multirow{3}{*}{$2 / 25 / 0$} \\
\hline & 3 & $5.55 \mathrm{E}-1_{(7.70 \mathrm{E}-2)}-$ & $1.82 \mathrm{E}-1_{(5.38 \mathrm{E}-3)^{-}}$ & $1.19 \mathrm{E}-1_{(8.98 \mathrm{E}-3)}-$ & $2.22 \mathrm{E}-1_{(9.79 \mathrm{E}-4)}-$ & $2.13 \mathrm{E}-1_{(4.39 \mathrm{E}-4)^{-}}$ & $2.51 \mathrm{E}-1_{(1.27 \mathrm{E}-2)^{-}}$ & $2.22 \mathrm{E}-1_{(4.19 \mathrm{E}-4)}-$ & $2.95 \mathrm{E}-1_{(5.07 \mathrm{E}-3)^{-}}$ & $2.35 \mathrm{E}-1(3.10 \mathrm{E}-2)^{-}$ & \\
\hline & 7 & $1.58 \mathrm{E}+0_{(1.43 \mathrm{E}-1)}-$ & $3.35 \mathrm{E}+0_{(2.2 \mathrm{E}+0)^{-}}$ & $1.21 \mathrm{E}+0_{(2.9 \mathrm{E}-1)}-$ & $2.66 \mathrm{E}+0_{(4.57 \mathrm{E}-2)^{-}}$ & $2.60 \mathrm{E}+0_{(7.9 \mathrm{E}-3)^{-}}$ & $2.66 \mathrm{E}+0_{(1.9 \mathrm{E}-2)^{-}}$ & $2.66 \mathrm{E}+0_{(9.73 \mathrm{E}-3)}-$ & $2.68 \mathrm{E}+0_{(1.67 \mathrm{E}-1)^{-}}$ & $2.54 \mathrm{E}+0_{(1.9 \mathrm{E}-2)^{-}}$ & \\
\hline \multirow{3}{*}{ KnEA } & 2 & $2.88 \mathrm{E}-1_{(1.39 \mathrm{E}-1)}-$ & $9.19 \mathrm{E}-1_{(2.70 \mathrm{E}-1)}-$ & $1.79 \mathrm{E}-2_{(8.33 \mathrm{E}-4)^{-}}$ & $2.52 \mathrm{E}-2_{(4.50 \mathrm{E}-3)^{-}}$ & $7.86 \mathrm{E}-2_{(9.41 \mathrm{E}-3)^{-}}$ & $3.09 \mathrm{E}-1_{(6.94 \mathrm{E}-2)^{-}}$ & $1.41 \mathrm{E}-1_{(5.41 \mathrm{E}-2)^{-}}$ & $5.02 \mathrm{E}-1_{(7.25 \mathrm{E}-2)}-$ & $3.74 \mathrm{E}-2_{(4.19 \mathrm{E}-2)}-$ & \multirow{3}{*}{$0 / 27 / 0$} \\
\hline & 3 & $3.79 \mathrm{E}-1_{(5.38 \mathrm{E}-2)}-$ & $2.36 \mathrm{E}-1_{(4.36 \mathrm{E}-2)^{-}}$ & $1.36 \mathrm{E}-1_{(5.76 \mathrm{E}-2)}-$ & $2.54 \mathrm{E}-1_{(1.04 \mathrm{E}-2)}-$ & $2.68 \mathrm{E}-1_{(1.54 \mathrm{E}-2)^{-}}$ & $3.02 \mathrm{E}-1_{(1.45 \mathrm{E}-2)^{-}}$ & $2.52 \mathrm{E}-1_{(1.36 \mathrm{E}-2)}-$ & $3.38 \mathrm{E}-1_{(1.29 \mathrm{E}-2)^{-}}$ & $2.29 \mathrm{E}-1_{(5.63 \mathrm{E}-3)^{-}}$ & \\
\hline & 7 & $1.29 \mathrm{E}+0_{(1.32 \mathrm{E}-1)}-$ & $2.16 \mathrm{E}+0_{(3.84 \mathrm{E}-1)^{-}}$ & $1.56 \mathrm{E}+0_{(5.8 \mathrm{E}-1)}-$ & $2.83 \mathrm{E}+0_{(3.81 \mathrm{E}-2)^{-}}$ & $2.85 \mathrm{E}+0_{(3.7 \mathrm{E}-2)^{-}}$ & $3.04 \mathrm{E}+0_{(8.7 \mathrm{E}-2)^{-}}$ & $2.90 \mathrm{E}+0_{(5.22 \mathrm{E}-2)}-$ & $2.87 \mathrm{E}+0_{(7.35 \mathrm{E}-2)^{-}}$ & $2.66 \mathrm{E}+0_{(4.7 \mathrm{E}-2)^{-}}$ & \\
\hline \multirow{3}{*}{ RVEA } & 2 & $\left.5.81 \mathrm{E}-1_{(4.75 \mathrm{E}-2)}\right)^{-}$ & $7.72 \mathrm{E}-2_{(1.07 \mathrm{E}-2)}-$ & $5.79 \mathrm{E}-2_{(1.04 \mathrm{E}-2)^{-}}$ & $9.44 \mathrm{E}-2_{(1.59 \mathrm{E}-2)^{-}}$ & $1.01 \mathrm{E}-1_{(1.40 \mathrm{E}-2)^{-}}$ & $1.69 \mathrm{E}-1_{(2.42 \mathrm{E}-2)^{-}}$ & $6.65 \mathrm{E}-2_{(1.26 \mathrm{E}-2)}-$ & $2.06 \mathrm{E}-1_{(1.51 \mathrm{E}-2)}-$ & $6.04 \mathrm{E}-2_{(5.71 \mathrm{E}-3)^{-}}$ & \multirow{3}{*}{$0 / 27 / 0$} \\
\hline & 3 & $6.54 \mathrm{E}-1_{(6.52 \mathrm{E}-2)}-$ & $2.17 \mathrm{E}-1_{(2.05 \mathrm{E}-2)^{-}}$ & $2.30 \mathrm{E}-1_{(1.96 \mathrm{E}-2)}-$ & $2.43 \mathrm{E}-1_{(5.85 \mathrm{E}-3)}-$ & $2.37 \mathrm{E}-1_{(2.78 \mathrm{E}-3)^{-}}$ & $2.72 \mathrm{E}-1_{(1.72 \mathrm{E}-2)^{-}}$ & $2.39 \mathrm{E}-1_{(5.28 \mathrm{E}-3)}-$ & $3.28 \mathrm{E}-1_{(1.62 \mathrm{E}-2)^{-}}$ & $2.36 \mathrm{E}-1_{(6.77 \mathrm{E}-3)^{-}}$ & \\
\hline & 7 & $1.37 \mathrm{E}+0_{(1.27 \mathrm{E}-1)}-$ & $5.39 \mathrm{E}+0_{(1.1 \mathrm{E}+0)^{-}}$ & $1.93 \mathrm{E}+0_{(5.3 \mathrm{E}-1)}-$ & $2.63 \mathrm{E}+0_{(1.09 \mathrm{E}-2)^{-}}$ & $2.62 \mathrm{E}+0_{(8.8 \mathrm{E}-3)^{-}}$ & $2.64 \mathrm{E}+0_{(3.4 \mathrm{E}-2)^{-}}$ & $2.65 \mathrm{E}+0_{(1.85 \mathrm{E}-2)}-$ & $2.68 \mathrm{E}+0_{(4.91 \mathrm{E}-2)^{-}}$ & $2.57 \mathrm{E}+0_{(3.1 \mathrm{E}-2)^{-}}$ & \\
\hline \multirow{3}{*}{ Two-Arch2 } & 2 & $2.57 \mathrm{E}-1_{(9.01 \mathrm{E}-2)}-$ & $1.29 \mathrm{E}-2_{(1.9 \mathrm{E}-3)}+$ & $1.47 \mathrm{E}-2_{(1.46 \mathrm{E}-3)^{-}}$ & $1.62 \mathrm{E}-2_{(8.82 \mathrm{E}-4)^{-}}$ & $6.59 \mathrm{E}-2_{(2.36 \mathrm{E}-3)^{-}}$ & $7.38 \mathrm{E}-2_{(2.00 \mathrm{E}-2)^{-}}$ & $1.62 \mathrm{E}-2_{(2.69 \mathrm{E}-4)^{-}}$ & $1.18 \mathrm{E}-1_{(8.79 \mathrm{E}-3)^{-}}$ & $2.02 \mathrm{E}-2_{(2.34 \mathrm{E}-3)^{-}}$ & \multirow{3}{*}{$1 / 26 / 0$} \\
\hline & 3 & $4.58 \mathrm{E}-1_{(1.14 \mathrm{E}-1)}-$ & $1.53 \mathrm{E}-1_{(3.41 \mathrm{E}-3)^{-}}$ & $8.74 \mathrm{E}-2_{(6.22 \mathrm{E}-3)}-$ & $2.27 \mathrm{E}-1_{(5.49 \mathrm{E}-3)}-$ & $2.37 \mathrm{E}-1_{(3.98 \mathrm{E}-3)^{-}}$ & $2.53 \mathrm{E}-1_{(1.38 \mathrm{E}-2)^{-}}$ & $2.25 \mathrm{E}-1_{(4.51 \mathrm{E}-3)}-$ & $3.11 \mathrm{E}-1_{(5.61 \mathrm{E}-3)^{-}}$ & $2.22 \mathrm{E}-1_{(3.75 \mathrm{E}-3)^{-}}$ & \\
\hline & 7 & $\left.1.62 \mathrm{E}+0_{(1.57 \mathrm{E}-1)}\right)^{-}$ & $2.02 \mathrm{E}+0_{(4.16 \mathrm{E}-1)^{-}}$ & $9.56 \mathrm{E}-1_{(1.15 \mathrm{E}-1)}-$ & $2.59 \mathrm{E}+0_{(2.16 \mathrm{E}-2)^{-}}$ & $2.54 \mathrm{E}+0_{(2.4 \mathrm{E}-2)^{-}}$ & $2.61 \mathrm{E}+0_{(3.2 \mathrm{E}-2)^{-}}$ & $2.56 \mathrm{E}+0_{(2.17 \mathrm{E}-2)^{-}}$ & $2.87 \mathrm{E}+0_{(3.88 \mathrm{E}-2)^{-}}$ & $2.58 \mathrm{E}+0_{(3.7 \mathrm{E}-2)^{-}}$ & \\
\hline \multirow{3}{*}{$\boldsymbol{\theta}$-DEA } & 2 & $2.70 \mathrm{E}-1_{(8.29 \mathrm{E}-2)}-$ & $3.02 \mathrm{E}-2_{(4.77 \mathrm{E}-2)}-$ & $1.29 \mathrm{E}-2_{(5.23 \mathrm{E}-4)^{-}}$ & $1.40 \mathrm{E}-2_{(1.21 \mathrm{E}-3)^{-}}$ & $6.52 \mathrm{E}-2_{(2.14 \mathrm{E}-3)^{-}}$ & $8.09 \mathrm{E}-2_{(1.42 \mathrm{E}-2)^{-}}$ & $1.27 \mathrm{E}-2_{(1.9 \mathrm{E}-4)}+$ & $1.15 \mathrm{E}-1_{(3.42 \mathrm{E}-3)}-$ & $2.18 \mathrm{E}-2_{(2.34 \mathrm{E}-3)^{-}}$ & \multirow{3}{*}{$1 / 26 / 0$} \\
\hline & 3 & $4.75 \mathrm{E}-1_{(6.57 \mathrm{E}-2)}-$ & $2.10 \mathrm{E}-1_{(2.24 \mathrm{E}-2)^{-}}$ & $1.34 \mathrm{E}-1_{(1.84 \mathrm{E}-2)}-$ & $2.22 \mathrm{E}-1_{(5.44 \mathrm{E}-4)}-$ & $2.30 \mathrm{E}-1_{(8.14 \mathrm{E}-4)^{-}}$ & $2.46 \mathrm{E}-1_{(1.13 \mathrm{E}-2)^{-}}$ & $2.22 \mathrm{E}-1_{(4.77 \mathrm{E}-4)}-$ & $2.93 \mathrm{E}-1_{(4.59 \mathrm{E}-3)^{-}}$ & $2.32 \mathrm{E}-1_{(3.04 \mathrm{E}-2)^{-}}$ & \\
\hline & 7 & $1.29 \mathrm{E}+0_{(2.93 \mathrm{E}-1)^{-}}$ & $3.60 \mathrm{E}+0_{(1.7 \mathrm{E}+0)^{-}}$ & $1.22 \mathrm{E}+0_{(2.0 \mathrm{E}-1)}-$ & $2.65 \mathrm{E}+0_{(1.08 \mathrm{E}-2)^{-}}$ & $2.61 \mathrm{E}+0_{(7.9 \mathrm{E}-3)^{-}}$ & $2.65 \mathrm{E}+0_{(1.6 \mathrm{E}-2)^{-}}$ & $2.66 \mathrm{E}+0_{(1.14 \mathrm{E}-2)}-$ & $2.61 \mathrm{E}+0_{(1.21 \mathrm{E}-2)^{-}}$ & $2.54 \mathrm{E}+0_{(7.8 \mathrm{E}-3)^{-}}$ & \\
\hline & 2 & $3.11 \mathrm{E}-1_{(3.60 \mathrm{E}-2)}-$ & $2.48 \mathrm{E}-2_{(1.68 \mathrm{E}-3)}-$ & $1.58 \mathrm{E}-2_{(1.21 \mathrm{E}-3)^{-}}$ & $1.43 \mathrm{E}-2_{(4.79 \mathrm{E}-4)^{-}}$ & $6.71 \mathrm{E}-2_{(2.75 \mathrm{E}-3)^{-}}$ & $8.35 \mathrm{E}-2_{(1.87 \mathrm{E}-2)^{-}}$ & $1.39 \mathrm{E}-2_{(3.5 \mathrm{E}-4)}+$ & $1.10 \mathrm{E}-1_{(1.98 \mathrm{E}-3)}-$ & $2.21 \mathrm{E}-2_{(2.23 \mathrm{E}-3)^{-}}$ & \\
\hline MOEA/DD & 3 & $1.02 \mathrm{E}+0_{(1.49 \mathrm{E}-1)^{-}}$ & $4.85 \mathrm{E}-1_{(1.11 \mathrm{E}-1)^{-}}$ & $2.61 \mathrm{E}-1_{(1.01 \mathrm{E}-1)}-$ & $2.41 \mathrm{E}-1_{(9.34 \mathrm{E}-4)}-$ & $2.46 \mathrm{E}-1_{(1.68 \mathrm{E}-3)^{-}}$ & $2.61 \mathrm{E}-1_{(1.29 \mathrm{E}-2)^{-}}$ & $2.44 \mathrm{E}-1_{(1.85 \mathrm{E}-3)}-$ & $3.05 \mathrm{E}-1_{(3.66 \mathrm{E}-3)^{-}}$ & $2.39 \mathrm{E}-1_{(1.92 \mathrm{E}-3)^{-}}$ & $1 / 26 / 0$ \\
\hline & 7 & $1.86 \mathrm{E}+0_{(1.17 \mathrm{E}-1)}-$ & $8.91 \mathrm{E}+0_{(2.73 \mathrm{E}-1)^{-}}$ & $1.78 \mathrm{E}+0_{(1.4 \mathrm{E}-1)}-$ & $2.93 \mathrm{E}+0_{(7.84 \mathrm{E}-2)^{-}}$ & $3.05 \mathrm{E}+0_{(1.1 \mathrm{E}-1)^{-}}$ & $2.98 \mathrm{E}+0_{(9.4 \mathrm{E}-2)^{-}}$ & $2.93 \mathrm{E}+0_{(1.13 \mathrm{E}-1)}-$ & $2.83 \mathrm{E}+0_{(2.01 \mathrm{E}-2)^{-}}$ & $3.11 \mathrm{E}+0_{(1.2 \mathrm{E}-1)^{-}}$ & \\
\hline & 2 & $2.84 \mathrm{E}-1_{(2.60 \mathrm{E}-2)}-$ & $3.03 \mathrm{E}-2_{(3.96 \mathrm{E}-3)^{-}}$ & $1.90 \mathrm{E}-2_{(1.64 \mathrm{E}-3)^{-}}$ & $1.98 \mathrm{E}-2_{(2.00 \mathrm{E}-3)^{-}}$ & $6.69 \mathrm{E}-2_{(1.91 \mathrm{E}-3)^{-}}$ & $8.42 \mathrm{E}-2_{(1.87 \mathrm{E}-2)^{-}}$ & $1.97 \mathrm{E}-2_{(1.68 \mathrm{E}-3)^{-}}$ & $1.18 \mathrm{E}-1_{(2.65 \mathrm{E}-3)^{-}}$ & $2.89 \mathrm{E}-2_{(3.46 \mathrm{E}-3)^{-}}$ & \\
\hline AnD & 3 & $4.79 \mathrm{E}-1_{(4.94 \mathrm{E}-2)}-$ & $2.49 \mathrm{E}-1_{(2.26 \mathrm{E}-2)^{-}}$ & $1.54 \mathrm{E}-1_{(1.87 \mathrm{E}-2)}-$ & $2.28 \mathrm{E}-1_{(6.08 \mathrm{E}-3)}-$ & $2.38 \mathrm{E}-1_{(4.09 \mathrm{E}-3)^{-}}$ & $2.55 \mathrm{E}-1_{(1.69 \mathrm{E}-2)^{-}}$ & $2.29 \mathrm{E}-1_{(4.27 \mathrm{E}-3)}-$ & $3.28 \mathrm{E}-1_{(9.38 \mathrm{E}-3)^{-}}$ & $2.26 \mathrm{E}-1_{(9.73 \mathrm{E}-3)^{-}}$ & $0 / 27 / 0$ \\
\hline & 7 & $1.26 \mathrm{E}+0_{(1.07 \mathrm{E}-1)^{-}}$ & $3.29 \mathrm{E}+0_{(1.0 \mathrm{E}+0)^{-}}$ & $1.15 \mathrm{E}+0_{(1.7 \mathrm{E}-1)}-$ & $2.57 \mathrm{E}+0_{(2.35 \mathrm{E}-2)^{-}}$ & $2.56 \mathrm{E}+0_{(1.9 \mathrm{E}-2)^{-}}$ & $2.63 \mathrm{E}+0_{(3.3 \mathrm{E}-2)^{-}}$ & $2.63 \mathrm{E}+0_{(3.41 \mathrm{E}-2)}-$ & $2.63 \mathrm{E}+0_{(2.59 \mathrm{E}-2)^{-}}$ & $2.48 \mathrm{E}+0_{(2.4 \mathrm{E}-2)^{-}}$ & \\
\hline & 2 & & $1.92 \mathrm{E}-2_{(1.80 \mathrm{E}-3)}$ & $1.10 \mathrm{E}-2_{(1.20 \mathrm{E}-3)}$ & $1.01 \mathrm{E}-2_{(8.10 \mathrm{E}-4)}$ & $2.46 \mathrm{E}-4_{(3.50 \mathrm{E}-5)}$ & $2.50 \mathrm{E}-\mathbf{4}_{(4.30 \mathrm{E}-5)}$ & $1.46 \mathrm{E}-2_{(2.20 \mathrm{E}-3)}$ & $1.56 \mathrm{E}-2_{(2.40 \mathrm{E}-3)}$ & $3.85 E-4_{(5.10 E-5)}$ & \\
\hline DB-CSA & 3 & $3.13 \mathrm{E}-4_{(3.40 \mathrm{E}-5)}$ & $7.68 \mathrm{E}-3_{(3.70 \mathrm{E}-4)}$ & $2.37 \mathrm{E}-4_{(7.10 \mathrm{E}-6)}$ & $5.08 \mathrm{E}-3_{(2.70 \mathrm{E}-4)}$ & $1.38 \mathrm{E}-4_{(2.30 \mathrm{E}-6)}$ & $1.53 \mathrm{E}-4_{(4.40 \mathrm{E}-6)}$ & $6.61 \mathrm{E}-3_{(4.40 \mathrm{E}-4)}$ & $6.26 \mathrm{E}-3_{(2.80 \mathrm{E}-4)}$ & $5.51 \mathrm{E}-4_{(3.10 \mathrm{E}-5)}$ & \\
\hline & 7 & $2.42 \mathrm{E}-\mathbf{4}_{(1.60 \mathrm{E}-5)}$ & $3.70 \mathrm{E}-4_{(1.70 \mathrm{E}-5)}$ & $\mathbf{5 . 8 7 E - 5 _ { ( 7 . 5 0 E - 7 ) }}$ & $1.08 \mathrm{E}-3_{(2.00 \mathrm{E}-5)}$ & $1.65 \mathrm{E}-\mathbf{4}_{(5.00 \mathrm{E}-6)}$ & $6.97 \mathrm{E}-\mathbf{4}_{(6.40 \mathrm{E}-5)}$ & $2.20 \mathrm{E}-3_{(6.90 \mathrm{E}-5)}$ & $1.91 \mathrm{E}-3_{(4.40 \mathrm{E}-5)}$ & $7.93 E-4_{(3.70 E-5)}$ & \\
\hline
\end{tabular}

The symbols "+", " $\approx$ " and " " " denote that the performance of the compared algorithm is statistically better than, equivalent to, and worse than DB-CSA. 
Table 15. IGD results (Mean and Standard Deviation) of the 13 MOEAs [58] compared to DB-CSA on the 2, 3 and 7 objectives MaF problems.

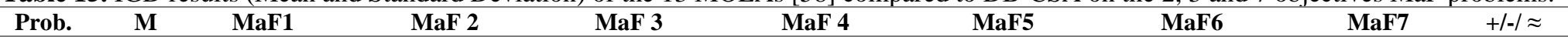

\begin{tabular}{|c|c|c|c|c|c|c|c|c|c|}
\hline & & & & & & & & & \multirow{4}{*}{$0 / 21 / 0$} \\
\hline & 2 & $5.68 \mathrm{E}-3(2.82 \mathrm{E}-4)-$ & $3.03 \mathrm{E}-3(1.52 \mathrm{E}-4)-$ & $1.83 \mathrm{E}+0_{(2.4 \mathrm{E}+0)-}$ & $2.92 \mathrm{E}-1_{(3.55 \mathrm{E}-1)}-$ & $5.49 \mathrm{E}-1_{(9.11 \mathrm{E}-1)-}$ & 7.55E-2(5.84E-2) - & $7.76 \mathrm{E}-2(1.52 \mathrm{E}-1)-$ & \\
\hline \multirow[t]{2}{*}{ MSOPS-II } & 3 & $5.40 \mathrm{E}-2_{(5.31 \mathrm{E}-3)}-$ & $3.72 \mathrm{E}-2_{(1.18 \mathrm{E}-3)}-$ & $5.48 \mathrm{E}+0_{(7.03 \mathrm{E}+0)^{-}}$ & $2.14 \mathrm{E}+0_{(1.5 \mathrm{E}+0)}-$ & $7.77 \mathrm{E}-1_{(6.97 \mathrm{E}-1)}-$ & $2.70 \mathrm{E}-2_{(5.22 \mathrm{E}-2)}-$ & $1.40 \mathrm{E}-1_{(1.21 \mathrm{E}-2)}-$ & \\
\hline & 7 & $2.39 \mathrm{E}-1_{(1.83 \mathrm{E}-2)}-$ & $1.70 \mathrm{E}-1_{(4.50 \mathrm{E}-3)}-$ & $2.39 \mathrm{E}+1_{(5.1 \mathrm{E}+1)}-$ & $1.56 \mathrm{E}+2(1.3 \mathrm{E}+2)-$ & $2.08 \mathrm{E}+1_{(8.71 \mathrm{E}+0)}-$ & $1.45 \mathrm{E}-2_{(2.29 \mathrm{E}-3)-}$ & $9.27 \mathrm{E}-1_{(2.52 \mathrm{E}-1)}-$ & \\
\hline \multirow{3}{*}{ MOEA/D } & 2 & $3.57 \mathrm{E}-3(1.21 \mathrm{E}-7)-$ & $2.58 \mathrm{E}-3(1.54 \mathrm{E}-4)-$ & $6.66 \mathrm{E}-1_{(1.32 \mathrm{E}+0)-}$ & $7.41 \mathrm{E}-1_{(6.20 \mathrm{E}-1)}-$ & $1.46 \mathrm{E}-1_{(5.15 \mathrm{E}-1)-}$ & $4.14 \mathrm{E}-3(1.52 \mathrm{E}-4)-$ & $7.03 \mathrm{E}-2_{(1.53 \mathrm{E}-1)}-$ & \multirow{3}{*}{$0 / 21 / 0$} \\
\hline & 3 & $7.05 \mathrm{E}-2_{(1.70 \mathrm{E}-5)}-$ & $4.14 \mathrm{E}-2_{(1.20 \mathrm{E}-3)}-$ & $9.03 \mathrm{E}-1_{(1.18 \mathrm{E}+0)}-$ & $2.27 \mathrm{E}+0_{(1.1 \mathrm{E}+0)}-$ & $1.58 \mathrm{E}+0_{(1.22 \mathrm{E}+0)}-$ & $9.94 \mathrm{E}-2_{(1.48 \mathrm{E}-1)-}$ & $1.54 \mathrm{E}-1_{(1.74 \mathrm{E}-3)}-$ & \\
\hline & 7 & $4.77 \mathrm{E}-1_{(3.74 \mathrm{E}-2)}-$ & $2.09 \mathrm{E}-1_{(2.95 \mathrm{E}-3)}-$ & $4.64 \mathrm{E}-1_{(4.54 \mathrm{E}-1)}-$ & $7.24 \mathrm{E}+1_{(5.3 \mathrm{E}+0)}-$ & $4.47 \mathrm{E}+1_{(2.70 \mathrm{E}+0)}-$ & $4.14 \mathrm{E}-1_{(2.02 \mathrm{E}-1)}-$ & $1.36 \mathrm{E}+0_{(1.75 \mathrm{E}-1)}-$ & \\
\hline \multirow{3}{*}{ HypE } & 2 & $3.68 \mathrm{E}-3(1.28 \mathrm{E}-5)-$ & $2.06 \mathrm{E}-3(1.27 \mathrm{E}-5)-$ & $1.66 \mathrm{E}+0_{(2.7 \mathrm{E}+0)}-$ & $2.12 \mathrm{E}-1_{(3.69 \mathrm{E}-1)}-$ & $6.28 \mathrm{E}-1_{(8.89 \mathrm{E}-1)}-$ & $9.56 \mathrm{E}-3(3.88 \mathrm{E}-3)-$ & $3.26 \mathrm{E}-1_{(2.01 \mathrm{E}-1)}-$ & \multirow{3}{*}{$0 / 21 / 0$} \\
\hline & 3 & $8.51 \mathrm{E}-2(5.82 \mathrm{E}-3)-$ & $4.56 \mathrm{E}-2_{(1.71 \mathrm{E}-3)}-$ & $3.71 \mathrm{E}+0_{(5.4 \mathrm{E}+0)}-$ & $2.68 \mathrm{E}+0_{(2.5 \mathrm{E}+0)}-$ & $1.64 \mathrm{E}+0_{(1.09 \mathrm{E}+0)}-$ & $1.96 \mathrm{E}-1_{(2.54 \mathrm{E}-2)}-$ & $8.22 \mathrm{E}-1_{(5.03 \mathrm{E}-3)}-$ & \\
\hline & 7 & $2.99 \mathrm{E}-1_{(6.63 \mathrm{E}-3)}-$ & $4.29 \mathrm{E}-1_{(2.29 \mathrm{E}-2)}-$ & $1.09 \mathrm{E}+5_{(1.6 \mathrm{E}+5)}-$ & $7.59 \mathrm{E}+1_{(5.9 \mathrm{E}+1)}-$ & $1.97 \mathrm{E}+1_{(3.79 \mathrm{E}+0)-}$ & $2.01 \mathrm{E}-1_{(3.26 \mathrm{E}-2)}-$ & $3.28 \mathrm{E}+0_{(2.32 \mathrm{E}-1)}-$ & \\
\hline \multirow{3}{*}{ PICEA-g } & 2 & 3.82E-3(3.90E-5) - & $2.21 \mathrm{E}-3_{(3.00 \mathrm{E}-5)}-$ & $2.18 \mathrm{E}+2_{(1.4 \mathrm{E}+2)}-$ & $9.79 \mathrm{E}-1_{(1.05 \mathrm{E}+0)}-$ & $1.46 \mathrm{E}-1_{(5.15 \mathrm{E}-1)}-$ & $4.57 \mathrm{E}-3_{(3.10 \mathrm{E}-4)}-$ & $3.47 \mathrm{E}+2_{(1.14 \mathrm{E}-1)^{-}}$ & \multirow{3}{*}{$0 / 21 / 0$} \\
\hline & 3 & $4.16 \mathrm{E}-2_{(4.72 \mathrm{E}-4)}-$ & $3.04 \mathrm{E}-2_{(7.07 \mathrm{E}-4)}-$ & $2.63 \mathrm{E}+1_{(1.8 \mathrm{E}+1)}-$ & $6.26 \mathrm{E}+0_{(5.5 \mathrm{E}+0)}-$ & $7.78 \mathrm{E}-1_{(6.90 \mathrm{E}-1)}-$ & $4.58 \mathrm{E}-3_{(3.02 \mathrm{E}-4)-}$ & $3.77 \mathrm{E}-1_{(2.65 \mathrm{E}-1)}-$ & \\
\hline & 7 & $2.16 \mathrm{E}-1_{(3.34 \mathrm{E}-3)}-$ & $2.16 \mathrm{E}-1_{(4.08 \mathrm{E}-2)}-$ & $1.31 \mathrm{E}+9(1.3 \mathrm{E}+9)-$ & $2.95 \mathrm{E}+2(3.4 \mathrm{E}+2)-$ & $1.07 \mathrm{E}+1_{(3.50 \mathrm{E}+0)}-$ & $4.38 \mathrm{E}+3(1.77 \mathrm{E}-4)-$ & $3.03 \mathrm{E}+0_{(8.23 \mathrm{E}-1)}-$ & \\
\hline \multirow{3}{*}{ SPEA2/SDE } & 2 & $3.99 \mathrm{E}-3(6.27 \mathrm{E}-5)-$ & $2.38 \mathrm{E}-3(6.38 \mathrm{E}-5)-$ & $7.44 \mathrm{E}-1_{(1.20 \mathrm{E}+0)}-$ & $3.47 \mathrm{E}-1_{(4.34 \mathrm{E}-1)}-$ & $1.63 \mathrm{E}-1_{(5.10 \mathrm{E}-1)}-$ & $1.08 \mathrm{E}-2(1.32 \mathrm{E}-3)-$ & $5.22 \mathrm{E}-3(2.02 \mathrm{E}-4)-$ & \multirow{3}{*}{$0 / 21 / 0$} \\
\hline & 3 & $4.20 \mathrm{E}-2(6.20 \mathrm{E}-4)-$ & $3.09 \mathrm{E}-2(7.86 \mathrm{E}-4)-$ & $5.51 \mathrm{E}-1_{(9.40 \mathrm{E}-1)}-$ & $1.89 \mathrm{E}+0_{(1.9 \mathrm{E}+0)}-$ & $6.60 \mathrm{E}-1_{(6.28 \mathrm{E}-1)}-$ & $9.57 \mathrm{E}-3(1.19 \mathrm{E}-3)-$ & $5.86 \mathrm{E}-2(2.56 \mathrm{E}-3)-$ & \\
\hline & 7 & $2.05 \mathrm{E}-1_{(2.51 \mathrm{E}-3)}-$ & $1.60 \mathrm{E}-1_{(7.08 \mathrm{E}-3)}-$ & $2.09 \mathrm{E}+0_{(5.6 \mathrm{E}+0)}-$ & $2.44 \mathrm{E}+1_{(1.4 \mathrm{E}+1)}-$ & $1.09 \mathrm{E}+1_{(2.47 \mathrm{E}+0)}-$ & $1.03 \mathrm{E}-2_{(1.33 \mathrm{E}-3)}-$ & $5.40 \mathrm{E}-1_{(9.29 \mathrm{E}-3)}-$ & \\
\hline \multirow[t]{3}{*}{ GrEA } & 2 & 7.83E-3(6.05E-5) - & 3.99E-3(8.78E-5) - & $1.07 \mathrm{E}+0_{(2.1 \mathrm{E}+0)}-$ & $7.02 \mathrm{E}-1_{(6.75 \mathrm{E}-1)-}$ & $3.20 \mathrm{E}-2(1.18 \mathrm{E}-3)-$ & 9.85E-3(6.53E-4) - & $2.98 \mathrm{E}-2(7.39 \mathrm{E}-3)-$ & \multirow{3}{*}{$0 / 21 / 0$} \\
\hline & 3 & $4.03 \mathrm{E}-2_{(9.01 \mathrm{E}-4)}-$ & $3.13 \mathrm{E}-2(6.19 \mathrm{E}-4)-$ & $2.37 \mathrm{E}+0_{(3.1 \mathrm{E}+0)}-$ & $3.02 \mathrm{E}+0_{(3.2 \mathrm{E}+0)}-$ & $5.39 \mathrm{E}-1_{(5.10 \mathrm{E}-1)}-$ & $2.09 \mathrm{E}-2_{(5.31 \mathrm{E}-4)}-$ & $8.29 \mathrm{E}-2_{(4.07 \mathrm{E}-3)}-$ & \\
\hline & 7 & $2.21 \mathrm{E}-1_{(4.66 \mathrm{E}-3)}-$ & $1.66 \mathrm{E}-1_{(3.06 \mathrm{E}-3)}-$ & $2.79 \mathrm{E}+5_{(6.6 \mathrm{E}+5)}-$ & $6.41 \mathrm{E}+1_{(6.7 \mathrm{E}+1)}-$ & $8.60 \mathrm{E}+0_{(2.44 \mathrm{E}-1)}-$ & $8.24 \mathrm{E}-2_{(1.54 \mathrm{E}-1)}-$ & $7.13 \mathrm{E}-1_{(7.15 \mathrm{E}-2)}-$ & \\
\hline \multirow{3}{*}{ NSGA-III } & 2 & $3.57 \mathrm{E}-3(2.33 \mathrm{E}-6)-$ & $2.05 \mathrm{E}-3(7.13 \mathrm{E}-5)-$ & $3.12 \mathrm{E}+0_{(7.7 \mathrm{E}+0)}-$ & $7.50 \mathrm{E}-1_{(9.42 \mathrm{E}-1)-}$ & $1.45 \mathrm{E}-1_{(5.15 \mathrm{E}-1)-}$ & 4.02E-3(3.97E-5) - & $6.85 \mathrm{E}-3(1.74 \mathrm{E}-4)-$ & \multirow{3}{*}{$0 / 21 / 0$} \\
\hline & 3 & $6.16 \mathrm{E}-2_{(1.91 \mathrm{E}-3)}-$ & $3.67 \mathrm{E}-2_{(8.54 \mathrm{E}-4)}-$ & $4.09 \mathrm{E}+0_{(3.5 \mathrm{E}+0)}-$ & $4.64 \mathrm{E}+0_{(3.3 \mathrm{E}+0)}-$ & $4.95 \mathrm{E}-1_{(6.22 \mathrm{E}-1)}-$ & $1.49 \mathrm{E}-2_{(1.56 \mathrm{E}-3)}-$ & $7.67 \mathrm{E}-2_{(2.96 \mathrm{E}-3)}-$ & \\
\hline & 7 & $2.56 \mathrm{E}-1_{(1.70 \mathrm{E}-2)}-$ & $1.96 \mathrm{E}-1_{(1.60 \mathrm{E}-2)}-$ & $4.46 \mathrm{E}+2(5.9 \mathrm{E}+2)-$ & $1.30 \mathrm{E}+2_{(1.4 \mathrm{E}+2)}-$ & $1.21 \mathrm{E}+1_{(9.47 \mathrm{E}-1)}-$ & $2.08 \mathrm{E}-1_{(2.67 \mathrm{E}-1)-}$ & $7.25 \mathrm{E}-1_{(3.74 \mathrm{E}-2)-}$ & \\
\hline \multirow{3}{*}{ KnEA } & 2 & $5.06 \mathrm{E}-3(2.14 \mathrm{E}-4)-$ & $2.15 \mathrm{E}-2(7.69 \mathrm{E}-3)-$ & $9.27 \mathrm{E}-1_{(1.16 \mathrm{E}+0)}-$ & $4.63 \mathrm{E}-1_{(3.83 \mathrm{E}-1)}-$ & $5.71 \mathrm{E}-1_{(8.97 \mathrm{E}-1)-}$ & $1.48 \mathrm{E}-1_{(1.80 \mathrm{E}-2)-}$ & $3.40 \mathrm{E}-2(1.48 \mathrm{E}-2)-$ & \multirow{3}{*}{$0 / 21 / 0$} \\
\hline & 3 & $4.84 \mathrm{E}-2(7.05 \mathrm{E}-3)-$ & $3.42 \mathrm{E}-2(1.66 \mathrm{E}-3)-$ & $2.33 \mathrm{E}+0_{(5.1 \mathrm{E}+0)}-$ & $1.54 \mathrm{E}+0_{(1.6 \mathrm{E}+0)}-$ & $3.11 \mathrm{E}-1_{(9.91 \mathrm{E}-3)}-$ & $4.74 \mathrm{E}-2(3.94 \mathrm{E}-2)-$ & $6.81 \mathrm{E}-2(6.14 \mathrm{E}-3)-$ & \\
\hline & 7 & $2.05 \mathrm{E}-1_{(5.09 \mathrm{E}-3)}-$ & $1.63 \mathrm{E}-1_{(7.03 \mathrm{E}-3)}-$ & $6.37 \mathrm{E}+6_{(1.7 \mathrm{E}+7)-}$ & $3.03 \mathrm{E}+2(2.7 \mathrm{E}+2)-$ & $1.29 \mathrm{E}+1_{(5.11 \mathrm{E}-1)}-$ & $4.50 \mathrm{E}-1_{(1.62 \mathrm{E}+0)}-$ & $5.07 \mathrm{E}-1_{(1.38 \mathrm{E}-2)}-$ & \\
\hline \multirow{3}{*}{ RVEA } & 2 & $3.60 \mathrm{E}-3(3.29 \mathrm{E}-5)-$ & $2.76 \mathrm{E}-3(1.61 \mathrm{E}-4)-$ & $1.98 \mathrm{E}+2(2.8 \mathrm{E}+2)-$ & $2.33 \mathrm{E}+0_{(1.8 \mathrm{E}+0)}-$ & $1.37 \mathrm{E}-2(1.25 \mathrm{E}-3)-$ & $7.55 \mathrm{E}-3(8.55 \mathrm{E}-4)-$ & $2.91 \mathrm{E}-2(4.64 \mathrm{E}-3)-$ & \multirow{3}{*}{$0 / 21 / 0$} \\
\hline & 3 & $8.23 \mathrm{E}-2(2.56 \mathrm{E}-4)-$ & $4.22 \mathrm{E}-2(1.36 \mathrm{E}-3)-$ & $8.04 \mathrm{E}+2_{(1.3 \mathrm{E}+3)}-$ & $7.71 \mathrm{E}+0_{(5.8 \mathrm{E}+0)}-$ & $2.60 \mathrm{E}-1_{(9.96 \mathrm{E}-4)}-$ & $5.11 \mathrm{E}-2_{(2.43 \mathrm{E}-2)-}$ & $1.08 \mathrm{E}-1_{(2.83 \mathrm{E}-3)}-$ & \\
\hline & 7 & $4.99 \mathrm{E}-1_{(7.00 \mathrm{E}-2)}-$ & $4.58 \mathrm{E}-1_{(1.47 \mathrm{E}-1)}-$ & $5.75 \mathrm{E}+1_{(5.0 \mathrm{E}+1)}-$ & $4.09 \mathrm{E}+1_{(1.9 \mathrm{E}+1)}-$ & $1.51 \mathrm{E}+1_{(3.26 \mathrm{E}+0)}-$ & $1.31 \mathrm{E}-1_{(2.53 \mathrm{E}-2)}-$ & $1.24 \mathrm{E}+0_{(2.41 \mathrm{E}-1)-}$ & \\
\hline \multirow{3}{*}{ Two-Arch2 } & 2 & $4.00 \mathrm{E}-3_{(3.10 \mathrm{E}-6)}-$ & $2.24 \mathrm{E}-3_{(2.06 \mathrm{E}-5)}-$ & $2.09 \mathrm{E}+1_{(2.4 \mathrm{E}+1)}-$ & $2.10 \mathrm{E}+0_{(2.6 \mathrm{E}+0)}-$ & $1.61 \mathrm{E}+0_{(8.25 \mathrm{E}-1)}-$ & $5.18 \mathrm{E}-3_{(1.66 \mathrm{E}-4)-}$ & $6.33 \mathrm{E}-2_{(1.54 \mathrm{E}-1)-}$ & \multirow{3}{*}{$0 / 21 / 0$} \\
\hline & 3 & $4.15 \mathrm{E}-2(4.28 \mathrm{E}-4)-$ & $2.91 \mathrm{E}-2(4.68 \mathrm{E}-4)-$ & $1.25 \mathrm{E}+1_{(1.3 \mathrm{E}+1)}-$ & $5.49 \mathrm{E}+0_{(3.6 \mathrm{E}+0)}-$ & $2.54 \mathrm{E}-1_{(6.40 \mathrm{E}-3)}-$ & $5.84 \mathrm{E}-3(2.83 \mathrm{E}-4)-$ & $9.69 \mathrm{E}-2_{(1.03 \mathrm{E}-1)}-$ & \\
\hline & 7 & $2.07 \mathrm{E}-1_{(4.22 \mathrm{E}-3)}-$ & $1.62 \mathrm{E}-1_{(3.64 \mathrm{E}-3)}-$ & $2.09 \mathrm{E}+5_{(7.0 \mathrm{E}+5)}-$ & $1.50 \mathrm{E}+2(1.3 \mathrm{E}+2)-$ & $8.95 \mathrm{E}+0_{(2.39 \mathrm{E}-1)}-$ & $7.65 \mathrm{E}-3_{(7.45 \mathrm{E}-4)-}$ & $5.56 \mathrm{E}-1_{(3.59 \mathrm{E}-2)}-$ & \\
\hline \multirow{3}{*}{$\boldsymbol{\theta}$-DEA } & 2 & $3.57 \mathrm{E}-3(4.88 \mathrm{E}-7)-$ & $2.01 \mathrm{E}-3(7.51 \mathrm{E}-6)-$ & $1.09 \mathrm{E}+1_{(3.2 \mathrm{E}+1)}-$ & $2.12 \mathrm{E}-1_{(3.12 \mathrm{E}-1)}-$ & $4.11 \mathrm{E}-1_{(8.26 \mathrm{E}-1)}-$ & $4.01 \mathrm{E}-3(6.45 \mathrm{E}-5)-$ & $5.11 \mathrm{E}-3(7.25 \mathrm{E}-5)-$ & \multirow{3}{*}{$0 / 21 / 0$} \\
\hline & 3 & $8.04 \mathrm{E}-2_{(9.64 \mathrm{E}-4)}-$ & $3.65 \mathrm{E}-2_{(4.26 \mathrm{E}-4)-}$ & $3.81 \mathrm{E}+0_{(4.8 \mathrm{E}+0)}-$ & $1.79 \mathrm{E}+0_{(2.7 \mathrm{E}+0)}-$ & $6.66 \mathrm{E}-1_{(7.11 \mathrm{E}-1)-}$ & $3.34 \mathrm{E}-2_{(2.28 \mathrm{E}-3)-}$ & $1.10 \mathrm{E}-1_{(6.96 \mathrm{E}-2)}-$ & \\
\hline & 7 & $2.63 \mathrm{E}-1_{(5.71 \mathrm{E}-3)}-$ & $2.03 \mathrm{E}-1_{(1.32 \mathrm{E}-2)}-$ & $2.09 \mathrm{E}+1_{(1.8 \mathrm{E}+1)}-$ & $4.99 \mathrm{E}+1_{(4.0 \mathrm{E}+1)}-$ & $1.18 \mathrm{E}+1_{(5.89 \mathrm{E}-1)}-$ & $1.46 \mathrm{E}-1_{(5.93 \mathrm{E}-2)}-$ & $7.14 \mathrm{E}-1_{(7.91 \mathrm{E}-2)}-$ & \\
\hline & 2 & $3.57 \mathrm{E}-3_{(9.24 \mathrm{E}-8)}-$ & $4.44 \mathrm{E}-3(1.38 \mathrm{E}-4)-$ & $4.14 \mathrm{E}+1_{(3.7 \mathrm{E}+1)}-$ & $2.18 \mathrm{E}+0_{(1.8 \mathrm{E}+0)}-$ & $1.31 \mathrm{E}-2_{(1.20 \mathrm{E}-6)}-$ & $4.06 \mathrm{E}-3_{(4.73 \mathrm{E}-5)}-$ & $2.01 \mathrm{E}-2_{(1.15 \mathrm{E}-3)}-$ & \\
\hline MOEA/DD & 3 & $7.82 \mathrm{E}-2_{(1.97 \mathrm{E}-3)}-$ & $5.58 \mathrm{E}-2_{(2.08 \mathrm{E}-3)}-$ & $2.66 \mathrm{E}+1_{(2.7 \mathrm{E}+1)}-$ & $2.01 \mathrm{E}+0_{(2.4 \mathrm{E}+0)}-$ & $2.97 \mathrm{E}-1_{(1.89 \mathrm{E}-4)}-$ & $3.05 \mathrm{E}-2_{(1.45 \mathrm{E}-3)-}$ & $5.06 \mathrm{E}-1_{(2.54 \mathrm{E}-1)}-$ & $0 / 21 / 0$ \\
\hline & 7 & $3.34 \mathrm{E}-1_{(3.01 \mathrm{E}-2)}-$ & $2.28 \mathrm{E}-1_{(2.34 \mathrm{E}-2)}-$ & $2.04 \mathrm{E}+2_{(1.6 \mathrm{E}+2)}-$ & $4.56 \mathrm{E}+1_{(1.0 \mathrm{E}+1)}-$ & $3.94 \mathrm{E}+1_{(2.30 \mathrm{E}+0)}-$ & $1.29 \mathrm{E}-1_{(1.10 \mathrm{E}-2)}-$ & $2.09 \mathrm{E}+0_{(5.77 \mathrm{E}-1)}-$ & \\
\hline & 2 & $4.18 \mathrm{E}-3(2.25 \mathrm{E}-4)-$ & $2.52 \mathrm{E}-3(9.47 \mathrm{E}-5)-$ & $1.24 \mathrm{E}+4(1.9 \mathrm{E}+4)-$ & $2.95 \mathrm{E}+0_{(1.5 \mathrm{E}+0)}-$ & $1.59 \mathrm{E}-2(1.23 \mathrm{E}-3)-$ & $2.23 \mathrm{E}-3(7.01 \mathrm{E}-4)-$ & $9.38 \mathrm{E}-3(8.54 \mathrm{E}-4)-$ & \\
\hline AnD & 3 & $4.38 \mathrm{E}-2(6.16 \mathrm{E}-4)-$ & 3.03E-2(4.94E-4) - & $7.97 \mathrm{E}+3(9.7 \mathrm{E}+3)-$ & $8.69 \mathrm{E}+0_{(5.1 \mathrm{E}+0)}-$ & $2.63 \mathrm{E}-1_{(5.32 \mathrm{E}-3)}-$ & $6.26 \mathrm{E}-2(1.53 \mathrm{E}-2)-$ & $8.54 \mathrm{E}-2_{(3.08 \mathrm{E}-3)-}$ & $0 / 21 / 0$ \\
\hline & 7 & $2.17 \mathrm{E}-1_{(1.24 \mathrm{E}-3)}-$ & $1.57 \mathrm{E}-1_{(5.08 \mathrm{E}-3)}-$ & $7.43 \mathrm{E}+3_{(1.4 \mathrm{E}+4)}-$ & $9.23 \mathrm{E}+1_{(8.0 \mathrm{E}+1)}-$ & $9.57 \mathrm{E}+0_{(4.03 \mathrm{E}-1)}-$ & $3.12 \mathrm{E}-1_{(6.39 \mathrm{E}-2)}-$ & $5.66 \mathrm{E}-1_{(2.63 \mathrm{E}-2)}-$ & \\
\hline & 2 & $4.86 \mathrm{E}-4_{(2.40 \mathrm{E}-5)}$ & $6.16 \mathrm{E}-5_{(2.5 \mathrm{E}-7)}$ & $2.88 \mathrm{E}-4_{(5.60 \mathrm{E}-6)}$ & $2.16 \mathrm{E}-4_{(6.20 \mathrm{E}-7)}$ & $3.89 \mathrm{E}-4_{(2.80 \mathrm{E}-5)}$ & $3.17 \mathrm{E}-5(1.20 \mathrm{E}-7)$ & $7.13 E-4(5.30 \mathrm{E}-6)$ & \\
\hline DB-CSA & 3 & $1.72 \mathrm{E}-2(1.60 \mathrm{E}-3)$ & $6.16 \mathrm{E}-5_{(2.60 \mathrm{E}-7)}$ & $2.96 \mathrm{E}-4_{(3.40 \mathrm{E}-6)}$ & 2.12E-4(6.30E-7) & $3.72 \mathrm{E}-4_{(3.30 \mathrm{E}-5)}$ & $3.16 \mathrm{E}-5(1.10 \mathrm{E}-7)$ & $7.14 \mathrm{E}-4_{(5.70 \mathrm{E}-6)}$ & \\
\hline & 7 & $2.10 \mathrm{E}-2_{(1.50 \mathrm{E}-3)}$ & $6.17 \mathrm{E}-5_{(2.30 \mathrm{E}-7)}$ & $2.77 \mathrm{E}-4_{(3.90 \mathrm{E}-6)}$ & 2.15E-4 (7.90E-7) & $3.84 \mathrm{E}-4_{(3.10 \mathrm{E}-5)}$ & $3.26 \mathrm{E}-5(1.30 \mathrm{E}-7)$ & $7.13 E-4(4.90 \mathrm{E}-6)$ & \\
\hline
\end{tabular}

The symbols “+”, “ $\approx$ " and "-" denote that the performance of the compared algorithm is statistically better than, equivalent to, and worse than DB-CSA. 
Table 16. IGD results (Mean and Standard Deviation) of the 8 MOEAs on the WFG test suite.

\begin{tabular}{|c|c|c|c|c|c|c|c|c|c|c|}
\hline & & & & & & Reference : [57] & & & & \\
\hline Prob. & $\mathrm{M}$ & $\mathrm{D}$ & PMEA-MA & PMEA*-MA & SPEA2/SDE & NSGA-II+SDR & MaOEA/IGD & VaEA & SPEAR & DB-CSA \\
\hline \multirow{5}{*}{ WFG1 } & 3 & 12 & $6.38 \mathrm{E}-1_{(6.61 \mathrm{E}-2)^{-}}$ & $3.42 \mathrm{E}-1_{(4.42 \mathrm{E}-2)}-$ & $2.37 \mathrm{E}-1_{(2.90 \mathrm{E}-2)}-$ & $2.79 \mathrm{E}-1_{(4.02 \mathrm{E}-2)}-$ & $2.04 \mathrm{E}+0_{(3.9 \mathrm{E}-1)}-$ & $2.34 \mathrm{E}-1_{(2.91 \mathrm{E}-2)}-$ & $2.63 \mathrm{E}-1_{(4.78 \mathrm{E}-2)}-$ & $4.24 \mathrm{E}-3_{(1.6 \mathrm{E}-3)}$ \\
\hline & 5 & 14 & $9.24 \mathrm{E}-1_{(1.33 \mathrm{E}-1)^{-}}$ & $6.07 \mathrm{E}-1_{(5.13 \mathrm{E}-2)}-$ & $4.31 \mathrm{E}-1_{(2.50 \mathrm{E}-2)}-$ & $6.49 \mathrm{E}-1_{(5.68 \mathrm{E}-2)}-$ & $3.52 \mathrm{E}+0_{(1.56 \mathrm{E}+0)^{-}}$ & $\left.7.12 \mathrm{E}-1_{(7.52 \mathrm{E}-2)}\right)^{-}$ & $4.56 \mathrm{E}-1_{(7.98 \mathrm{E}-2)}-$ & $1.98 \mathrm{E}-3_{(7.3 \mathrm{E}-4)}$ \\
\hline & 8 & 17 & $\left.1.55 \mathrm{E}+0_{(9.4 \mathrm{E}-2)}\right)^{-}$ & $1.31 \mathrm{E}+0_{(9.67 \mathrm{E}-2)}-$ & $1.04 \mathrm{E}+0_{(3.85 \mathrm{E}-2)^{-}}$ & $1.52 \mathrm{E}+0_{(1.44 \mathrm{E}-1)}-$ & $5.57 \mathrm{E}+0_{(2.43 \mathrm{E}+0)^{-}}$ & $1.55 \mathrm{E}+0_{(1.44 \mathrm{E}-1)}-$ & $1.45 \mathrm{E}+0_{(1.14 \mathrm{E}-1)^{-}}$ & $1.82 \mathrm{E}-3_{(6.5 \mathrm{E}-4)}$ \\
\hline & 10 & 19 & $1.65 \mathrm{E}+0_{(1.0 \mathrm{E}-1)^{-}}$ & $1.48 \mathrm{E}+0_{(7.64 \mathrm{E}-2)^{-}}$ & $1.09 \mathrm{E}+0_{(2.59 \mathrm{E}-2)^{-}}$ & $1.71 \mathrm{E}+0_{(1.20 \mathrm{E}-1)^{-}}$ & $9.49 \mathrm{E}+0_{(3.40 \mathrm{E}+0)^{-}}$ & $1.93 \mathrm{E}+0_{(2.13 \mathrm{E}-1)}-$ & $1.49 \mathrm{E}+0_{(9.24 \mathrm{E}-2)}-$ & $1.53 \mathrm{E}-3_{(3.6 \mathrm{E}-4)}$ \\
\hline & 15 & 24 & $2.07 \mathrm{E}+0_{(9.8 \mathrm{E}-2)^{-}}$ & $2.44 \mathrm{E}+0_{(1.56 \mathrm{E}-1)^{-}}$ & $1.97 \mathrm{E}+0_{(8.29 \mathrm{E}-2)^{-}}$ & $2.48 \mathrm{E}+0_{(4.01 \mathrm{E}-2)^{-}}$ & $4.35 \mathrm{E}+0_{(2.52 \mathrm{E}+0)^{-}}$ & $2.73 \mathrm{E}+0_{(2.19 \mathrm{E}-1)}-$ & $2.47 \mathrm{E}+0_{(1.57 \mathrm{E}-1)^{-}}$ & $1.47 \mathrm{E}-3_{(2.3 \mathrm{E}-4)}$ \\
\hline \multirow{5}{*}{ WFG2 } & 3 & 12 & $1.70 \mathrm{E}-1_{(4.62 \mathrm{E}-3)^{-}}$ & $1.68 \mathrm{E}-1_{(3.82 \mathrm{E}-3)}-$ & $2.18 \mathrm{E}-1_{(1.10 \mathrm{E}-2)}-$ & $2.03 \mathrm{E}-1_{(1.45 \mathrm{E}-2)}-$ & $1.32 \mathrm{E}+0_{(3.25 \mathrm{E}-1)^{-}}$ & $1.72 \mathrm{E}-1_{(4.75 \mathrm{E}-3)}$ & $1.71 \mathrm{E}-1_{(2.95 \mathrm{E}-3)}-$ & $7.22 \mathrm{E}-3_{(7.3 \mathrm{E}-4)}$ \\
\hline & 5 & 14 & $8.66 \mathrm{E}-1_{(1.28 \mathrm{E}-1)^{-}}$ & $4.01 \mathrm{E}-1_{(7.17 \mathrm{E}-3)}-$ & $4.98 \mathrm{E}-1_{(2.14 \mathrm{E}-2)}-$ & $4.95 \mathrm{E}-1_{(5.28 \mathrm{E}-2)}-$ & $1.16 \mathrm{E}+0_{(2.65 \mathrm{E}-1)^{-}}$ & $3.91 \mathrm{E}-1_{(4.48 \mathrm{E}-3)}-$ & $3.94 \mathrm{E}-1_{(2.38 \mathrm{E}-3)}-$ & $3.82 \mathrm{E}-3_{(2.9 \mathrm{E}-4)}$ \\
\hline & 8 & 17 & $1.85 \mathrm{E}+0_{(1.0 \mathrm{E}-1)^{-}}$ & $1.07 \mathrm{E}+0_{(3.55 \mathrm{E}-2)^{-}}$ & $1.08 \mathrm{E}+0_{(3.65 \mathrm{E}-2)^{-}}$ & $1.47 \mathrm{E}+0_{(1.67 \mathrm{E}-1)^{-}}$ & $2.12 \mathrm{E}+0_{(3.91 \mathrm{E}-1)^{-}}$ & $9.35 \mathrm{E}-1_{(1.27 \mathrm{E}-2)}-$ & $9.65 \mathrm{E}-1_{(1.84 \mathrm{E}-2)}-$ & $4.27 \mathrm{E}-3_{(6.8 \mathrm{E}-4)}$ \\
\hline & 10 & 19 & $1.94 \mathrm{E}+0_{(3,1 \mathrm{E}-2)}{ }^{-}$ & $1.18 \mathrm{E}+0_{(3.62 \mathrm{E}-2)^{-}}$ & $1.14 \mathrm{E}+0_{(3.81 \mathrm{E}-2)^{-}}$ & $1.62 \mathrm{E}+0_{(1.38 \mathrm{E}-1)^{-}}$ & $2.28 \mathrm{E}+0_{(5.57 \mathrm{E}-1)^{-}}$ & $1.01 \mathrm{E}+0_{(1.17 \mathrm{E}-2)}-$ & $1.08 \mathrm{E}+0_{(1.08 \mathrm{E}-2)^{-}}$ & $2.75 \mathrm{E}-3_{(5.5 \mathrm{E}-4)}$ \\
\hline & 15 & 24 & $2.52 \mathrm{E}+0_{(4.0 \mathrm{E}-2)^{-}}$ & $1.89 \mathrm{E}+0_{(4.72 \mathrm{E}-2)^{-}}$ & $1.88 \mathrm{E}+0_{(5.98 \mathrm{E}-2)^{-}}$ & $2.42 \mathrm{E}+0_{(4.94 \mathrm{E}-2)^{-}}$ & $3.15 \mathrm{E}+0_{(1.38 \mathrm{E}+0)^{-}}$ & $1.76 \mathrm{E}+0_{(4.39 \mathrm{E}-2)}-$ & $1.87 \mathrm{E}+0_{(7.38 \mathrm{E}-2)^{-}}$ & $5.06 \mathrm{E}-3_{(1.1 \mathrm{E}-3)}$ \\
\hline \multirow{5}{*}{ WFG3 } & 3 & 12 & $1.16 \mathrm{E}-1_{(1.29 \mathrm{E}-2)^{-}}$ & $1.12 \mathrm{E}-1_{(8.45 \mathrm{E}-3)}-$ & $7.16 \mathrm{E}-2_{(6.18 \mathrm{E}-3)}-$ & $1.15 \mathrm{E}-1_{(6.24 \mathrm{E}-2)}-$ & $3.19 \mathrm{E}+0_{(3.23 \mathrm{E}-2)^{-}}$ & $1.36 \mathrm{E}-1_{(1.22 \mathrm{E}-2)}-$ & $1.46 \mathrm{E}-1_{(1.27 \mathrm{E}-2)}-$ & $1.28 \mathrm{E}-3_{(6.8 \mathrm{E}-5)}$ \\
\hline & 5 & 14 & $5.02 \mathrm{E}-1_{(4.61 \mathrm{E}-2)^{-}}$ & $5.09 \mathrm{E}-1_{(6.16 \mathrm{E}-2)}-$ & $4.86 \mathrm{E}-1_{(1.56 \mathrm{E}-1)}-$ & $3.59 \mathrm{E}-1_{(3.76 \mathrm{E}-2)}-$ & $4.73 \mathrm{E}+0_{(1.83 \mathrm{E}+0)^{-}}$ & $5.38 \mathrm{E}-1_{(4.57 \mathrm{E}-2)}-$ & $4.65 \mathrm{E}-1_{(5.11 \mathrm{E}-2)}-$ & $7.90 \mathrm{E}-4_{(5.1 \mathrm{E}-5)}$ \\
\hline & 8 & 17 & $1.49 \mathrm{E}+0_{(1.6 \mathrm{E}-1)^{-}}$ & $1.45 \mathrm{E}+0_{(1.74 \mathrm{E}-1)^{-}}$ & $1.44 \mathrm{E}+0_{(5.51 \mathrm{E}-1)^{-}}$ & $1.13 \mathrm{E}+0_{(8.43 \mathrm{E}-1)^{-}}$ & $6.08 \mathrm{E}+0_{(3.76 \mathrm{E}+0)^{-}}$ & $1.50 \mathrm{E}+0_{(1.53 \mathrm{E}-1)}-$ & $1.78 \mathrm{E}+0_{(2.00 \mathrm{E}-1)^{-}}$ & $6.10 \mathrm{E}-\mathbf{4}_{(5.8 \mathrm{E}-5)}$ \\
\hline & 10 & 19 & $1.97 \mathrm{E}+0_{(1.8 \mathrm{E}-1)^{-}}$ & $2.00 \mathrm{E}+0_{(2.34 \mathrm{E}-1)^{-}}$ & $1.66 \mathrm{E}+0_{(7.33 \mathrm{E}-1)^{-}}$ & $1.63 \mathrm{E}+0_{(6.21 \mathrm{E}-1)^{-}}$ & $4.76 \mathrm{E}+0_{(4.49 \mathrm{E}+0)^{-}}$ & $1.79 \mathrm{E}+0_{(2.11 \mathrm{E}-1)}-$ & $1.94 \mathrm{E}+0_{(1.63 \mathrm{E}-1)^{-}}$ & $4.81 \mathrm{E}-4_{(5.7 \mathrm{E}-5)}$ \\
\hline & 15 & 24 & $3.77 \mathrm{E}+0_{(4.3 \mathrm{E}-1)^{-}}$ & $3.51 \mathrm{E}+0_{(5.24 \mathrm{E}-1)^{-}}$ & $7.13 \mathrm{E}+0_{(2.08 \mathrm{E}+0)^{-}}$ & $4.53 \mathrm{E}+0_{(1.35 \mathrm{E}+0)^{-}}$ & $7.55 \mathrm{E}+0_{(4.55 \mathrm{E}+0)^{-}}$ & $3.82 \mathrm{E}+0_{(4.41 \mathrm{E}-1)}-$ & $4.39 \mathrm{E}+0_{(5.34 \mathrm{E}-1)^{-}}$ & $9.57 \mathrm{E}-4_{(1.0 \mathrm{E}-4)}$ \\
\hline \multirow{5}{*}{ WFG4 } & 3 & 12 & $2.24 \mathrm{E}-1_{(4.05 \mathrm{E}-3)^{-}}$ & $2.29 \mathrm{E}-1_{(4.17 \mathrm{E}-3)}-$ & $3.36 \mathrm{E}-1_{(1.97 \mathrm{E}-2)}-$ & $2.55 \mathrm{E}-1_{(8.55 \mathrm{E}-3)}-$ & $3.82 \mathrm{E}+0_{(5.07 \mathrm{E}-1)^{-}}$ & $2.31 \mathrm{E}-1_{(4.01 \mathrm{E}-3)}-$ & $2.27 \mathrm{E}-1_{(3.06 \mathrm{E}-3)}-$ & $5.28 \mathrm{E}-3_{(3.9 \mathrm{E}-4)}$ \\
\hline & 5 & 14 & $9.35 \mathrm{E}-1_{(6.44 \mathrm{E}-3)^{-}}$ & $9.54 \mathrm{E}-1_{(6.05 E-3)}-$ & $1.39 \mathrm{E}+0_{(1.42 \mathrm{E}-2)^{-}}$ & $9.89 \mathrm{E}-1_{(7.86 \mathrm{E}-3)}-$ & $6.39 \mathrm{E}+0_{(1.17 \mathrm{E}+0)^{-}}$ & $9.47 \mathrm{E}-1_{(5.63 \mathrm{E}-3)}-$ & $9.75 \mathrm{E}-1_{(3.62 \mathrm{E}-3)}-$ & $2.23 \mathrm{E}-3_{(6.9 \mathrm{E}-5)}$ \\
\hline & 8 & 17 & $2.92 \mathrm{E}+0_{(2.2 \mathrm{E}-2)^{-}}$ & $3.06 \mathrm{E}+0_{(2.38 \mathrm{E}-)^{-}}$ & $3.24 \mathrm{E}+0_{(3.89 \mathrm{E}-2)^{-}}$ & $3.21 \mathrm{E}+0_{(3.16 \mathrm{E}-2)^{-}}$ & $9.55 \mathrm{E}+0_{(1.25 \mathrm{E}+0)^{-}}$ & $3.00 \mathrm{E}+0_{(3.17 \mathrm{E}-2)}-$ & $2.98 \mathrm{E}+0_{(1.05 \mathrm{E}-2)^{-}}$ & $2.19 \mathrm{E}-3_{(7.4 \mathrm{E}-5)}$ \\
\hline & 10 & 19 & $3.97 \mathrm{E}+0_{(2.5 \mathrm{E}-2)^{-}}$ & $4.19 \mathrm{E}+0_{(3.08 \mathrm{E}-2)^{-}}$ & $4.44 \mathrm{E}+0_{(5.25 \mathrm{E}-2)^{-}}$ & $4.38 \mathrm{E}+0_{(3.72 \mathrm{E}-2)^{-}}$ & $1.13 \mathrm{E}+1_{(2.11 \mathrm{E}+0)^{-}}$ & $4.03 \mathrm{E}+0_{(2.45 \mathrm{E}-2)}-$ & $4.56 \mathrm{E}+0_{(1.08 \mathrm{E}-2)^{-}}$ & $1.45 \mathrm{E}-3_{(3.9 \mathrm{E}-5)}$ \\
\hline & 15 & 24 & $8.27 \mathrm{E}+0_{(9.1 \mathrm{E}-2)^{-}}$ & $8.81 \mathrm{E}+0_{(9.68 \mathrm{E}-2)^{-}}$ & $9.98 \mathrm{E}+0_{(7.35 \mathrm{E}-1)^{-}}$ & $9.39 \mathrm{E}+0_{(5.28 \mathrm{E}-1)^{-}}$ & $1.69 \mathrm{E}+1_{(9.10 \mathrm{E}+0)^{-}}$ & $8.26 \mathrm{E}+0_{(7.86 \mathrm{E}-2)}-$ & $9.41 \mathrm{E}+0_{(3.17 \mathrm{E}-2)^{-}}$ & $2.01 \mathrm{E}-3_{(4.6 \mathrm{E}-5)}$ \\
\hline \multirow{5}{*}{ WFG5 } & 3 & 12 & $2.33 \mathrm{E}-1_{(3.46 \mathrm{E}-3)^{-}}$ & $2.40 \mathrm{E}-1_{(3.60 \mathrm{E}-3)}-$ & $3.44 \mathrm{E}-1_{(1.57 \mathrm{E}-2)}-$ & $2.60 \mathrm{E}-1_{(5.91 \mathrm{E}-3)}-$ & $2.16 \mathrm{E}+0_{(1.30 \mathrm{E}+0)^{-}}$ & $2.39 \mathrm{E}-1_{(2.59 \mathrm{E}-3)}-$ & $2.37 \mathrm{E}-1_{(3.25 \mathrm{E}-3)}-$ & $7.94 \mathrm{E}-\mathbf{4}_{(7.0 \mathrm{E}-5)}$ \\
\hline & 5 & 14 & $9.29 \mathrm{E}-1_{(6.58 \mathrm{E}-3)^{-}}$ & $9.57 \mathrm{E}-1_{(6.75 \mathrm{E}-3)}-$ & $1.15 \mathrm{E}+0_{(1.60 \mathrm{E}-2)^{-}}$ & $9.87 \mathrm{E}-1_{(1.35 \mathrm{E}-2)}-$ & $2.11 \mathrm{E}+0_{(1.38 \mathrm{E}+0)^{-}}$ & $9.42 \mathrm{E}-1_{(6.17 \mathrm{E}-3)}-$ & $9.66 \mathrm{E}-1_{(3.79 \mathrm{E}-3)}-$ & $1.06 \mathrm{E}-3_{(2.9 \mathrm{E}-5)}$ \\
\hline & 8 & 17 & $2.94 \mathrm{E}+0_{(2.2 \mathrm{E}-2)^{-}}$ & $3.13 \mathrm{E}+0_{(3.12 \mathrm{E}-2)^{-}}^{-}$ & $3.24 \mathrm{E}+0_{(4.37 \mathrm{E}-2)^{-}}$ & $3.25 \mathrm{E}+0_{(3.30 \mathrm{E}-2)^{-}}$ & $7.09 \mathrm{E}+0_{(4.97 \mathrm{E}+0)^{-}}$ & $3.04 \mathrm{E}+0_{(3.93 \mathrm{E}-2)}-$ & $2.95 \mathrm{E}+0_{(8.36 \mathrm{E}-3)^{-}}$ & $1.64 \mathrm{E}-3_{(3.2 \mathrm{E}-5)}$ \\
\hline & 10 & 19 & $3.91 \mathrm{E}+0_{(2.6 \mathrm{E}-2)^{-}}$ & $4.23 \mathrm{E}+0_{(4.61 \mathrm{E}-2)^{-}}$ & $4.43 \mathrm{E}+0_{(3.62 \mathrm{E}-2)^{-}}$ & $4.42 \mathrm{E}+0_{(5.99 \mathrm{E}-2)^{-}}$ & $9.18 \mathrm{E}+0_{(6.57 \mathrm{E}+0)^{-}}$ & $4.00 \mathrm{E}+0_{(2.50 \mathrm{E}-2)}-$ & $4.54 \mathrm{E}+0_{(8.28 \mathrm{E}-3)^{-}}$ & $1.57 \mathrm{E}-3_{(1.3 \mathrm{E}-5)}$ \\
\hline & 15 & 24 & $8.04 \mathrm{E}+0_{(8.9 \mathrm{E}-2)^{-}}$ & $8.87 \mathrm{E}+0_{(4.42 \mathrm{E}-2)^{-}}$ & $1.13 \mathrm{E}+1_{(5.60 \mathrm{E}-1)^{-}}$ & $9.39 \mathrm{E}+0_{(2.86 \mathrm{E}-1)^{-}}$ & $1.85 \mathrm{E}+1_{(1.11 \mathrm{E}+1)^{-}}$ & $7.98 \mathrm{E}+0_{(6.16 \mathrm{E}-2)}-$ & $9.27 \mathrm{E}+0_{(2.42 \mathrm{E}-2)^{-}}$ & $1.99 \mathrm{E}-3_{(3.1 \mathrm{E}-5)}$ \\
\hline \multirow{5}{*}{ WFG6 } & 3 & 12 & $2.47 \mathrm{E}-1_{(1.22 \mathrm{E}-2)^{-}}$ & $2.54 \mathrm{E}-1_{(1.23 \mathrm{E}-2)}-$ & $3.53 \mathrm{E}-1_{(1.47 \mathrm{E}-2)}-$ & $2.69 \mathrm{E}-1_{(1.04 \mathrm{E}-2)}-$ & $2.33 \mathrm{E}+0_{(1.21 \mathrm{E}+0)^{-}}$ & $2.56 \mathrm{E}-1_{(1.03 \mathrm{E}-2)}-$ & $2.46 \mathrm{E}-1_{(8.54 \mathrm{E}-3)}-$ & $1.21 \mathrm{E}-3_{(2.8 \mathrm{E}-4)}$ \\
\hline & 5 & 14 & $9.44 \mathrm{E}-1_{(7.53 \mathrm{E}-3)^{-}}$ & $9.77 \mathrm{E}-1_{(8.15 \mathrm{E}-3)}-$ & $1.19 \mathrm{E}+0_{(1.81 \mathrm{E}-2)^{-}}$ & $9.99 \mathrm{E}-1_{(1.13 \mathrm{E}-2)}-$ & $1.05 \mathrm{E}+0_{(1.49 \mathrm{E}-2)^{-}}$ & $5.5 \mathrm{E}+0_{(1.21 \mathrm{E}+0)}-$ & $9.69 \mathrm{E}-1_{(3.67 \mathrm{E}-3)}-$ & $1.92 \mathrm{E}-3_{(2.0 \mathrm{E}-4)}$ \\
\hline & 8 & 17 & $3.02 \mathrm{E}+0_{(3.4 \mathrm{E}-2)^{-}}$ & $3.22 \mathrm{E}+0_{(3.37 \mathrm{E}-2)^{-}}$ & $3.34 \mathrm{E}+0_{(5.37 \mathrm{E}-2)^{-}}$ & $3.34 \mathrm{E}+0_{(3.90 \mathrm{E}-2)^{-}}$ & $9.22 \mathrm{E}+0_{(4.16 \mathrm{E}+0)^{-}}$ & $3.12 \mathrm{E}+0_{(4.26 \mathrm{E}-2)}-$ & $2.99 \mathrm{E}+0_{(1.80 \mathrm{E}-2)^{-}}$ & $3.33 E-3_{(2.6 E-4)}$ \\
\hline & 10 & 19 & $3.98 \mathrm{E}+0_{(3.1 \mathrm{E}-2)^{-}}$ & $4.35 \mathrm{E}+0_{(4.86 \mathrm{E}-2)^{-}}$ & $4.56 \mathrm{E}+0_{(4.35 \mathrm{E}-2)^{-}}$ & $4.53 \mathrm{E}+0_{(7.34 \mathrm{E}-2)^{-}}$ & $9.16 \mathrm{E}+0_{(5.32 \mathrm{E}+0)^{-}}$ & $4.09 \mathrm{E}+0_{(3.27 \mathrm{E}-2)}-$ & $4.58 \mathrm{E}+0_{(1.07 \mathrm{E}-2)^{-}}$ & $2.82 \mathrm{E}-3_{(1.1 \mathrm{E}-4)}$ \\
\hline & 15 & 24 & $7.96 \mathrm{E}+0_{(9.1 \mathrm{E}-2)^{-}}$ & $8.97 \mathrm{E}+0_{(5.20 \mathrm{E}-2)^{-}}$ & $1.05 \mathrm{E}+1_{(7.98 \mathrm{E}-1)^{-}}$ & $1.03 \mathrm{E}+1_{(1.27 \mathrm{E}+0)^{-}}$ & $2.07 \mathrm{E}+1_{(8.74 \mathrm{E}+0)^{-}}$ & $7.92 \mathrm{E}+0_{(7.55 \mathrm{E}-2)}-$ & $9.44 \mathrm{E}+0_{(9.96 \mathrm{E}-2)^{-}}$ & $3.83 \mathrm{E}-3_{(1.5 \mathrm{E}-4)}$ \\
\hline \multirow{5}{*}{ WFG7 } & 3 & 12 & $2.24 \mathrm{E}-1_{(2.77 \mathrm{E}-3)^{-}}$ & $2.29 \mathrm{E}-1_{(4.00 \mathrm{E}-3)}-$ & $3.43 \mathrm{E}-1_{(1.46 \mathrm{E}-2)}-$ & $2.50 \mathrm{E}-1_{(4.85 \mathrm{E}-3)}-$ & $2.57 \mathrm{E}+0_{(1.18 \mathrm{E}+0)^{-}}$ & $2.33 \mathrm{E}-1_{(3.94 \mathrm{E}-3)}-$ & $2.28 \mathrm{E}-1_{(3.63 \mathrm{E}-3)}-$ & $6.40 \mathrm{E}-3_{(3.8 \mathrm{E}-4)}$ \\
\hline & 5 & 14 & $9.37 \mathrm{E}-1_{(7.57 \mathrm{E}-3)^{-}}$ & $9.66 \mathrm{E}-1_{(6.15 \mathrm{E}-3)}-$ & $1.17 \mathrm{E}+0_{(2.05 \mathrm{E}-2)^{-}}$ & $9.93 \mathrm{E}-1_{(1.13 \mathrm{E}-2)}-$ & $3.89 \mathrm{E}+0_{(1.66 \mathrm{E}+0)^{-}}$ & $9.51 \mathrm{E}-1_{(7.33 \mathrm{E}-3)}-$ & $9.71 \mathrm{E}-1_{(2.05 \mathrm{E}-3)}-$ & $3.42 \mathrm{E}-3_{(1.2 \mathrm{E}-4)}$ \\
\hline & 8 & 17 & $2.94 \mathrm{E}+0_{(2.4 \mathrm{E}-2)^{-}}$ & $3.14 \mathrm{E}+0_{(3.66 \mathrm{E}-2)^{-}}^{-}$ & $3.18 \mathrm{E}+0_{(3.76 \mathrm{E}-2)^{-}}$ & $3.29 \mathrm{E}+0_{(4.93 \mathrm{E}-2)^{-}}$ & $8.39 \mathrm{E}+0_{(3.76 \mathrm{E}+0)^{-}}$ & $3.07 \mathrm{E}+0_{(4.85 \mathrm{E}-2)}-$ & $2.98 \mathrm{E}+0_{(1.01 \mathrm{E}-2)^{-}}$ & $3.82 \mathrm{E}-3_{(1.1 \mathrm{E}-4)}$ \\
\hline & 10 & 19 & $3.93 \mathrm{E}+0_{(2.7 \mathrm{E}-2)^{-}}$ & $4.23 \mathrm{E}+0_{(3.26 \mathrm{E}-2)^{-}}$ & $4.40 \mathrm{E}+0_{(4.95 \mathrm{E}-2)^{-}}$ & $4.43 \mathrm{E}+0_{(6.35 \mathrm{E}-2)^{-}}$ & $7.61 \mathrm{E}+0_{(3.31 \mathrm{E}+0)^{-}}$ & $4.01 \mathrm{E}+3_{(2.21 \mathrm{E}-2)}-$ & $4.55 \mathrm{E}+0_{(2.81 \mathrm{E}-2)^{-}}$ & $2.72 \mathrm{E}-3_{(1.0 \mathrm{E}-4)}$ \\
\hline & 15 & 24 & $8.14 \mathrm{E}+0_{(1.1 \mathrm{E}-1)^{-}}$ & $8.68 \mathrm{E}+0_{(6.56 \mathrm{E}-2)^{-}}$ & $9.23 \mathrm{E}+0_{(4.17 \mathrm{E}-1)^{-}}$ & $1.11 \mathrm{E}+1_{(1.24 \mathrm{E}+0)^{-}}$ & $1.85 \mathrm{E}+1_{(8.66 \mathrm{E}+0)^{-}}$ & $8.08 \mathrm{E}+0_{(7.35 \mathrm{E}-2)}-$ & $9.36 \mathrm{E}+0_{(4.33 \mathrm{E}-2)^{-}}$ & $4.08 \mathrm{E}-3_{(1.7 \mathrm{E}-4)}$ \\
\hline \multirow{5}{*}{ WFG8 } & 3 & 12 & $2.76 \mathrm{E}-1_{(3.48 \mathrm{E}-3)^{-}}$ & $2.95 \mathrm{E}-1_{(4.12 \mathrm{E}-3)}-$ & $3.76 \mathrm{E}-1_{(1.08 \mathrm{E}-2)}-$ & $3.31 \mathrm{E}-1_{(7.75 \mathrm{E}-3)}-$ & $3.65 \mathrm{E}+0_{(4.00 \mathrm{E}-1)^{-}}$ & $3.06 \mathrm{E}-1_{(5.90 \mathrm{E}-3)}-$ & $2.74 \mathrm{E}-1_{(2.41 \mathrm{E}-3)}-$ & $6.92 \mathrm{E}-3_{(3.1 \mathrm{E}-4)}$ \\
\hline & 5 & 14 & $9.68 \mathrm{E}-1_{(4.84 \mathrm{E}-3)^{-}}$ & $1.02 \mathrm{E}+0_{(6.57 \mathrm{E}-3)^{-}}$ & $1.16 \mathrm{E}+0_{(1.61 \mathrm{E}-2)^{-}}$ & $1.05 \mathrm{E}+0_{(1.31 \mathrm{E}-2)^{-}}$ & $4.57 \mathrm{E}+0_{(9.65 \mathrm{E}-1)^{-}}$ & $1.07 \mathrm{E}+0_{(1.28 \mathrm{E}-2)}-$ & $9.89 \mathrm{E}-1_{(3.03 \mathrm{E}-3)}-$ & $2.89 \mathrm{E}-3_{(9.3 \mathrm{E}-5)}$ \\
\hline & 8 & 17 & $3.06 \mathrm{E}+0_{(4.05 \mathrm{E}-2)^{-}}$ & $3.23 \mathrm{E}+0_{(4.12 \mathrm{E}-2)^{-}}^{-}$ & $3.39 \mathrm{E}+0_{(3.62 \mathrm{E}-2)^{-}}$ & $3.32 \mathrm{E}+0_{(4.09 \mathrm{E}-2)^{-}}$ & $9.09 \mathrm{E}+0_{(2.85 \mathrm{E}+0)^{-}}$ & $3.28 \mathrm{E}+0_{(3.03 \mathrm{E}-2)}-$ & $3.09 \mathrm{E}+0_{(3.27 \mathrm{E}-2)^{-}}$ & $3.71 \mathrm{E}-3_{(9.1 \mathrm{IE}-5)}$ \\
\hline & 10 & 19 & $3.99 \mathrm{E}+0_{(6.9 \mathrm{E}-2)^{-}}$ & $4.39 \mathrm{E}+0_{(5.12 \mathrm{E}-2)^{-}}$ & $4.55 \mathrm{E}+0_{(3.82 \mathrm{E}-2)^{-}}$ & $4.52 \mathrm{E}+0_{(5.66 \mathrm{E}-2)^{-}}$ & $1.31 \mathrm{E}+1_{(2.37 \mathrm{E}+0)^{-}}$ & $4.32 \mathrm{E}+0_{(5.20 \mathrm{E}-2)}-$ & $4.65 \mathrm{E}+0_{(1.97 \mathrm{E}-2)^{-}}$ & $2.70 \mathrm{E}-3_{(7.3 \mathrm{E}-5)}$ \\
\hline & 15 & 24 & $8.52 \mathrm{E}+0_{(1.4 \mathrm{E}-1)^{-}}$ & $8.71 \mathrm{E}+0_{(7.50 \mathrm{E}-2)^{-}}$ & $9.04 \mathrm{E}+0_{(1.26 \mathrm{E}-1)^{-}}$ & $9.83 \mathrm{E}+0_{(9.41 \mathrm{E}-1)^{-}}$ & $2.46 \mathrm{E}+1_{(2.95 \mathrm{E}+0)^{-}}$ & $8.59 \mathrm{E}+0_{(1.57 \mathrm{E}-1)}-$ & $9.39 \mathrm{E}+0_{(5.40 \mathrm{E}-2)^{-}}$ & 3.92E-3 $3_{(1.7 E-4)}$ \\
\hline \multirow{5}{*}{ WFG9 } & 3 & 12 & $2.18 \mathrm{E}-1_{(2.70 \mathrm{E}-3)^{-}}$ & $2.25 \mathrm{E}-1_{(3.27 \mathrm{E}-3)}-$ & $3.27 \mathrm{E}-1_{(1.94 \mathrm{E}-2)}-$ & $2.51 \mathrm{E}-1_{(7.00 \mathrm{E}-3)}-$ & $2.07 \mathrm{E}+0_{(7.20 \mathrm{E}-1)^{-}}$ & $2.33 \mathrm{E}-1_{(2.35 \mathrm{E}-2)}-$ & $2.24 \mathrm{E}-1_{(1.50 \mathrm{E}-3)}-$ & $2.11 \mathrm{E}-3_{(2.5 \mathrm{E}-4)}$ \\
\hline & 5 & 14 & $9.14 \mathrm{E}-1_{(5.30 \mathrm{E}-3)^{-}}$ & $9.27 \mathrm{E}-1_{(5.68 \mathrm{E}-3)}-$ & $1.09 \mathrm{E}+0_{(1.82 \mathrm{E}-2)^{-}}$ & $9.77 \mathrm{E}-1_{(1.12 \mathrm{E}-2)}-$ & $3.71 \mathrm{E}+0_{(1.60 \mathrm{E}+0)^{-}}$ & $9.30 \mathrm{E}-1_{(6.40 \mathrm{E}-3)}-$ & $9.44 \mathrm{E}-1_{(2.86 \mathrm{E}-3)}-$ & $2.55 \mathrm{E}-3_{(8.6 \mathrm{E}-5)}$ \\
\hline & 8 & 17 & $2.95 \mathrm{E}+0_{(1.7 \mathrm{E}-2)^{-}}$ & $3.03 \mathrm{E}+0_{(3.18 \mathrm{E}-2)^{-}}$ & $3.22 \mathrm{E}+0_{(3.34 \mathrm{E}-2)^{-}}$ & $3.18 \mathrm{E}+0_{(4.37 \mathrm{E}-2)^{-}}$ & $4.77 \mathrm{E}+0_{(2.08 \mathrm{E}+0)^{-}}$ & $3.02 \mathrm{E}+0_{(2.65 \mathrm{E}-2)}-$ & $2.94 \mathrm{E}+0_{(8.74 \mathrm{E}-3)^{-}}$ & $3.56 \mathrm{E}-3_{(1.1 \mathrm{E}-4)}$ \\
\hline & 10 & 19 & $3.94 \mathrm{E}+0_{(3.2 \mathrm{E}-2)^{-}}$ & $4.09 \mathrm{E}+0_{(3.35 \mathrm{E}-2)^{-}}$ & $4.64 \mathrm{E}+0_{(2.54 \mathrm{E}-1)^{-}}$ & $4.43 \mathrm{E}+0_{(1.05 \mathrm{E}-1)^{-}}$ & $4.38 \mathrm{E}+0_{(4.74 \mathrm{E}-2)^{-}}$ & $3.98 \mathrm{E}+0_{(2.75 \mathrm{E}-2)}-$ & $4.52 \mathrm{E}+0_{(1.56 \mathrm{E}-2)^{-}}$ & $2.96 \mathrm{E}-3_{(5.7 \mathrm{E}-5)}$ \\
\hline & 15 & 24 & $7.92 \mathrm{E}+0_{(1.4 \mathrm{E}-1)^{-}}$ & $8.47 \mathrm{E}+0_{(1.07 \mathrm{E}-1)^{-}}$ & $8.88 \mathrm{E}+0_{(3.66 \mathrm{E}-1)^{-}}$ & $8.89 \mathrm{E}+0_{(4.25 \mathrm{E}-1)^{-}}$ & $9.02 \mathrm{E}+0_{(7.35 \mathrm{E}-1)^{-}}$ & $7.79 \mathrm{E}+0_{(7.89 \mathrm{E}-2)}-$ & $9.12 \mathrm{E}+0_{(2.73 \mathrm{E}-2)^{-}}$ & $4.24 \mathrm{E}-3_{(8.1 \mathrm{E}-5)}$ \\
\hline$+/-/ \approx$ & & & $0 / 45 / 0$ & $0 / 45 / 0$ & $0 / 45 / 0$ & $0 / 45 / 0$ & $0 / 45 / 0$ & $0 / 45 / 0$ & $0 / 45 / 0$ & \\
\hline
\end{tabular}

The symbols "+", " $\approx$ " and "-" denote that the performance of the compared algorithm is statistically better than, equivalent to, and worse than DB-CSA. 
Table 17. IGD results (Mean and Standard Deviation) of the 8 MOEAs on the DTLZ test suite.

\begin{tabular}{|c|c|c|c|c|c|c|c|c|c|c|}
\hline \multirow[b]{2}{*}{ Prob. } & \multirow[b]{2}{*}{$\mathrm{M}$} & \multirow[b]{2}{*}{$\mathrm{D}$} & \multicolumn{7}{|c|}{ Reference : [57] } & \multirow[b]{2}{*}{ DB-CSA } \\
\hline & & & PMEA-MA & PMEA*-MA & SPEA2/SDE & NSGA-II+SDR & MaOEA/IGD & VaEA & SPEAR & \\
\hline \multirow{5}{*}{ DTLZ1 } & 3 & 7 & $2.58 \mathrm{E}-2(1.71 \mathrm{E}-3)^{-}$ & $2.20 \mathrm{E}-2(3.79 \mathrm{E}-4)-$ & $2.16 \mathrm{E}-2_{(3.45 \mathrm{E}-4)}=$ & $3.43 \mathrm{E}-2(8.40 \mathrm{E}-3)-$ & $7.48 \mathrm{E}-1_{(4.05 \mathrm{E}-1)}-$ & $3.62 \mathrm{E}-2(2.38 \mathrm{E}-2)=$ & $2.58 \mathrm{E}-2(1.59 \mathrm{E}-2)-$ & $1.19 \mathrm{E}-2(1.4 \mathrm{E}-3)$ \\
\hline & 5 & 9 & $5.29 \mathrm{E}-2(9.08 \mathrm{E}-4)-$ & $5.29 \mathrm{E}-2(4.77 \mathrm{E}-4)-$ & $5.00 \mathrm{E}-2_{(2.76 \mathrm{E}-4)}-$ & $7.38 \mathrm{E}-2(9.06 \mathrm{E}-3)=$ & $3.33 \mathrm{E}-1_{(2.69 \mathrm{E}-1)}-$ & $1.06 \mathrm{E}-1_{(3.24 \mathrm{E}-2)}=$ & $8.07 \mathrm{E}-2_{(2.33 \mathrm{E}-2)}-$ & $1.47 \mathrm{E}-2_{(1.3 \mathrm{E}-3)}$ \\
\hline & 8 & 12 & $1.15 \mathrm{E}-1_{(2.57 \mathrm{E}-3)}-$ & $1.04 \mathrm{E}-1_{(1.19 \mathrm{E}-3)}-$ & $9.61 \mathrm{E}-2(5.25 \mathrm{E}-4)$ - & $1.61 \mathrm{E}-1_{(1.18 \mathrm{E}-2)}-$ & $4.78 \mathrm{E}-1_{(4.28 \mathrm{E}-1)}-$ & $1.99 \mathrm{E}-1_{(2.25 \mathrm{E}-2)}-$ & $1.26 \mathrm{E}-1_{(1.48 \mathrm{E}-2)}-$ & $1.52 \mathrm{e}-2(2.8 \mathrm{e}-3)$ \\
\hline & 10 & 14 & $1.15 \mathrm{E}-1_{(1.31 \mathrm{E}-3)}-$ & $1.08 \mathrm{E}-1_{(1.50 \mathrm{E}-3)}-$ & $1.01 \mathrm{E}-1_{(5.01 \mathrm{E}-4)}-$ & $1.68 \mathrm{E}-1_{(1.29 \mathrm{E}-2)}-$ & $1.40 \mathrm{E}-1_{(1.02 \mathrm{E}-1)}-$ & $1.92 \mathrm{E}-1_{(1.83 \mathrm{E}-2)}-$ & $1.52 \mathrm{E}-1_{(2.87 \mathrm{E}-2)}-$ & $2.20 \mathrm{e}-2(3.3 \mathrm{e}-3)$ \\
\hline & 15 & 19 & $1.39 \mathrm{E}-1_{(1.41 \mathrm{E}-3)}-$ & 2.62E-1(6.19E-2) - & $1.34 \mathrm{E}-1_{(1.17 \mathrm{E}-3)}-$ & $2.00 \mathrm{E}-1_{(2.76 \mathrm{E}-2)}-$ & $6.09 \mathrm{E}-1_{(9.50 \mathrm{E}-1)}-$ & $2.48 \mathrm{E}-1_{(8.41 \mathrm{E}-2)}-$ & $3.11 \mathrm{E}-1_{(1.53 \mathrm{E}-1)}-$ & $2.80 \mathrm{e}-2(4.6 \mathrm{e}-3)$ \\
\hline \multirow{5}{*}{ DTLZ 2} & 3 & 12 & $5.59 \mathrm{E}-2_{(5.74 \mathrm{E}-4)}-$ & $5.72 \mathrm{E}-2_{(5.53 \mathrm{E}-4)}-$ & 7.92E-2(2.61E-3) - & $4.70 \mathrm{E}-1_{(1.99 \mathrm{E}-2)}-$ & $1.81 \mathrm{E}-1_{(4.98 \mathrm{E}-2)}-$ & $5.78 \mathrm{E}-2_{(6.49 \mathrm{E}-4)}-$ & $5.77 \mathrm{E}-2_{(1.81 \mathrm{E}-3)}-$ & $9.52 \mathrm{E}-3_{(1.8 \mathrm{E}-3)}$ \\
\hline & 5 & 14 & $1.63 \mathrm{E}-1_{(1.00 \mathrm{E}-3)}=$ & $1.66 \mathrm{E}-1_{(6.93 \mathrm{E}-4)}-$ & $1.90 \mathrm{E}-1_{(1.68 \mathrm{E}-3)}=$ & $1.65 \mathrm{E}-1_{(3.04 \mathrm{E}-5)}-$ & $1.69 \mathrm{E}-1_{(6.53 \mathrm{E}-4)}-$ & $1.68 \mathrm{E}-1_{(9.78 \mathrm{E}-4)}-$ & $1.69 \mathrm{E}-1_{(1.18 \mathrm{E}-3)}=$ & $4.54 \mathrm{E}-3_{(2.0 \mathrm{E}-4)}$ \\
\hline & 8 & 17 & $3.51 \mathrm{E}-1_{(2.36 \mathrm{E}-3)}-$ & $3.56 \mathrm{E}-1_{(2.03 \mathrm{E}-3)}-$ & $3.60 \mathrm{E}-1_{(1.68 \mathrm{E}-3)}-$ & $4.18 \mathrm{E}-1_{(8.53 \mathrm{E}-2)}-$ & $3.44 \mathrm{E}-1_{(2.07 \mathrm{E}-2)}-$ & $3.66 \mathrm{E}-1_{(2.34 \mathrm{E}-3)}-$ & $3.25 \mathrm{E}-1_{(2.07 \mathrm{E}-3)}-$ & $3.98 \mathrm{e}-3_{(1.8 \mathrm{e}-4)}$ \\
\hline & 10 & 19 & $3.98 \mathrm{E}-1_{(2.08 \mathrm{E}-3)}-$ & $4.15 \mathrm{E}-1_{(1.90 \mathrm{E}-3)}-$ & $4.23 \mathrm{E}-1_{(2.19 \mathrm{E}-3)}-$ & $4.35 \mathrm{E}-1_{(6.45 \mathrm{E}-3)}-$ & $4.33 \mathrm{E}-1_{(3.30 \mathrm{E}-3)}-$ & $4.28 \mathrm{E}-1_{(4.66 \mathrm{E}-3)}-$ & $4.31 \mathrm{E}-1_{(2.60 \mathrm{E}-3)}-$ & $2.32 e-3(7.3 e-5)$ \\
\hline & 15 & 24 & $5.77 \mathrm{E}-1_{(7.07 \mathrm{E}-3)}-$ & $6.12 \mathrm{E}-1_{(2.09 \mathrm{E}-3)}-$ & $6.03 \mathrm{E}-1_{(2.70 \mathrm{E}-3)}-$ & $6.71 \mathrm{E}-1_{(6.17 \mathrm{E}-2)}-$ & $7.83 \mathrm{E}-1_{(7.52 \mathrm{E}-2)}-$ & $6.29 \mathrm{E}-1_{(2.09 \mathrm{E}-2)}-$ & $6.63 \mathrm{E}-1_{(1.10 \mathrm{E}-2)}-$ & $2.52 \mathrm{e}-3_{(4.7 e-5)}$ \\
\hline \multirow{5}{*}{ DTLZ 3} & 3 & 12 & $5.73 \mathrm{E}-2(1.05 \mathrm{E}-3)-$ & $6.41 \mathrm{E}-2_{(2.73 \mathrm{E}-2)}-$ & 7.84E-2(3.16E-3) - & $4.42 \mathrm{E}-1_{(3.39 \mathrm{E}-2)}-$ & $1.64 \mathrm{E}+1_{(7.51 \mathrm{E}+0)-}$ & $5.92 \mathrm{E}-2(6.55 \mathrm{E}-3)-$ & $2.14 \mathrm{E}-1_{(7.45 \mathrm{E}-2)}-$ & $1.41 \mathrm{E}-2_{(1.4 \mathrm{E}-3)}$ \\
\hline & 5 & 14 & $1.66 \mathrm{E}-1_{(1.91 \mathrm{E}-3)}-$ & $2.45 \mathrm{E}-1_{(9.39 \mathrm{E}-2)}-$ & $1.89 \mathrm{E}-1_{(1.65 \mathrm{E}-3)}-$ & $1.82 \mathrm{E}-1_{(3.49 \mathrm{E}-3)}-$ & $1.15 \mathrm{E}+1_{(3.85 \mathrm{E}+0)^{-}}$ & $3.35 \mathrm{E}-1_{(7.89 \mathrm{E}-2)}-$ & $5.06 \mathrm{E}-1_{(1.78 \mathrm{E}-1)}-$ & $4.52 \mathrm{E}-3_{(2.0 \mathrm{E}-4)}$ \\
\hline & 8 & 17 & $3.56 \mathrm{E}-1_{(4.14 \mathrm{E}-3)}-$ & $4.84 \mathrm{E}-1_{(5.03 \mathrm{E}-2)}-$ & $3.69 \mathrm{E}-1_{(1.44 \mathrm{E}-2)}-$ & $4.55 \mathrm{E}-1_{(1.19 \mathrm{E}-1)}-$ & $1.03 \mathrm{E}+1_{(6.52 \mathrm{E}+0)}-$ & $2.25 \mathrm{E}+0_{(1.44 \mathrm{E}+0)}-$ & $6.42 \mathrm{E}+0_{(3.37 \mathrm{E}+0)}-$ & $1.89 e-3(4.5 e-5)$ \\
\hline & 10 & 19 & $4.00 \mathrm{E}-1_{(2.94 \mathrm{E}-3)}-$ & $6.09 \mathrm{E}-1_{(3.87 \mathrm{E}-2)}-$ & $4.27 \mathrm{E}-1_{(5.62 \mathrm{E}-3)}-$ & $4.37 \mathrm{E}-1_{(5.48 \mathrm{E}-3)}-$ & $4.98 \mathrm{E}+0_{(3.15 \mathrm{E}+0)}-$ & $3.99 \mathrm{E}+0_{(2.30 \mathrm{E}+0)^{-}}$ & $1.31 \mathrm{E}+1_{(8.98 \mathrm{E}+0)}$ & $1.17 e-3_{(2.0 e-5)}$ \\
\hline & 15 & 24 & $5.81 \mathrm{E}-1_{(6.33 \mathrm{E}-3)}-$ & $1.42 \mathrm{E}+0_{(8.27 \mathrm{E}-1)}-$ & $6.22 \mathrm{E}-1_{(8.34 \mathrm{E}-3)}=$ & $8.01 \mathrm{E}-1_{(8.22 \mathrm{E}-2)}-$ & $6.46 \mathrm{E}+0_{(6.28 \mathrm{E}+0)^{-}}$ & $9.22 \mathrm{E}+0_{(5.83 \mathrm{E}+0)^{-}}$ & $4.91 \mathrm{E}+1_{(1.91 \mathrm{E}+1)^{-}}$ & $8.90 \mathrm{e}-4_{(2.2 \mathrm{e}-5)}$ \\
\hline \multirow{5}{*}{ DTLZ 4} & 3 & 12 & $5.61 \mathrm{E}-2_{(6.58 \mathrm{E}-4)}-$ & $5.73 \mathrm{E}-2_{(6.68 \mathrm{E}-4)}-$ & $2.45 \mathrm{E}-1_{(2.74 \mathrm{E}-1)}-$ & $5.17 \mathrm{E}-1_{(9.85 \mathrm{E}-2)}-$ & $3.64 \mathrm{E}-1_{(1.80 \mathrm{E}-1)}-$ & $5.78 \mathrm{E}-2_{(7.26 \mathrm{E}-4)}-$ & $5.78 \mathrm{E}-2_{(1.33 \mathrm{E}-3)}-$ & 5.07E-2 (1.1E-2) \\
\hline & 5 & 14 & $1.64 \mathrm{E}-1_{(1.04 \mathrm{E}-3)}-$ & $1.66 \mathrm{E}-1_{(5.25 \mathrm{E}-4)}-$ & $1.98 \mathrm{E}-1_{(4.08 \mathrm{E}-2)}-$ & $6.45 \mathrm{E}-1_{(8.57 \mathrm{E}-2)}-$ & $2.61 \mathrm{E}-1_{(1.43 \mathrm{E}-1)}-$ & $1.70 \mathrm{E}-1_{(1.24 \mathrm{E}-3)}-$ & $1.69 \mathrm{E}-1_{(1.19 \mathrm{E}-3)}-$ & $7.12 \mathrm{E}-3_{(8.5 \mathrm{E}-4)}$ \\
\hline & 8 & 17 & $3.52 \mathrm{E}-1_{(1.46 \mathrm{E}-3)}-$ & $3.53 \mathrm{E}-1_{(1.20 \mathrm{E}-3)}-$ & $3.63 \mathrm{E}-1_{(1.62 \mathrm{E}-2)}=$ & $7.72 \mathrm{E}-1_{(9.05 \mathrm{E}-2)}-$ & $3.79 \mathrm{E}-1_{(5.66 \mathrm{E}-2)}-$ & $3.69 \mathrm{E}-1_{(4.46 \mathrm{E}-3)}-$ & $3.46 \mathrm{E}-1_{(3.71 \mathrm{E}-3)}-$ & $7.13 e-3(4.8 e-4)$ \\
\hline & 10 & 19 & $3.99 \mathrm{E}-1_{(1.08 \mathrm{E}-3)}-$ & $4.11 \mathrm{E}-1_{(1.29 \mathrm{E}-3)}-$ & $4.17 \mathrm{E}-1_{(1.30 \mathrm{E}-3)}-$ & $7.65 \mathrm{E}-1_{(8.29 \mathrm{E}-2)}-$ & $4.49 \mathrm{E}-1_{(2.43 \mathrm{E}-2)}-$ & $4.39 \mathrm{E}-1_{(8.96 \mathrm{E}-3)}-$ & $4.62 \mathrm{E}-1_{(4.10 \mathrm{E}-3)}-$ & $2.57 e-3_{(1.3 e-4)}$ \\
\hline & 15 & 24 & $5.72 \mathrm{E}-1_{(2.01 \mathrm{E}-3)}-$ & $6.05 \mathrm{E}-1_{(3.25 \mathrm{E}-3)}-$ & $6.03 \mathrm{E}-1_{(1.06 \mathrm{E}-2)}-$ & $8.19 \mathrm{E}-1_{(2.38 \mathrm{E}-2)}-$ & $6.57 \mathrm{E}-1_{(2.57 \mathrm{E}-2)}-$ & $6.21 \mathrm{E}-1_{(1.23 \mathrm{E}-2)}-$ & $6.59 \mathrm{E}-1_{(9.19 \mathrm{E}-3)}-$ & $6.77 \mathrm{e}-4_{(2.9 \mathrm{e}-5)}$ \\
\hline \multirow{5}{*}{ DTLZ 5} & 3 & 12 & $4.89 \mathrm{E}-3_{(1.28 \mathrm{E}-4)}+$ & $5.03 \mathrm{E}-3_{(9.89 \mathrm{E}-5)+}+$ & $1.09 \mathrm{E}-2_{(1.27 \mathrm{E}-3)-}$ & $3.13 \mathrm{E}-2_{(5.2 \mathrm{E}-3)+}+$ & $5.12 \mathrm{E}-1_{(2.12 \mathrm{E}-1)}-$ & $5.44 \mathrm{E}-3_{(2.21 \mathrm{E}-4)}+$ & $2.99 \mathrm{E}-2_{(3.46 \mathrm{E}-3)-}$ & $8.54 \mathrm{E}-3(6.6 \mathrm{E}-4)$ \\
\hline & 5 & 14 & $9.02 \mathrm{E}-2(1.69 \mathrm{E}-2)-$ & $9.72 \mathrm{E}-2(1.98 \mathrm{E}-2)-$ & $6.08 \mathrm{E}-2(1.09 \mathrm{E}-2)-$ & $6.25 \mathrm{E}-2_{(1.39 \mathrm{E}-2)}-$ & $3.77 \mathrm{E}-1_{(1.54 \mathrm{E}-1)}-$ & $1.13 \mathrm{E}-1_{(2.67 \mathrm{E}-2)}-$ & $2.02 \mathrm{E}-1_{(4.24 \mathrm{E}-2)}-$ & $3.21 \mathrm{E}-4_{(1.6 \mathrm{E}-5)}$ \\
\hline & 8 & 17 & $1.75 \mathrm{E}-1_{(2.36 \mathrm{E}-2)}-$ & $2.71 \mathrm{E}-1_{(4.95 \mathrm{E}-2)}-$ & $1.21 \mathrm{E}-1_{(2.18 \mathrm{E}-2)}-$ & $1.23 \mathrm{E}-1_{(2.09 \mathrm{E}-2)}-$ & $5.57 \mathrm{E}-1_{(1.89 \mathrm{E}-1)}-$ & $3.13 \mathrm{E}-1_{(7.07 \mathrm{E}-2)}-$ & $4.43 \mathrm{E}-1_{(8.34 \mathrm{E}-2)}-$ & $2.49 \mathrm{e}-4_{(6.7 e-6)}$ \\
\hline & 10 & 19 & $2.04 \mathrm{E}-1_{(3.23 \mathrm{E}-2)}=$ & $3.36 \mathrm{E}-1_{(5.81 \mathrm{E}-2)}-$ & $1.48 \mathrm{E}-1_{(3.15 \mathrm{E}-2)}-$ & $1.63 \mathrm{E}-1_{(3.13 \mathrm{E}-2)}-$ & $4.91 \mathrm{E}-1_{(1.94 \mathrm{E}-1)}-$ & $3.97 \mathrm{E}-1_{(9.26 \mathrm{E}-2)}-$ & $6.75 \mathrm{E}-1_{(1.55 \mathrm{E}-1)}-$ & $1.79 \mathrm{e}-4_{(2.6 e-6)}$ \\
\hline & 15 & 24 & $3.53 \mathrm{E}-1_{(7.07 \mathrm{E}-2)}-$ & $4.97 \mathrm{E}-1_{(9.04 \mathrm{E}-2)}-$ & $1.64 \mathrm{E}-1_{(3.22 \mathrm{E}-2)}-$ & $1.02 \mathrm{E}-1_{(2.00 \mathrm{E}-2)}-$ & $6.58 \mathrm{E}-1_{(1.69 \mathrm{E}-1)}-$ & $5.29 \mathrm{E}-1_{(1.15 \mathrm{E}-1)}-$ & $9.39 \mathrm{E}-1_{(2.96 \mathrm{E}-1)}-$ & $2.71 \mathrm{e}-4_{(2.9 \mathrm{e}-6)}$ \\
\hline \multirow{5}{*}{ DTLZ 6} & 3 & 12 & 4.84E-3(1.09E-4) - & $4.92 \mathrm{E}-3(1.04 \mathrm{E}-4)-$ & $1.07 \mathrm{E}-2(1.25 \mathrm{E}-3)=$ & $5.98 \mathrm{E}-2_{(1.52 \mathrm{E}-2)}-$ & $6.45 \mathrm{E}-1_{(1.18 \mathrm{E}-1)}-$ & $5.08 \mathrm{E}-3(1.50 \mathrm{E}-4)-$ & $3.91 \mathrm{E}-2(8.74 \mathrm{E}-3)-$ & $2.82 \mathrm{E}-4_{(5.9 \mathrm{E}-5)}$ \\
\hline & 5 & 14 & $1.47 \mathrm{E}-1_{(4.03 \mathrm{E}-2)}-$ & $1.49 \mathrm{E}-1_{(4.74 \mathrm{E}-2)}-$ & $7.14 \mathrm{E}-2_{(1.18 \mathrm{E}-2)}=$ & $9.32 \mathrm{E}-2_{(1.99 \mathrm{E}-2)}-$ & $6.19 \mathrm{E}-1_{(8.32 \mathrm{E}-2)}-$ & $2.65 \mathrm{E}-1_{(4.63 \mathrm{E}-2)}-$ & $2.95 \mathrm{E}-1_{(9.84 \mathrm{E}-2)}-$ & $3.08 E-4_{(3.7 E-5)}$ \\
\hline & 8 & 17 & $2.77 \mathrm{E}-1_{(7.58 \mathrm{E}-2)}-$ & $4.07 \mathrm{E}-1_{(1.47 \mathrm{E}-1)}-$ & $2.14 \mathrm{E}-1_{(4.37 \mathrm{E}-2)}-$ & $2.27 \mathrm{E}-1_{(5.24 \mathrm{E}-2)}-$ & $8.40 \mathrm{E}-1_{(4.31 \mathrm{E}-1)}-$ & $1.16 \mathrm{E}+0_{(6.51 \mathrm{E}-1)}-$ & $8.82 \mathrm{E}-1_{(2.01 \mathrm{E}-1)}-$ & $6.02 \mathrm{e}-4_{(6.1 e-5)}$ \\
\hline & 10 & 19 & $3.07 \mathrm{E}-1_{(7.55 \mathrm{E}-2)}-$ & $4.69 \mathrm{E}-1_{(1.37 \mathrm{E}-1)}-$ & $2.09 \mathrm{E}-1_{(3.64 \mathrm{E}-2)}-$ & $2.52 \mathrm{E}-1_{(7.25 \mathrm{E}-2)}-$ & $6.65 \mathrm{E}-1_{(1.18 \mathrm{E}-1)}-$ & $1.43 \mathrm{E}+0_{(5.42 \mathrm{E}-1)}-$ & $1.12 \mathrm{E}+0_{(1.84 \mathrm{E}-1)}-$ & $5.50 e-4_{(3.0 e-5)}$ \\
\hline & 15 & 24 & $4.86 \mathrm{E}-1_{(1.51 \mathrm{E}-1)}-$ & $5.85 \mathrm{E}-1_{(2.00 \mathrm{E}-1)}-$ & $3.38 \mathrm{E}-1_{(2.59 \mathrm{E}-2)}-$ & $1.24 \mathrm{E}-1_{(2.70 \mathrm{E}-2)}-$ & $7.07 \mathrm{E}-1_{(7.32 \mathrm{E}-2)}-$ & $5.71 \mathrm{E}-1_{(3.50 \mathrm{E}-1)}-$ & $9.02 \mathrm{E}+0_{(6.38 \mathrm{E}-1)}-$ & $9.69 \mathrm{e}-4_{(7.6 e-5)}$ \\
\hline \multirow{5}{*}{ DTLZ 7} & 3 & 22 & $5.98 \mathrm{E}-2_{(1.48 \mathrm{E}-3)}-$ & $6.95 \mathrm{E}-2_{(5.27 \mathrm{E}-2)}-$ & $8.24 \mathrm{E}-2_{(7.77 \mathrm{E}-2)}-$ & $9.15 \mathrm{E}-2_{(6.18 \mathrm{E}-3)}-$ & $8.03 \mathrm{E}-1_{(4.39 \mathrm{E}-1)}-$ & $7.42 \mathrm{E}-2_{(5.20 \mathrm{E}-2)}-$ & $9.53 \mathrm{E}-2_{(1.96 \mathrm{E}-3)}-$ & $1.40 \mathrm{E}-3_{(2.9 \mathrm{E}-4)}$ \\
\hline & 5 & 24 & $2.71 \mathrm{E}-1_{(1.19 \mathrm{E}-2)}-$ & $2.51 \mathrm{E}-1_{(5.56 \mathrm{E}-3)}-$ & $2.71 \mathrm{E}-1_{(2.65 \mathrm{E}-2)}-$ & $3.15 \mathrm{E}-1_{(2.61 \mathrm{E}-2)}-$ & $6.64 \mathrm{E}-1_{(4.04 \mathrm{E}-2)}-$ & $2.74 \mathrm{E}-1_{(5.88 \mathrm{E}-3)}-$ & $3.56 \mathrm{E}-1_{(5.13 \mathrm{E}-3)}-$ & $1.53 \mathrm{E}-3_{(1.2 \mathrm{E}-4)}$ \\
\hline & 8 & 27 & $9.87 \mathrm{E}-1_{(1.00 \mathrm{E}-1)}-$ & $1.06 \mathrm{E}+0_{(1.77 \mathrm{E}-1)}=$ & $7.42 \mathrm{E}-1_{(2.00 \mathrm{E}-2)}-$ & $9.76 \mathrm{E}-1_{(1.22 \mathrm{E}-1)}-$ & $1.23 \mathrm{E}+0_{(3.81 \mathrm{E}-2)}-$ & $7.32 \mathrm{E}-1_{(1.98 \mathrm{E}-2)}-$ & $1.24 \mathrm{E}+0_{(5.22 \mathrm{E}-2)}-$ & $2.17 e-3_{(9.9 e-5)}$ \\
\hline & 10 & 29 & $1.20 \mathrm{E}+0_{(1.38 \mathrm{E}-1)}-$ & $1.22 \mathrm{E}+0_{(1.88 \mathrm{E}-1)}-$ & $8.79 \mathrm{E}-1_{(5.94 \mathrm{E}-2)}-$ & $1.57 \mathrm{E}+0_{(2.8 \mathrm{E}-1)}-$ & $1.47 \mathrm{E}+0_{(4.08 \mathrm{E}-2)}-$ & $1.07 \mathrm{E}+0_{(2.98 \mathrm{E}-2)}-$ & $2.16 \mathrm{E}+0_{(5.17 \mathrm{E}-2)}-$ & $1.97 e-3(6.1 e-5)$ \\
\hline & 15 & 34 & $3.51 \mathrm{E}+0_{(3.90 \mathrm{E}-1)}-$ & $6.95 \mathrm{E}+0_{(2.03 \mathrm{E}+0)-}$ & $1.55 \mathrm{E}+0_{(3.47 \mathrm{E}-2)}-$ & $4.66 \mathrm{E}+0_{(6.6 \mathrm{E}-1)}-$ & $2.65 \mathrm{E}+0_{(1.43 \mathrm{E}-1)}-$ & $2.74 \mathrm{E}+0_{(2.72 \mathrm{E}-1)}-$ & $8.97 \mathrm{E}+0_{(6.69 \mathrm{E}-2)}-$ & $2.99 \mathrm{e}-3_{(7.2 e-5)}$ \\
\hline$+/-/ \approx$ & & & $1 / 34 / 0$ & $1 / 34 / 0$ & $0 / 35 / 0$ & $1 / 34 / 0$ & $0 / 35 / 0$ & $1 / 34 / 0$ & $0 / 35 / 0$ & \\
\hline
\end{tabular}

The symbols “+”, “ $\approx$ " and "-" denote that the performance of the compared algorithm is statistically better than, equivalent to, and worse than DB-CSA. 


\section{References}

[1] K. Deb, U. B. Rao N., and S. Karthik, "Dynamic multi-objective optimization and decision-making using modified NSGA-II: A case study on hydro-thermal power scheduling," in Lecture Notes in Computer Science (including subseries Lecture Notes in Artificial Intelligence and Lecture Notes in Bioinformatics), 2007, vol. 4403 LNCS, pp. 803-817. doi: 10.1007/978-3-540-70928-2_60.

[2] A. Aboud, R. Fdhila, and A. M. Alimi, "Dynamic Multi Objective Particle Swarm Optimization Based on a New Environment Change Detection Strategy," in Lecture Notes in Computer Science (including subseries Lecture Notes in Artificial Intelligence and Lecture Notes in Bioinformatics), Nov. 2017, vol. 10637 LNCS, pp. 258-268. doi: 10.1007/978-3-319-70093-9_27.

[3] A. Aboud, R. Fdhila, and A. M. Alimi, "MOPSO for dynamic feature selection problem based big data fusion," in 2016 IEEE International Conference on Systems, Man, and Cybernetics, SMC 2016 Conference Proceedings, Feb. 2017, pp. 3918-3923. doi: 10.1109/SMC.2016.7844846.

[4] A. Aboud, R. Fdhila, A. Hussain, and A. M. Alimi, "A novel Dynamic Pareto bi-level Multi-Objective Particle Swarm Optimization (DPb-MOPSO) algorithm," TechRxiv, Dec. 2020. doi: 10.36227/TECHRXIV.13325354.V1.

[5] J. Kennedy and R. Eberhart, "Particle swarm optimization," in Proceedings of ICNN'95 - International Conference on Neural Networks, vol. 4, pp. 1942-1948. doi: 10.1109/ICNN.1995.488968.

[6] M. Farina, K. Deb, and P. Amato, "Dynamic multiobjective optimization problems: Test cases, approximations, and applications," IEEE Transactions on Evolutionary Computation, vol. 8, no. 5, pp. 425-442, Oct. 2004, doi: 10.1109/TEVC.2004.831456.

[7] J. Ou et al., "A pareto-based evolutionary algorithm using decomposition and truncation for dynamic multi-objective optimization," Applied Soft Computing, vol. 85, p. 105673, Dec. 2019, doi: 10.1016/J.ASOC.2019.105673.

[8] J. Zou, Q. Li, S. Yang, H. Bai, and J. Zheng, “A prediction strategy based on center points and knee points for evolutionary dynamic multi-objective optimization," Applied Soft Computing, vol. 61, pp. 806-818, Dec. 2017, doi: 10.1016/J.ASOC.2017.08.004.

[9] S. Jiang and S. Yang, "A Steady-State and Generational Evolutionary Algorithm for Dynamic Multiobjective Optimization," IEEE Transactions on Evolutionary Computation, vol. 21, no. 1, pp. 6582, Feb. 2017, doi: 10.1109/TEVC.2016.2574621.

[10] J. Kennedy and R. Eberhart, "Particle swarm optimization," in Proceedings of ICNN'95 - International Conference on Neural Networks, Nov. 1995, vol. 4, pp. 1942-1948 vol.4. doi: 10.1109/ICNN.1995.488968.

[11] R. Poli, J. Kennedy, and T. Blackwell, "Particle swarm optimization," Swarm Intelligence, vol. 1, no. 1, pp. 33-57, Oct. 2007, doi: 10.1007/s11721-007-0002-0.

[12] T. Zeugmann et al., "Particle Swarm Optimization," in Encyclopedia of Machine Learning, Boston, MA: Springer US, 2011, pp. 760-766. doi: 10.1007/978-0-387-30164-8_630.

[13] R. C. Purshouse and P. J. Fleming, "On the evolutionary optimization of many conflicting objectives," IEEE Transactions on Evolutionary Computation, vol. 11, no. 6, pp. 770-784, Dec. 2007, doi: 10.1109/TEVC.2007.910138.

[14] E. J. Hughes, "Multiple single objective Pareto sampling," in 2003 Congress on Evolutionary Computation, CEC 2003 - Proceedings, 2003, vol. 4, pp. 2678-2684. doi: 10.1109/CEC.2003.1299427.

[15] E. J. Hughes, "MSOPS-II: A general-purpose many-objective optimiser," in 2007 IEEE Congress on Evolutionary Computation, CEC 2007, 2007, pp. 3944-3951. doi: 10.1109/CEC.2007.4424985.

[16] Q. Zhang and H. Li, "MOEA/D: A multiobjective evolutionary algorithm based on decomposition," IEEE Transactions on Evolutionary Computation, vol. 11, no. 6, pp. 712-731, Dec. 2007, doi: 10.1109/TEVC.2007.892759. 
[17] R. Cheng, Y. Jin, M. Olhofer, and B. Sendhoff, "A Reference Vector Guided Evolutionary Algorithm for Many-Objective Optimization,” IEEE Transactions on Evolutionary Computation, vol. 20, no. 5, pp. 773791, Oct. 2016, doi: 10.1109/TEVC.2016.2519378.

[18] H. L. Liu, F. Gu, and Q. Zhang, "Decomposition of a multiobjective optimization problem into a number of simple multiobjective subproblems," IEEE Transactions on Evolutionary Computation, vol. 18, no. 3, pp. 450-455, 2014, doi: 10.1109/TEVC.2013.2281533.

[19] K. Deb and H. Jain, "An evolutionary many-objective optimization algorithm using reference-point-based nondominated sorting approach, Part I: Solving problems with box constraints," IEEE Transactions on Evolutionary Computation, vol. 18, no. 4, pp. 577-601, 2014, doi: 10.1109/TEVC.2013.2281535.

[20] K. Li, K. Deb, Q. Zhang, and S. Kwong, “An evolutionary many-objective optimization algorithm based on dominance and decomposition," IEEE Transactions on Evolutionary Computation, vol. 19, no. 5, pp. 694-716, Oct. 2015, doi: 10.1109/TEVC.2014.2373386.

[21] X. Lu, Y. Tan, W. Zheng, and L. Meng, “A Decomposition Method Based on Random Objective Division for MOEA/D in Many-Objective Optimization," IEEE Access, vol. 8, pp. 103550-103564, 2020, doi: 10.1109/ACCESS.2020.2999417.

[22] J. Bader and E. Zitzler, "HypE: An algorithm for fast hypervolume-based many-objective optimization," Evolutionary Computation, vol. 19, no. 1, pp. 45-76, 2011, doi: 10.1162/EVCO_a_00009.

[23] N. Beume, B. Naujoks, and M. Emmerich, "SMS-EMOA: Multiobjective selection based on dominated hypervolume," European Journal of Operational Research, vol. 181, no. 3, pp. 1653-1669, Sep. 2007, doi: 10.1016/j.ejor.2006.08.008.

[24] E. Zitzler and S. Künzli, "Indicator-based selection in multiobjective search," Lecture Notes in Computer Science (including subseries Lecture Notes in Artificial Intelligence and Lecture Notes in Bioinformatics), vol. 3242, pp. 832-842, 2004, doi: 10.1007/978-3-540-30217-9_84.

[25] S. Feng and J. Wen, "An Evolutionary Many-Objective Optimization Algorithm Based on IGD Indicator and Region Decomposition," in Proceedings - 2019 15th International Conference on Computational Intelligence and Security, CIS 2019, Dec. 2019, pp. 206-210. doi: 10.1109/CIS.2019.00051.

[26] Y. Sun, G. G. Yen, and Z. Yi, "IGD Indicator-Based Evolutionary Algorithm for Many-Objective Optimization Problems," IEEE Transactions on Evolutionary Computation, vol. 23, no. 2, pp. 173-187, Apr. 2019, doi: 10.1109/TEVC.2018.2791283.

[27] X. Zou, Y. Chen, M. Liu, and L. Kang, "A new evolutionary algorithm for solving many-objective optimization problems," IEEE Transactions on Systems, Man, and Cybernetics, Part B: Cybernetics, vol. 38, no. 5, pp. 1402-1412, 2008, doi: 10.1109/TSMCB.2008.926329.

[28] D. Hadka and P. Reed, "Borg: An auto-adaptive many-objective evolutionary computing framework," Evolutionary Computation, vol. 21, no. 2, pp. 231-259, 2013, doi: 10.1162/EVCO_a_00075.

[29] W. Gaoping and J. Huawei, "Fuzzy-dominance and its application in evolutionary many objective optimization," in Proceedings - CIS Workshops 2007, 2007 International Conference on Computational Intelligence and Security Workshops, 2007, pp. 195-198. doi: 10.1109/cisw.2007.4425478.

[30] S. Yang, M. Li, X. Liu, and J. Zheng, "A grid-based evolutionary algorithm for many-objective optimization," IEEE Transactions on Evolutionary Computation, vol. 17, no. 5, pp. 721-736, 2013, doi: 10.1109/TEVC.2012.2227145.

[31] Y. Yuan, H. Xu, B. Wang, and X. Yao, “A New Dominance Relation-Based Evolutionary Algorithm for Many-Objective Optimization," IEEE Transactions on Evolutionary Computation, vol. 20, no. 1, pp. 1637, Feb. 2016, doi: 10.1109/TEVC.2015.2420112.

[32] F. di Pierro, S. T. Khu, and D. A. Savić, "An investigation on preference order ranking scheme for multiobjective evolutionary optimization," IEEE Transactions on Evolutionary Computation, vol. 11, no. 1, pp. 17-45, Feb. 2007, doi: 10.1109/TEVC.2006.876362. 
[33] S. F. Adra and P. J. Fleming, "Diversity management in evolutionary many-objective optimization," IEEE Transactions on Evolutionary Computation, vol. 15, no. 2, pp. 183-195, Apr. 2011, doi: 10.1109/TEVC.2010.2058117.

[34] M. Li, S. Yang, and X. Liu, "Shift-based density estimation for pareto-based algorithms in many-objective optimization," IEEE Transactions on Evolutionary Computation, vol. 18, no. 3, pp. 348-365, 2014, doi: 10.1109/TEVC.2013.2262178.

[35] X. Zhang, Y. Tian, and Y. Jin, "A knee point-driven evolutionary algorithm for many-objective optimization," IEEE Transactions on Evolutionary Computation, vol. 19, no. 6, pp. 761-776, Dec. 2015, doi: 10.1109/TEVC.2014.2378512.

[36] R. Wang, R. C. Purshouse, and P. J. Fleming, "Preference-inspired coevolutionary algorithms for manyobjective optimization," IEEE Transactions on Evolutionary Computation, vol. 17, no. 4, pp. 474-494, 2013, doi: 10.1109/TEVC.2012.2204264.

[37] K. Praditwong and X. Yao, “A new multi-objective evolutionary optimisation algorithm: The two-archive algorithm," in 2006 International Conference on Computational Intelligence and Security, ICCIAS 2006, 2006, vol. 1, pp. 286-291. doi: 10.1109/ICCIAS.2006.294139.

[38] H. Wang, L. Jiao, and X. Yao, “Two Arch2: An Improved Two-Archive Algorithm for Many-Objective Optimization," IEEE Transactions on Evolutionary Computation, vol. 19, no. 4, pp. 524-541, Aug. 2015 , doi: 10.1109/TEVC.2014.2350987.

[39] A. B. de Carvalho and A. Pozo, "Measuring the convergence and diversity of CDAS Multi-Objective Particle Swarm Optimization Algorithms: A study of many-objective problems," Neurocomputing, vol. 75, no. 1, pp. 43-51, Jan. 2012, doi: 10.1016/j.neucom.2011.03.053.

[40] O. R. Castro and A. Pozo, "A MOPSO based on hyper-heuristic to optimize many-objective problems," in IEEE SSCI 2014 - 2014 IEEE Symposium Series on Computational Intelligence - SIS 2014: 2014 IEEE Symposium on Swarm Intelligence, Proceedings, Jan. 2015, pp. 251-258. doi: 10.1109/SIS.2014.7011803.

[41] X. Sun, Y. Chen, Y. Liu, and D. Gong, "Indicator-based set evolution particle swarm optimization for many-objective problems," Soft Computing, vol. 20, no. 6, pp. 2219-2232, Jun. 2016, doi: 10.1007/s00500-015-1637-1.

[42] W. Hu, G. G. Yen, and G. Luo, "Many-Objective Particle Swarm Optimization Using Two-Stage Strategy and Parallel Cell Coordinate System," IEEE Transactions on Cybernetics, vol. 47, no. 6, pp. 1446-1459, Jun. 2017, doi: 10.1109/TCYB.2016.2548239.

[43] J. Maltese, B. M. Ombuki-Berman, and A. P. Engelbrecht, "Pareto-based many-objective optimization using knee points," in 2016 IEEE Congress on Evolutionary Computation, CEC 2016, Nov. 2016, pp. 3678-3686. doi: 10.1109/CEC.2016.7744255.

[44] Y. Xiang, Y. Zhou, Z. Chen, and J. Zhang, “A Many-Objective Particle Swarm Optimizer with Leaders Selected from Historical Solutions by Using Scalar Projections," IEEE Transactions on Cybernetics, vol. 50, no. 5, pp. 2209-2222, May 2020, doi: 10.1109/TCYB.2018.2884083.

[45] M. F. Leung, C. A. Coello Coello, C. C. Cheung, S. C. Ng, and A. K. F. Lui, "A hybrid leader selection strategy for many-objective particle swarm optimization," IEEE Access, vol. 8, pp. 189527-189545, 2020, doi: 10.1109/ACCESS.2020.3031002.

[46] L. Ma, M. Huang, S. Yang, R. Wang, and X. Wang, "An Adaptive Localized Decision Variable Analysis Approach to Large-Scale Multiobjective and Many-Objective Optimization," IEEE Transactions on Cybernetics, 2021, doi: 10.1109/TCYB.2020.3041212.

[47] A. Askarzadeh, "A novel metaheuristic method for solving constrained engineering optimization problems: Crow search algorithm," Computers and Structures, vol. 169, pp. 1-12, Jun. 2016, doi: 10.1016/j.compstruc.2016.03.001.

[48] Z. W. Geem, J. H. Kim, and G. v. Loganathan, "A New Heuristic Optimization Algorithm: Harmony Search,” Simulation, vol. 76, no. 2, pp. 60-68, Aug. 2001, doi: 10.1177/003754970107600201. 
[49] C. K. Goh and K. C. Tan, "A competitive-cooperative coevolutionary paradigm for dynamic multiobjective optimization," IEEE Transactions on Evolutionary Computation, vol. 13, no. 1, pp. 103127, 2009, doi: 10.1109/TEVC.2008.920671.

[50] A. Zhou, Y. Jin, and Q. Zhang, “A Population prediction strategy for evolutionary dynamic multiobjective optimization," IEEE Transactions on Cybernetics, vol. 44, no. 1, pp. 40-53, Jan. 2014, doi: 10.1109/TCYB.2013.2245892.

[51] M. Jiang, Z. Wang, L. Qiu, S. Guo, X. Gao, and K. C. Tan, “A Fast Dynamic Evolutionary Multiobjective Algorithm via Manifold Transfer Learning," IEEE Transactions on Cybernetics, pp. 1-12, May 2020, doi: 10.1109/tcyb.2020.2989465.

[52] L. Cao, L. Xu, E. D. Goodman, C. Bao, and S. Zhu, "Evolutionary Dynamic Multiobjective Optimization Assisted by a Support Vector Regression Predictor," IEEE Transactions on Evolutionary Computation, vol. 24, no. 2, pp. 305-319, Apr. 2020, doi: 10.1109/TEVC.2019.2925722.

[53] M. Jiang, Z. Huang, L. Qiu, W. Huang, and G. G. Yen, “Transfer Learning-Based Dynamic Multiobjective Optimization Algorithms," IEEE Transactions on Evolutionary Computation, vol. 22, no. 4, pp. 501-514, Aug. 2018, doi: 10.1109/TEVC.2017.2771451.

[54] A. Muruganantham, K. C. Tan, and P. Vadakkepat, "Evolutionary Dynamic Multiobjective Optimization Via Kalman Filter Prediction," IEEE Transactions on Cybernetics, vol. 46, no. 12, pp. 2862-2873, Dec. 2016, doi: 10.1109/TCYB.2015.2490738.

[55] Y. Xiang, Y. Zhou, M. Li, and Z. Chen, "A Vector Angle-Based Evolutionary Algorithm for Unconstrained Many-Objective Optimization," IEEE Transactions on Evolutionary Computation, vol. 21, no. 1, pp. 131-152, Feb. 2017, doi: 10.1109/TEVC.2016.2587808.

[56] Y. Tian, R. Cheng, X. Zhang, Y. Su, and Y. Jin, “A Strengthened Dominance Relation Considering Convergence and Diversity for Evolutionary Many-Objective Optimization," IEEE Transactions on Evolutionary Computation, vol. 23, no. 2, pp. 331-345, Apr. 2019, doi: 10.1109/TEVC.2018.2866854.

[57] Y. Liu, N. Zhu, and M. Li, "Solving Many-Objective Optimization Problems by a Pareto-Based Evolutionary Algorithm With Preprocessing and a Penalty Mechanism," IEEE Transactions on Cybernetics, pp. 1-10, May 2020, doi: 10.1109/tcyb.2020.2988896.

[58] K. Li, R. Wang, T. Zhang, and H. Ishibuchi, "Evolutionary Many-Objective Optimization: A Comparative Study of the State-of-The-Art," IEEE Access, vol. 6, pp. 26194-26214, May 2018, doi: 10.1109/ACCESS.2018.2832181.

[59] S. Jiang and S. Yang, "A strength pareto evolutionary algorithm based on reference direction for multiobjective and many-objective optimization," IEEE Transactions on Evolutionary Computation, vol. 21, no. 3, pp. 329-346, Jun. 2017, doi: 10.1109/TEVC.2016.2592479.

[60] H. Chen, R. Cheng, W. Pedrycz, and Y. Jin, "Solving Many-Objective Optimization Problems via Multistage Evolutionary Search," IEEE Transactions on Systems, Man, and Cybernetics: Systems, pp. 113, Aug. 2019, doi: 10.1109/tsmc.2019.2930737.

[61] Y. Meraihi, A. B. Gabis, A. Ramdane-Cherif, and D. Acheli, "A comprehensive survey of Crow Search Algorithm and its applications," Artificial Intelligence Review, vol. 54, no. 4, pp. 2669-2716, Apr. 2021, doi: 10.1007/s10462-020-09911-9.

[62] H. Nobahari and A. Bighashdel, "MOCSA: A Multi-Objective Crow Search Algorithm for MultiObjective optimization," in 2nd Conference on Swarm Intelligence and Evolutionary Computation, CSIEC 2017 - Proceedings, Jun. 2017, pp. 60-65. doi: 10.1109/CSIEC.2017.7940171.

[63] J. John and P. Rodrigues, "MOTCO: Multi-objective Taylor Crow Optimization Algorithm for Cluster Head Selection in Energy Aware Wireless Sensor Network," Mobile Networks and Applications, vol. 24, no. 5, pp. 1509-1525, Oct. 2019, doi: 10.1007/s11036-019-01271-1.

[64] R. C. T. De Souza, L. D. S. Coelho, C. A. De MacEdo, and J. Pierezan, “A V-Shaped Binary Crow Search Algorithm for Feature Selection,” Sep. 2018. doi: 10.1109/CEC.2018.8477975. 
[65] S. Laabadi, M. Naimi, H. El Amri, and B. Achchab, "A Binary Crow Search Algorithm for Solving Twodimensional Bin Packing Problem with Fixed Orientation," in Procedia Computer Science, Jan. 2020 , vol. 167, pp. 809-818. doi: 10.1016/j.procs.2020.03.420.

[66] L. Dos Santos Coelho, C. Richter, V. C. Mariani, and A. Askarzadeh, "Modified crow search approach applied to electromagnetic optimization,” Jan. 2017. doi: 10.1109/CEFC.2016.7815927.

[67] D. Gupta, J. J. P. C. Rodrigues, S. Sundaram, A. Khanna, V. Korotaev, and V. H. C. de Albuquerque, "Usability feature extraction using modified crow search algorithm: a novel approach," Neural Computing and Applications, vol. 32, no. 15, pp. 10915-10925, Aug. 2020, doi: 10.1007/s00521-018-3688-6.

[68] F. Mohammadi and H. Abdi, "A modified crow search algorithm (MCSA) for solving economic load dispatch problem," Applied Soft Computing Journal, vol. 71, pp. 51-65, Oct. 2018, doi: 10.1016/j.asoc.2018.06.040.

[69] E. Cuevas, E. Barocio Espejo, and A. Conde Enríquez, "A modified crow search algorithm with applications to power system problems," in Studies in Computational Intelligence, vol. 822, Springer Verlag, 2019, pp. 137-166. doi: 10.1007/978-3-030-11593-7_6.

[70] A. Javidi, E. Salajegheh, and J. Salajegheh, "Enhanced crow search algorithm for optimum design of structures," Applied Soft Computing Journal, vol. 77, pp. 274-289, Apr. 2019, doi: 10.1016/j.asoc.2019.01.026.

[71] A. K. Bhullar, R. Kaur, and S. Sondhi, "Enhanced crow search algorithm for AVR optimization," Soft Computing, vol. 24, no. 16, pp. 11957-11987, Aug. 2020, doi: 10.1007/s00500-019-04640-w.

[72] E. Cuevas, J. Gálvez, and O. Avalos, "An Enhanced Crow Search Algorithm Applied to Energy Approaches," in Studies in Computational Intelligence, vol. 854, Springer Verlag, 2020, pp. 27-49. doi: 10.1007/978-3-030-28917-1_3.

[73] S. Moghaddam, M. Bigdeli, M. Moradlou, and P. Siano, "Designing of stand-alone hybrid PV/wind/battery system using improved crow search algorithm considering reliability index," International Journal of Energy and Environmental Engineering, vol. 10, no. 4, pp. 429-449, Dec. 2019, doi: 10.1007/s40095-019-00319-y.

[74] S. Arora, H. Singh, M. Sharma, S. Sharma, and P. Anand, "A New Hybrid Algorithm Based on Grey Wolf Optimization and Crow Search Algorithm for Unconstrained Function Optimization and Feature Selection," IEEE Access, vol. 7, pp. 26343-26361, 2019, doi: 10.1109/ACCESS.2019.2897325.

[75] K.-W. Huang and Z.-X. Wu, “CPO: A Crow Particle Optimization Algorithm,” International Journal of Computational Intelligence Systems, vol. 12, no. 1, 2019, doi: 10.2991/ijcis.2018.125905658.

[76] K. Gaddala and P. S. Raju, "Merging Lion with Crow Search Algorithm for Optimal Location and Sizing of UPQC in Distribution Network," Journal of Control, Automation and Electrical Systems, vol. 31, no. 2, pp. 377-392, Apr. 2020, doi: 10.1007/s40313-020-00564-1.

[77] A. M. Alimi, “BETA NEURO-FUZZY SYSTEMS,” vol. 1, no. 1, pp. 23-41, 2003.

[78] A. Garzelli, L. Capobianco, and F. Nencini, "Fusion of multispectral and panchromatic images as an optimisation problem," in Image Fusion, Elsevier, 2008, pp. 223-250. doi: 10.1016/b978-0-12-3725295.00005-6.

[79] J. J. Durillo and A. J. Nebro, "JMetal: A Java framework for multi-objective optimization," Advances in Engineering Software, vol. 42, no. 10, pp. 760-771, Oct. 2011, doi: 10.1016/j.advengsoft.2011.05.014.

[80] S. Biswas, S. Das, P. N. Suganthan, and C. A. C. Coello, "Evolutionary multiobjective optimization in dynamic environments: A set of novel benchmark functions," in Proceedings of the 2014 IEEE Congress on Evolutionary Computation, CEC 2014, Sep. 2014, pp. 3192-3199. doi: 10.1109/CEC.2014.6900487.

[81] A. Zhou, Y. Jin, and Q. Zhang, “A Population prediction strategy for evolutionary dynamic multiobjective optimization," IEEE Transactions on Cybernetics, vol. 44, no. 1, pp. 40-53, Jan. 2014, doi: 10.1109/TCYB.2013.2245892. 
[82] N. Rokbani et al., "Bi-heuristic ant colony optimization-based approaches for traveling salesman problem," Soft Computing, vol. 25, no. 5, pp. 3775-3794, Mar. 2021, doi: 10.1007/s00500-020-05406-5.

[83] M. Dordevic, "Statistical analysis of various hybridization of evolutionary algorithm for traveling salesman problem," in Proceedings of the IEEE International Conference on Industrial Technology, Feb. 2019, vol. 2019-February, pp. 899-904. doi: 10.1109/ICIT.2019.8755092. 